\title{
DESENVOLVIMENTO DE UM PROTOCOLO PARA A VALIDAÇÃO DE DADOS DO SISTEMA DE VIGILÂNCIA DAS INFECÇÕES DE SÍTIO CIRÚRGICO NO ESTADO DE SÃO PAULO.
}

Tese apresentada ao Programa de Pós-Graduação em Enfermagem da Escola de Enfermagem da Universidade de São Paulo para obtenção do título de Doutora em Ciências.

Área de Concentração: Cuidado em Saúde Orientadora: Prof. ${ }^{a}$ Dr. ${ }^{a}$ Maria Clara Padoveze 
AUTORIZO A REPRODUÇÃO E DIVULGAÇÃO TOTAL OU PARCIAL DESTE TRABALHO, POR QUALQUER MEIO CONVENCIONAL OU ELETRÔNICO, PARA FINS DE ESTUDO E PESQUISA, DESDE QUE CITADA A FONTE.

Assinatura:

Data:

\section{Catalogação na Publicação (CIP) \\ Biblioteca "Wanda de Aguiar Horta" \\ Escola de Enfermagem da Universidade de São Paulo}

Mello, Débora Silva de

Desenvolvimento de um protocolo para a validação de dados do sistema de vigilância das infecções de sítio cirúrgico no estado de São Paulo / Débora Silva de Mello. São Paulo, 2018.

$160 \mathrm{p}$.

Tese (Doutorado) - Escola de Enfermagem da Universidade de São Paulo.

Orientadora: Prof. a Dr. ${ }^{a}$ Maria Clara Padoveze

Área de concentração: Cuidado em Saúde

1. Infecção hospitalar. 2. Vigilância epidemiológica. 3. Estudos de validação. 4. Sistemas de Informação. 5. Enfermagem. I. Título.

Ficha catalográfica elaborada por Fabiana Gulin Longhi Palacio (CRB-8: 7257) 
Nome: Débora Silva de Mello

Título: Desenvolvimento de um protocolo para a validação de dados das infecções de sítio cirúrgico no Estado de São Paulo.

Tese apresentada ao Programa de Pós-Graduação em Enfermagem da Escola de Enfermagem da Universidade de São Paulo para obtenção do título de Doutora em Ciências.

Aprovado em:

\section{BANCA EXAMINADORA}

Prof. Dr. Instituição:

Julgamento: Assinatura:

Prof. Dr. Instituição:

Julgamento: Assinatura:

Prof. Dr. Instituição:

Julgamento: Assinatura:

Prof. Dr. Instituição:

Julgamento: Assinatura:

Prof. Dr. Instituição:

Julgamento: Assinatura: 



\section{DEDICATÓRIA}

À minha amada e querida mãe, Maria das Graças Silva, amor incondicional, generosidade e fonte de sabedoria. Apoio constante e estímulo para prosseguir ainda que nas intempéries.

Ao meu pai, José Eduardo de Mello (in memoriam) - se hoje estou aqui concluindo este trabalho devo muito a você. Esteja onde estiver espero que sinta minha felicidade e um eterno agradecimento por me dar a vida. Sem seus cuidados, proventos, princípios e orientações esse momento não existiria. Você está sempre em minhas lembranças, orações e coração.

Ao meu esposo Elier Broche Cristo. Além de apoio estatístico e de informática, teve muita paciência e foi compreensivo durante a longa jornada. Apoio de sempre, nas etapas mais difíceis da vida. Passamos por muitas surpresas ao longo desta jornada e sua presença, carinho e incentivo foram fundamentais para manter o foco.

À minha orientadora Dr ${ }^{\mathrm{a}}$ Maria Clara Padoveze, por ter confiado a mim a missão de conduzir este projeto de pesquisa sob sua supervisão. Pelos ensinamentos e incentivo durante todo o percurso. Admiro muito seu conhecimento técnico e sua capacidade de raciocínio frente aos problemas identificados. Foi sem dúvida um apoio fundamental para o desenvolvimento e condução deste projeto de pesquisa.

À minha abençoada amiga Valdirene Adão dos Santos, sempre disponível com suas palavras motivadoras e sempre disposta a ajudar.

Aos amigos mais que especiais, Paulinho e Izildinha. Obrigada por estarem sempre ao meu lado nesta trajetória.

Aos meus sogros Ines Cristo Perez e Juan Antonio Broche Sanchez que mesmo distantes se fizerem presentes acompanhando, compreendendo minha ausência em certos momentos e incentivando para que tudo desse certo. 



\section{AGRADECIMENTOS}

À equipe da Divisão de Infecção Hospitalar do Centro de Vigilância Epidemiológica "Prof. Alexandre Vranjac" (DIH/CVE) pela parceria de pesquisa e apoio técnico durante toda a condução deste projeto, em especial à $\operatorname{Dr}^{\mathrm{a}}$ Denise Brandão de Assis e $\operatorname{Dr}^{\mathrm{a}}$ Geraldine Madalosso.

À equipe do Centro de Estatística Aplicada do Instituto de Matemática e Estatística da USP (CEA/IME/USP) por aceitar o desafio e nos apoiar fornecendo uma proposta de metodologia para o cálculo do tamanho amostral. Em especial à Prof ${ }^{a}$. Dra ${ }^{a}$. Gisela Tunes da Silva, ao Prof ${ }^{\circ}$. Dr ${ }^{\circ}$. Antonio Carlos Pedroso de Lima e ao Prof ${ }^{\circ}$. Dr ${ }^{\circ}$. Carlos Alberto de Bragança Pereira.

À equipe do Grupo de Vigilância Epidemiológica de Santo André (GVE-Santo André), em especial à $\operatorname{Dr}^{\mathrm{a}}$ Tânia de Moura Guerschman, $\mathrm{Dr}^{\mathrm{a}}$ Angela Maria Mozena Moriwaki e a Enf ${ }^{\text {a }}$ Litsuko Mishima,

Aos hospitais que aceitaram participar voluntariamente deste projeto de pesquisa na realização do piloto: sem esta participação teria sido impossível desenvolver esta ferramenta que tem por objetivo melhorar a qualidade da informação das infecções de sítio cirúrgico no Estado de São Paulo.

Aos professores Dr $^{\circ}$. Carlos Magno Castelo Branco Fortaleza e Dro . Eliseu Alves Waldman por suas importantes contribuições no Exame de Qualificação.

À $\mathrm{Dr}^{\mathrm{a}}$. Denise Cardo pela colaboração com este projeto de pesquisa, na etapa de visita à um sistema governamental de vigilância das infecções relacionadas à assistência à saúde.

Aos amigos da Divisão de Informação da Coordenadoria de Vigilância em Saúde (COVISA), em especial Ao Dr. Júlio Cesar de Magalhães Alves pela compreensão, apoio, incentivo durante o projeto e por compartilhar seus conhecimentos de epidemiologia; à amiga Márcia Regina Buzzar, pelo carinho e apoio nos momentos mais difíceis; à querida Águida Gonçalvez pelo incentivo, ao Elder Sano Pereira, sempre disposto a colaborar com seus conhecimentos; à querida Maria Letícia Pineda Fungaro, pela disponibilidade em ensinar quando foi preciso; ao José Luis de Andrade Silva, sempre disposto à colaborar.

Ao querido amigo Helder Auro dos Santos, obrigada por compartilhar seus conhecimentos sobretudo no que diz respeito à vigilância em saúde e pelo grande incentivo ao longo do desenvolvimento deste projeto. 
Aos membros do subgrupo de pesquisa "Políticas Públicas e Epidemiologia em Infecções Relacionadas à Assistência à Saúde" da EEUSP, pela colaboração. Em especial, aos amigos Cristiane Schmitt, Cassimiro Nogueira Júnior e Amanda Pires Maciel.

A todos os colaboradores da EEUSP, que direta ou indiretamente contribuíram para que este trabalho pudesse ser realizado.

Á "The Society for Healthcare Epidemiology of America - SHEA" pela oportunidade de participar do "SHEA International Ambassor Program 2014".

Ao Conselho Nacional de Desenvolvimento Cientifico e Tecnológico (CNPq) pelo apoio por meio de financiamento (Processo: 460783/2014-9. Título do Projeto: Desenvolvimento de Tecnologias para Apoio a Políticas Públicas em Prevenção e Controle de Infecções Relacionadas a Assistência à Saúde) 
"Así es la vida, que no cabe en ella todo el bien que pudiera uno hacer"

(José Martí) 

Mello DS. Desenvolvimento de um protocolo para a validação de dados do sistema de vigilância das infecções de sítio cirúrgico no estado de São Paulo [tese]. São Paulo: Escola de Enfermagem, Universidade de São Paulo; 2018.

\section{RESUMO}

Introdução: a validação de dados de sistemas de vigilância das Infecções Relacionadas à Assistência à Saúde é fundamental para assegurar a qualidade das informações notificadas. Objetivo: desenvolver um protocolo que possa ser utilizado pelos serviços públicos de saúde brasileiros para validar os dados que compõe o sistema de vigilância epidemiológica das infecções de sítio cirúrgico (ISC), no Estado de São Paulo. Métodos: estudo metodológico, realizado entre fevereiro de 2014 e janeiro de 2018 em três etapas: I) Estudo de revisão de estratégias adotadas por sistemas governamentais para a validação de dados de sistemas de vigilância das ISC; II) Execução de um estudo piloto de validação de dados de ISC em uma região do Estado de São Paulo; III) Elaboração do protocolo de validação de dados de ISC para o Estado de São Paulo. Resultados: a revisão da literatura demonstrou não haver um método padrão adotado pelos sistemas governamentais de vigilância para a validação de dados de ISC. No entanto, foram identificados estratégias e elementos críticos para protocolos de validação como método para a identificação dos casos de ISC e para a análise dos resultados e, recursos humanos e materiais necessários. O piloto de validação foi realizado em cinco hospitais, com revisão de 168 prontuários de pacientes submetidos às cirurgias selecionadas. Esta etapa permitiu a identificação das adequações necessárias ao método proposto e seus resultados reforçaram a necessidade de verificar a acurácia dos dados de ISC reportados no Estado de São Paulo. O protocolo para a validação de dados de ISC desenvolvido descreve as etapas de planejamento de recursos, preparo da equipe de validadores, método para cálculo do tamanho da amostra de hospitais e prontuários, instrumento para coleta de dados e método de análise dos resultados. Conclusões: o protocolo elaborado mostrou-se ser exequível e possui potencial para ser utilizado por outros sistemas governamentais que possuam metodologia semelhante à adotada para a vigilância das ISC no Estado de São Paulo.

PALAVRAS-CHAVE: Infecção Hospitalar; Vigilância Epidemiológica; Estudos de Validação; Sistema de Informação; Enfermagem. 

Mello DS. Development of a protocol to validate the surgical site infection surveillance's system data in São Paulo State. [thesis]. São Paulo: Escola de Enfermagem, Universidade de São Paulo; 2018.

\begin{abstract}
Introduction: the validation of healthcare associated infections surveillance data it is very important to assure the quality of the information reported. Objective: to develop a protocol that can be used by the Brazilian public healthcare services to validate the surgical site infection (SSI) surveillance data, in São Paulo state. Methods: methodological study performed between February 2014 and January 2018 in three steps: I) Study of the revision of strategies used by governmental systems to validate the SSI surveillance data; II) Performance of a SSI data validation study in a region of Sao Paulo state; III) Development of a protocol to validate the SSI data in Sao Paulo state. Results: the revision of the literature showed have not a standard method used by the governmental surveillance systems to validate the SSI data. However, important strategies and elements to the validation protocol were identified through the review as method to identify the cases of SSI and to analyze the results and, humans resources and materials necessary. The validation study was performed in five hospitals; 168 medical records from patients submitted to the selected procedures were reviewed. This step allowed the identification of the improvements to the proposed method and their results highlighted the necessity to verify the accuracy of de SSI data reported in Sao Paulo state. The developed protocol for SSI data validation describe the steps as planning the operational process, validation staff requirements, instrument for data collection and method to analyze the results. Conclusions: the developed protocol showed to be practicable and have potential to be used by any other governmental system that use similar methodology as that used by Sao Paulo state.
\end{abstract}

KEYWORDS: Cross Infection; Epidemiological Surveillance; Validation Studies; Information Systems; Nursing. 



\section{LISTA DE ILUSTRAÇÕES}

Figura 1. Classificação das infecções de sítio cirúrgico de acordo com o plano tecidual acometido.

Figura 2. Divisão administrativa para as ações de vigilância epidemiológica no Estado de São Paulo, de acordo com os Grupos de Vigilância Epidemiológica. São Paulo, 2018.

Figura 3. Representação esquemática do fluxo de informações de notificação de infecções relacionadas à assistência à saúde no Estado de São Paulo. São Paulo, 2018. 31

Figura 4. Representação esquemática das estratégias utilizadas para identificar os elementos necessários ao protocolo de validação de dados de infecções de sítio cirúrgico, a ser estabelecido para o Estado de São Paulo. São Paulo, 2018

Figura 5. Tempo empregado para revisão de prontuários de acordo com o procedimento cirúrgico realizado. $\mathrm{N}$ prontuários revisados $=168$. Grupo de Vigilância Epidemiológica VII Santo André. São Paulo, 2018. 75

Quadro 1. Distribuição do número de hospitais notificantes, número de cirurgias e percentis das taxas de infecção de sítio cirúrgico em procedimentos cirúrgicos selecionados, referente ao ano de 2016. Centro de Vigilância Epidemiológica "Prof. Alexandre Vranjac". São Paulo, 2018 .

Quadro 2. Descrição das variáveis identificadas por meio do acesso à página eletrônica de sistemas governamentais de vigilância epidemiológica das infecções relacionadas à assistência à saúde identificadas pelo estudo de publicações científicas. São Paulo, 2018 ..... 71

Quadro 3. Resultados gerais em relação ao numerador e denominador, notificados e observados pela validação de dados. Grupo de Vigilância Epidemiológica VII - Santo André. São Paulo, 2018. 78

Quadro 4. Valor preditivo positivo, valor preditivo negativo, sensibilidade e especificidade calculados para cada hospital e procedimento cirúrgico validado. Grupo de Vigilância Epidemiológica VII - Santo André. São Paulo, 2018 



\section{LISTA DE TABELAS}

Tabela 1. Número amostral de hospitais para participar do piloto de validação de dados de infecções de sítio cirúrgico no Estado de São Paulo e número total de hospitais notificantes no ano de 2016. Grupo de Vigilância Epidemiológica VII - Santo André. São Paulo, 2018.

Tabela 2. Caracterização dos estudos identificados, de acordo com ano da publicação, país, região para a qual se delimita e nome do programa competente. São Paulo, 2018.

Tabela 3. Descrição dos estudos selecionados segundo o período e tipo de infecção relacionadas à assistência à saúde validado, objetivo da validação, método empregado, equipe de revisores critérios adotados para a seleção de hospitais e prontuários incluídos nos estudos. São Paulo. Brasil, 2018

Tabela 4. Descrição dos estudos selecionados segundo os métodos para seleção dos hospitais e seleção de prontuários descritos pelos estudos identificados por meio do estudo de publicações científicas. São Paulo, 2018.

Tabela 5. Valor preditivo positivo, valor preditivo negativo, sensibilidade e especificidade identificados pelos estudos, com intervalo de confiança de 95\%. São Paulo, 2018.

Tabela 6. Distribuição dos hospitais participantes de acordo com o estrato estabelecido segundo número de leitos. Grupo de Vigilância Epidemiológica VII - Santo André. São Paulo, 2018. 74

Tabela 7. Distribuição do número de prontuários revisados de acordo com o tipo de procedimento cirúrgico. Grupo de Vigilância Epidemiológica VII - Santo André. São Paulo, 2018

Tabela 8. Média de custos diários por validador e valor total estimado* do custo com o piloto de validação de dados de infecção de sítio cirúrgico realizado em uma região do Estado de São Paulo**. São Paulo, 2018. 76

Tabela 9. Acurácia quanto ao diagnóstico de infecção de sítio cirúrgico entre os dados notificados para o sistema de vigilância estadual, em 2016 e aquele estabelecido pelo revisor, no piloto de validação, segundo o tipo de procedimento cirúrgico. Grupo de Vigilância Epidemiológica VII - Santo André. São Paulo, 2018. 
Tabela 10. Acurária quanto à classificação em relação ao plano tecidual acometido realizada pelos hospitais e aquela identificada pelos validadores. Grupo de Vigilância Epidemiológica VII - Santo André. São Paulo, 2018. 


\section{LISTA DE ABREVIATURAS E SIGLAS}

ANVISA

APECIH

ASA

CDC

CMS

CEA/IME/USP

CVE

CVS

CEP-EEUSP

$\mathrm{CNPq}$

DIH/CVE

DHQP

ECDC

EEUSP

EUA

ENVIN

HELICS

SIRO

GVE

ICS

ISC

ICSRC

IRAS
Agência Nacional de Vigilância Sanitária

Associação Paulista de Epidemiologia e Controle de Infecção Relacionada à Assistência à Saúde

American Society of Anestesiology

Centers for Disease Control and Prevention

Centers for Medicare \& Medicaid Services

Centro de Estatística Aplicada do Instituto de Matemática e Estatística da Universidade de São Paulo

Centro de Vigilância Epidemiológica "Prof. Alexandre Vranjac"

Centro de Vigilância Sanitária

Comitê de Ética em Pesquisa da Escola de Enfermagem da Universidade de São Paulo

Conselho Nacional de Desenvolvimento Científico e Tecnológico

Divisão de Infecção Hospitalar do Centro de Vigilância Epidemiológica "Prof. Alexandre Vranjac"

Division of Healthcare Quality Promotion

European Centre for Disease Prevention and Control

Escola de Enfermagem da Universidade de São Paulo

Estados Unidos da América

Estudio Nacional de Vigilancia de Infecciones Nosocomiales en Unidades de Cuidados Intensivos

Hospitals in Europe Link for Infection Control through Surveillance

Finnish Hospital Infection Program

Grupos de Vigilância Epidemiológica

Infecção da Corrente Sanguínea

Infecções de Sítio Cirúrgico

Infecção da Corrente Sanguínea Relacionada ao Cateter

Infecções Relacionadas à Assistência à Saúde 
SPIN-UTI

GISIO-Stitl

FAPESP

NHSN

NNIS

NICE

MCR

PHE

OMS

PREZIES

RDC

RH

SSHAIP

SUS

SENIC

UTI

VPP

VPN

VICNNIS

VE

WHO
Italian Nosocomial Infections Surveillance in Intensive Care Units Project

Italian Hospital Hygiene Study Group

Fundação de Amparo à Pesquisa do Estado de São Paulo

National Healthcare Safety Network

National Nosocomial Infections Surveillance

National Institute for Health and Clinical Excellence

Micobactérias de crescimento rápido

Public Health England

Organização Mundial da Saúde

Preventie Ziekenhuisinfecties door Surveillance

Resolução da Diretoria Colegiada

Recursos Humanos

Scottish Surveillance of Healthcare Associated Infection Programme

Sistema Único de Saúde

Study on the the Efficacy of Nosocomial Infection Control

Unidades de Terapia Intensiva

Valor Preditivo Positivo

Valor Preditivo Negativo

Victorian Hospital Acquired Infection Surveillance System

Vigilância epidemiológica

World Health Organization 


\section{SUMÁRIO}

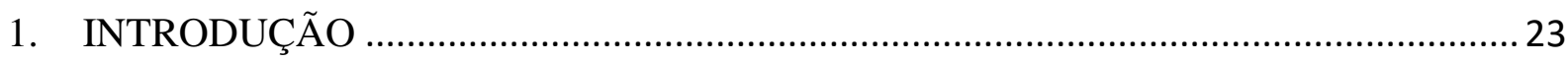

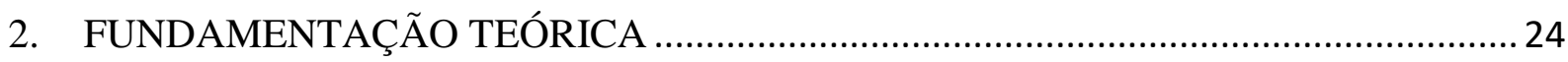

2.1. As infecções de sítio cirúrgico e sua magnitude........................................................................ 24

2.2. Vigilância epidemiológica como parte da estratégia de redução das ISC .................................... 26

2.3. Vigilância epidemiológica das ISC no estado de São Paulo ......................................................... 29

2.4. Validação dos dados de ISC de sistemas governamentais............................................................. 33

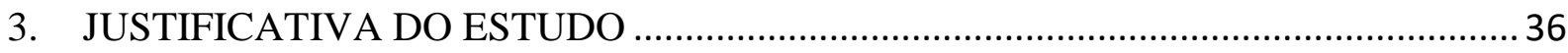

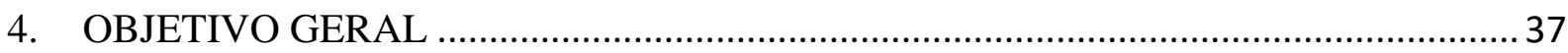

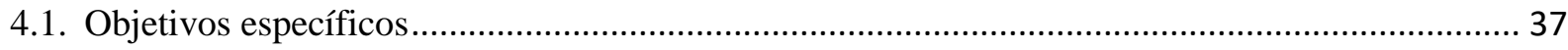

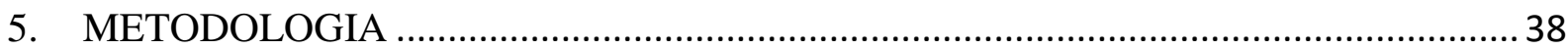

5.1. Estudo de revisão de estratégias adotadas por sistemas governamentais para a validação de dados de sistemas de vigilância das ISC, na última década. ........................................................................ 39

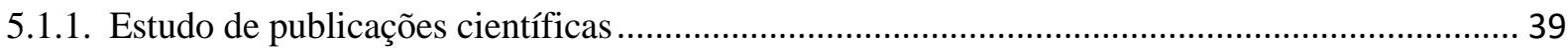

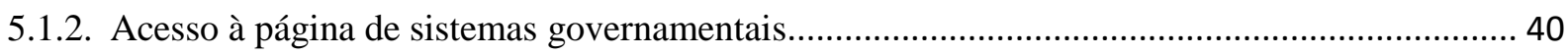

5.1.3. Visita a um sistema governamental de VE das IRAS ........................................................... 40

5.2. Piloto de validação de dados de ISC em uma região do estado de São Paulo............................ 41

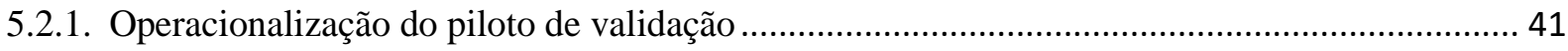

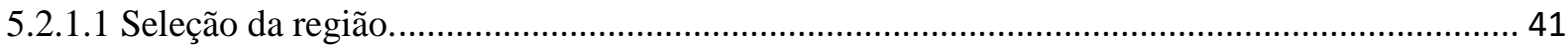

5.2.1.2. Definição dos procedimentos cirúrgicos selecionados para validação................................... 42

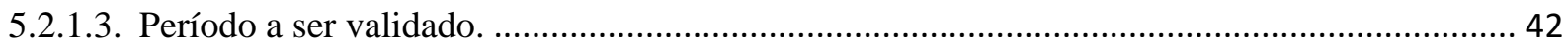

5.2.1.4. Elaboração de um formulário para coleta de dados............................................................... 42

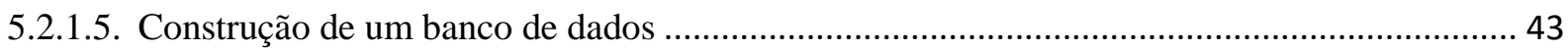

5.2.1.6. Estratégias operacionais para recrutamento de participantes e desenvolvimento do

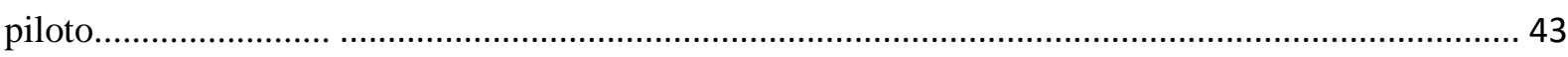

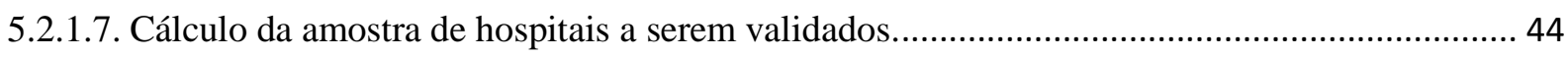

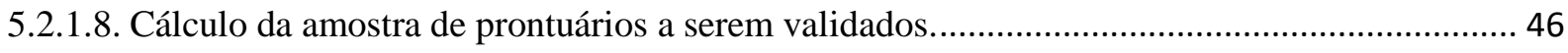

5.2.1.9. Análise dos resultados e retroalimentação para as instituições participantes do piloto de

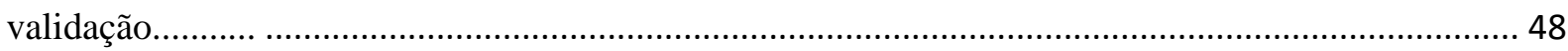

5.3. Elaboração do protocolo de validação de dados de ISC para o estado de São Paulo. ............... 50

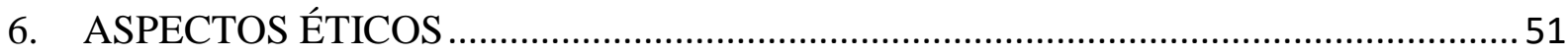

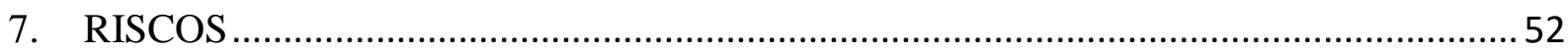

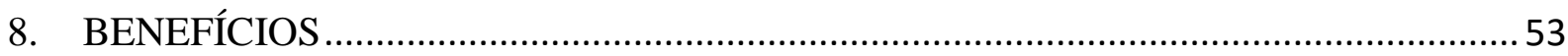

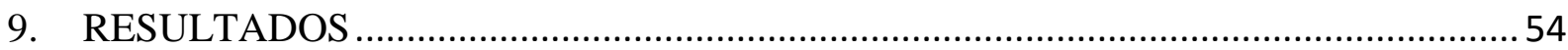


9.1. Estudo de revisão de estratégias adotadas por sistemas governamentais para a validação de dados

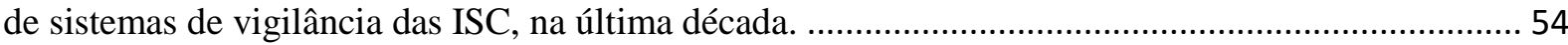

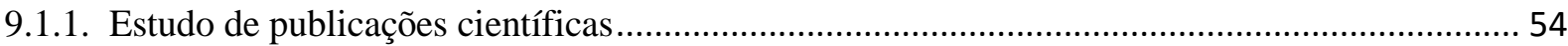

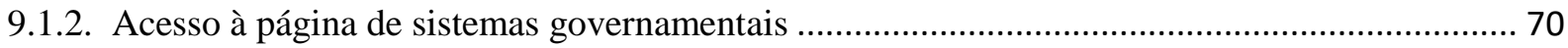

9.1.3. Visita técnica à sistema governamental de VE das IRAS ........................................................ 72

9.2. Desenvolvimento do protocolo de validação de dados de ISC para o estado de São Paulo

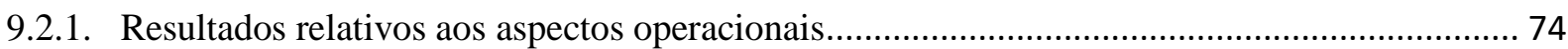

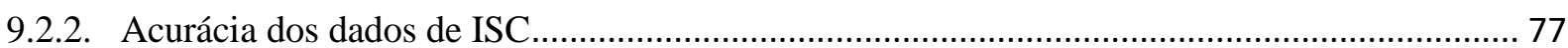

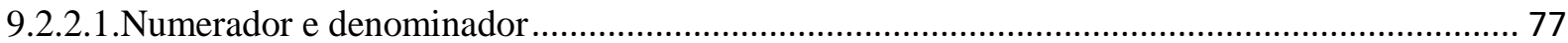

9.2.3. Avaliação da concordância de acordo com o critério diagnóstico das ISC ................................ 79

9.2.3.1. Verdadeiros e falsos positivos e negativos ............................................................................ 79

9.2.3.2. Valor preditivo positivo, valor preditivo negativo, sensibilidade e especificidade .................. 80

9.2.3.3. Classificação de acordo com o plano tecidual acometido ...................................................... 81

9.3. Elaboração do protocolo de validação de dados de ISC para o estado de São Paulo................ 82

10. DISCUSSÃO

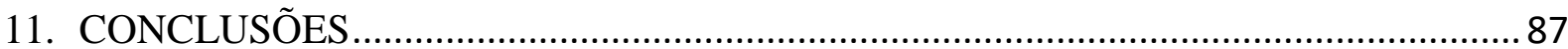

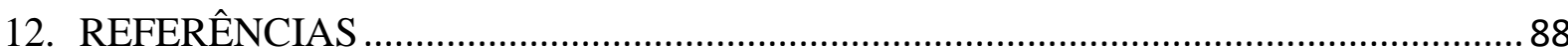

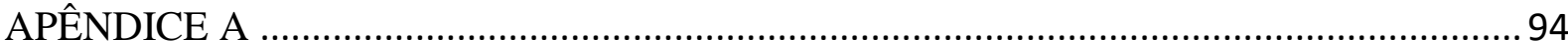

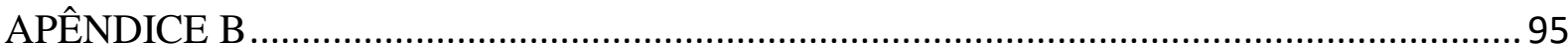

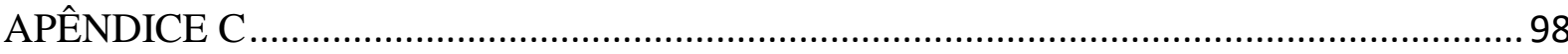

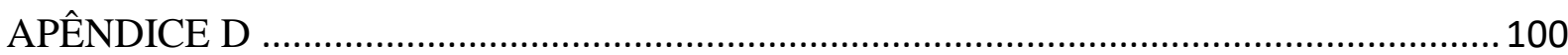

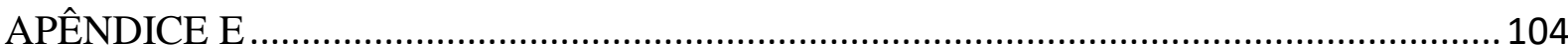

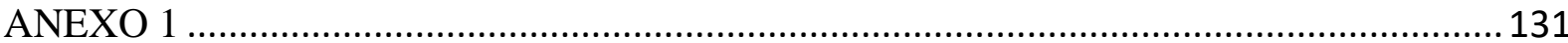

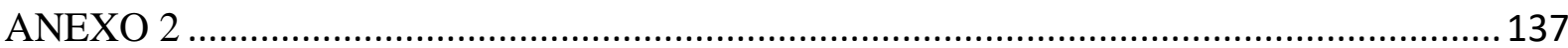

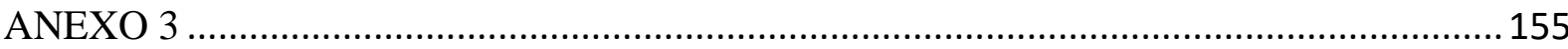

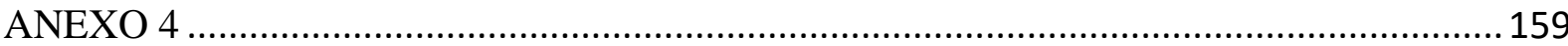




\section{INTRODUÇÃO}

A vigilância epidemiológica (VE) é reconhecida como um importante instrumento a ser utilizado como parte da estratégia para a redução das infecções relacionadas à assistência à saúde (IRAS) e tem sido adotada por vários sistemas governamentais de diversos países no mundo. Muitos destes sistemas, ativos há mais de três décadas, obtiveram êxito na redução das taxas de infecções de sítio cirúrgico (ISC) nas instituições de saúde participantes (Rioux, Grandbastien \& Astagneau, 2007; Geubbels et al., 2006; Gastmeier et al., 2008). No entanto, um importante aspecto a ser considerado em relação a estes sistemas refere-se a sua validação, considerada fundamental para assegurar a qualidade das informações notificadas (Manniën et al, 2007).

No Brasil, o estado de São Paulo foi o pioneiro dentre as unidades da federação ao estabelecer em 2004 um sistema de VE das IRAS, entre estas as ISC. Os resultados obtidos pela Divisão de Infecção Hospitalar do Centro de Vigilância Epidemiológica "Prof. Alexandre Vranjac" (DIH/CVE) por meio deste sistema, tem demonstrado que é possível conhecer a magnitude das IRAS no estado, por meio da coleta de dados dos hospitais participantes e que os resultados podem contribuir para o direcionamento e a elaboração de estratégias que visem à prevenção e o controle destes agravos à saúde (Padoveze et al., 2010). Em 2011, a DIH/CVE reconheceu a necessidade de implementar uma revisão do sistema de VE das ISC baseada no fato de que, embora a adesão das instituições fosse satisfatória, os resultados obtidos ainda eram pouco específicos (CVE, 2009). Para isto, no ano de 2012 as pesquisadoras deste projeto juntamente com a DIH/CVE e, apoiadas pela Fundação de Amparo à Pesquisa do Estado de São Paulo (FAPESP) desenvolveram um projeto de pesquisa que resultou na seleção e implementação de indicadores de ISC para o sistema de vigilância epidemiológica das infecções de sítio cirúrgico (SVISC) do Estado de São Paulo. Os resultados obtidos após um ano da implementação do sistema permitiram concluir adesão satisfatória por parte das instituições de saúde ao novo sistema. Ao mesmo tempo, reforçou a necessidade de garantir a acurácia dos dados notificados, para assegurar a confiabilidade do sistema. 


\section{FUNDAMENTAÇÃO TEÓRICA}

\subsection{AS INFECÇÕES DE SÍTIO CIRÚRGICO E SUA MAGNITUDE}

Atualmente, "infecções relacionadas à assistência à saúde" (IRAS) é o termo que tem sido utilizado em substituição ao termo "infecção hospitalar", ampliando o seu significado. As IRAS englobam não apenas as infecções que possam ter sua causa atribuída à assistência hospitalar, mas também o universo das infecções adquiridas por cuidados prestados em qualquer outro ambiente (Horan, Andrus \& Dudeck, 2008), tais como instituições de longa permanência, ambulatórios e outros. A ocorrência destes agravos apresenta relevância epidemiológica, sobretudo em países em desenvolvimento e estão relacionados à segurança do paciente (Allegranzi et al., 2011).

Vários fatores contribuem para a ocorrência das IRAS. Há fatores que são intrínsecos ao paciente como extremos de idade, mau estado nutricional, presença de processos infecciosos, tabagismo, entre outros (APECIH, 2009). Outros fatores incluem condições inadequadas de higiene do ambiente e equipamentos, infraestrutura e recursos humanos insuficientes, uso prolongado e inapropriado de dispositivos e antibióticos, entre outros (Allegranzi et al., 2011). Com base no conhecimento destes fatores, órgãos nacionais e internacionais elaboraram recomendações para a prevenção destas infecções (ANVISA, 2009a; APECIH, 2009, Anderson et al., 2008; NICE, 2008; Bratzler et al., 2013; Mangram et al., 1999; BRASIL, 2012).

As ISC lideram entre as IRAS de ocorrência hospitalar em países em desenvolvimento (Allegranzi et al., 2011, OMS, 2003; Astagneau \& Hériteau 2010; Díaz-Agero-Pérez et al., 2011). Além de impor sofrimento ao indivíduo acometido, as ISC podem gerar incapacidades (OMS, 2003) e em alguns casos levar a óbito; apresentam altas taxas de morbidade e mortalidade e aumentam tempo de hospitalização (Kirkland et al., 1999) e dos custos com o tratamento (Kirkland et al., 1999; Burke, 2003, Umsheid et al., 2011).

Em 1964 a National Academy of Sciences/National Research Council estabeleceu uma classificação para as ISC que considera o potencial de contaminação segundo a microbiota presente no tecido abordado durante o procedimento cirúrgico. Desta forma, a cirurgia é classificada em limpa, potencialmente contaminada, contaminada e infectada (APECIH, 2009). 
Os conceitos desta classificação são apresentados a seguir:

- Limpa: eletiva, fechamento por primeira intenção, sem qualquer sinal de inflamação, sem penetração nos tratos respiratório, gastrointestinal, geniturinário ou orofaringe, sem qualquer falha na técnica asséptica e sem drenos. Exemplos: a herniorrafia e a safenectomia.

- Potencialmente contaminada: abertura do trato respiratório, gastrointestinal ou genitourinário sob condições controladas, sem sinais de processo inflamatório. Penetração de orofaringe ou vagina. Pequena quebra de técnica. Exemplo: gastrectomia.

- Contaminada: incisão na presença de inflamação não purulenta aguda, quebra grosseira da técnica asséptica, trauma penetrante há menos de quatro horas, feridas abertas cronicamente. Contaminação do trato gastrointestinal. Penetração no trato biliar ou genitourinário na presença de bile ou urina infectada. Exemplo: colecistectomia com inflamação aguda.

- Infectada: quando há presença de secreção purulenta, perfuração de víscera, trauma penetrante há mais de quatro horas, ferida traumática com tecido desvitalizado, corpo estranho ou contaminação fecal. Exemplo: ceco perfurado.

(APECIH, 2009, p.12).

A agência americana "Centers for Disease Control and Prevention” (CDC) estabeleceu os critérios que definem o diagnóstico epidemiológico das ISC. Esta definição tem sido adotada por diversos sistemas governamentais de VE das IRAS de vários países (Mello, 2013) e é fundamental para a homogeneidade entre os resultados permitindo sua interpretação (Mangram et al., 1999). De acordo com o plano tecidual acometido as ISC são classificadas em incisional superficial, incisional profunda ou órgão-espaço. A Figura1 representa a classificação das ISC de acordo com o plano acometido. 
Figura 1. Classificação das infecções de sítio cirúrgico de acordo com o plano tecidual acometido.

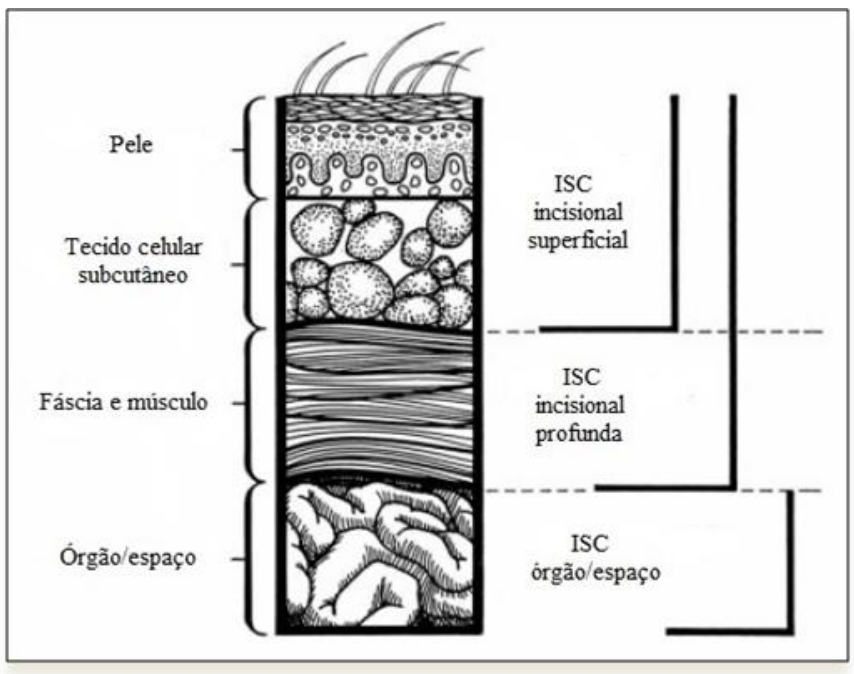

(Fonte: APECIH, 2009)

\subsection{VIGILÂNCIA EPIDEMIOLÓGICA COMO PARTE DA ESTRATÉGIA DE REDUÇÃO DAS ISC}

A magnitude e o comportamento das IRAS podem ser estimados pelas instituições de saúde e órgãos governamentais por meio da vigilância epidemiológica (VE). Os dados obtidos por meio da VE das IRAS podem apoiar os hospitais indicando o comportamento da ocorrência destes agravos, bem como a efetividade das intervenções adotadas para sua redução (McBryde et al., 2009). A utilização desta ferramenta contribui para a redução da ocorrência deste tipo de agravo à saúde (Jodrá et al., 2006; Bärwolff et al., 2006), direcionando as estratégias ao auxiliar na identificação dos focos de atuação para onde as ações de prevenção e controle devem ser priorizadas.

Sistemas governamentais que utilizam a VE tem demonstrado redução das ISC entre as instituições participantes, ao longo do tempo (Rioux, Grandbastien \& Astagneau, 2007; Geubbels et al., 2006; Gastmeier et al., 2008).

Considerado como o estudo pioneiro sobre epidemiologia das IRAS o "Study on the the Efficacy of Nosocomial Infection Control”, conhecido como estudo SENIC, foi conduzido pelo CDC no início dos anos setenta e teve por objetivo avaliar a eficácia de programas vigilância e controle das IRAS. Este estudo demonstrou que a presença de certos componentes considerados essenciais, entre estes um sistema de vigilância organizado, associava-se a 
redução do risco de infecções hospitalares em até 32\% (Haley et al., 1985). O estudo SENIC foi um importante propulsor para a utilização da VE na estratégia de controle destes agravos à saúde por sistemas governamentais.

Os Estados Unidos da América (EUA) por meio do CDC são referência mundial em vigilância das IRAS. O National Healthcare Safety Network (NHSN), que incorporou o anteriormente denominado National Nosocomial Infections Surveillance (NNIS) System, é um dos programas daquele país do qual atualmente fazem parte cerca de 17.000 instituições de saúde, incluindo hospitais de cuidados agudos, instituições de longa permanência, centros ambulatoriais que realizam cirurgias, hospitais de reabilitação entre outros (CDC, 2015).

Durante as últimas três décadas vários países desenvolveram sistemas governamentais de VE das IRAS (Nogueira et al, 2014). Sistemas de VE da Europa tiveram seus dados publicados demonstrando que a vigilância pode reduzir consideravelmente a ocorrência das ISC (Astagneau \& Hériteau 2010). Na Alemanha, hospitais que participaram voluntariamente do sistema de notificação das ISC relacionadas ao parto cesariano tiveram as taxas de ISC reduzidas ao longo do tempo (Bärwolff et al., 2006). Outro estudo também realizado neste país, identificou que a participação no sistema nacional de vigilância foi associada a significativa redução de infecção primária da corrente sanguínea associada ao cateter venoso central e pneumonia, em unidades de terapia intensiva (UTI) e infecções de sítio cirúrgico (Gastmeier et al., 2006). Rioux, Grandbastien \& Astagneau (2007) avaliaram o impacto de 6 anos de vigilância do sistema francês identificando uma significativa redução (de 3,8 para 1,7\%) na taxa de ISC.

Um documento publicado pela OMS em 2003 recomendou que as medidas preventivas destes agravos deveriam ser apoiadas por autoridades nacionais, regionais, a alta administração de instituições de saúde e por profissionais da área. Segundo este documento, as autoridades governamentais devem desenvolver um sistema nacional para monitorar infecções selecionadas, estimar a efetividade das intervenções e encorajar os estabelecimentos de assistência à saúde a monitorar estas infecções, com retroalimentação aos profissionais interessados. Em contrapartida, a administração de cada instituição de saúde deve apoiar a prevenção de riscos para pacientes e colaboradores, proporcionando recursos suficientes para que o programa seja desenvolvido (OMS, 2003).

No ano de 2008 ocorreu, em Genebra, o "Segundo Encontro da Rede Informal sobre Prevenção e Controle de Infecções", cujo objetivo foi o de identificar os principais componentes de programa nacionais e locais de controle das IRAS e recomendou a vigilância 
como prática a ser cumprida, considerando sua reconhecida eficácia na prevenção das IRAS (WHO, 2008).

No Brasil, vigilância epidemiológica, no seu sentido mais amplo, é definida pela Lei $\mathrm{N}^{\mathrm{o}}$ 8080/90 como:

conjunto de ações que proporcionam o conhecimento, a detecção ou prevenção de qualquer mudança nos fatores determinantes e condicionantes de saúde individual e coletiva, com a finalidade de recomendar e adotar as medidas de prevenção e controle das doenças ou agravos" (BRASIL, 1990).

Neste país, a Agência Nacional de Vigilância Sanitária (ANVISA) tem desenvolvido ações dirigidas a questão das ISC. Baseados nos critérios do CDC, foram publicados e padronizados em âmbito nacional em 2009, critérios definidores para a vigilância das ISC (ANVISA, 2009b), que vem sofrendo atualizações, desde então. Ainda naquele ano, devido à ocorrência de surtos de ISC causados por micobactérias de crescimento rápido (MCR) a ANVISA publicou por meio da RDC n 08, de 27 de fevereiro de 2009 medidas para a redução da ocorrência de infecções por estes microrganismos em serviços de saúde. Dentre estas, o seguimento mensal de pacientes submetidos a procedimentos previstos no Art. $1^{\circ}$ da referida RDC durante os primeiros 90 dias de pós-operatório com o objetivo de identificar a ocorrência de tais infecções (ANVISA, 2009c). Em 2011, a ANVISA elaborou critérios nacionais, também adaptados do CDC, para a definição e notificação das ISC que envolvem implantes e próteses relativas a procedimentos cirúrgicos cardiovasculares, implantes mamários, neurocirúrgicos e ortopédicos (ANVISA, 2011). A partir de 2014, esta agência iniciou a notificação mensal obrigatória dos dados de ISC de parto cesárea (ANVISA, 2014) e atualmente, de infecções de sítio cirúrgico com implante mamário, artroplastia de joelho primária, artroplastia total de quadril primária. A notificação é realizada por meio de formulários eletrônicos que são preenchidos diretamente nos sistemas pelos hospitais. Uma síntese destas informações retorna ao Estado notificante (ANVISA, 2018).

A ANVISA destaca a importância da definição de critérios diagnósticos para a VE das IRAS como fator que contribui para a qualidade, fidedignidade e representatividade das informações geradas e considera necessária sua atualização. Para tal, a agência instituiu grupos de trabalhos constituídos por profissionais capacitados, representantes de diversas instituições que contribuem com a proposição das atualizações necessárias (ANVISA, 2017). 


\subsection{VIGILÂNCIA EPIDEMIOLÓGICA DAS ISC NO ESTADO DE SÃO PAULO}

O estado de São Paulo foi pioneiro no Brasil ao iniciar em 2004 a vigilância das IRAS em âmbito governamental, utilizando desde então os critérios elaborados pelo CDC e acompanhando suas atualizações e incorporando as adaptações produzidas pela ANVISA. A Divisão de Infecção Hospitalar do Centro de Vigilância Epidemiológica "Prof. Alexandre Vranjac" (DIH/CVE), responsável pela implantação e condução deste sistema tem observado ao longo do tempo satisfatória participação das instituições de saúde, demonstrando que é possível conhecer a magnitude das IRAS no estado (Padoveze et al., 2010) e assim propor estratégias de redução destas infecções.

O estado de São Paulo possui 28 regiões administrativas chamadas de Grupos de Vigilância Epidemiológica (GVE), que são estruturas regionais às quais cabe entre outros, coordenar, supervisionar e controlar as ações de vigilância epidemiológica, bem como analisar o comportamento epidemiológico das doenças sob VE (SES, s/d). A Figura 2 apresenta esta divisão administrativa. 
Figura 2. Divisão administrativa para as ações de vigilância epidemiológica no Estado de São Paulo, de acordo com os Grupos de Vigilância Epidemiológica. São Paulo, 2018.

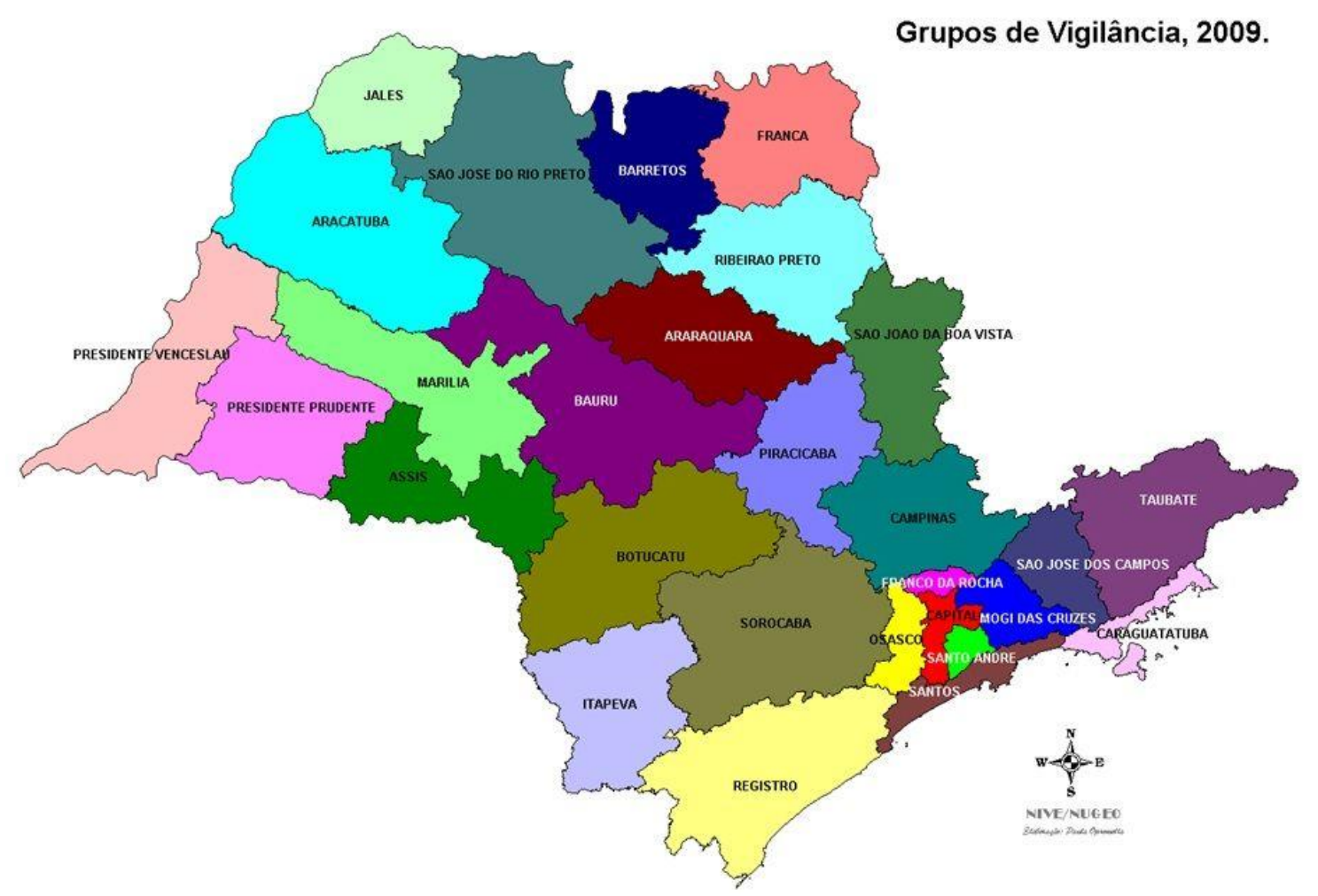

(Fonte: Divisão de Infecção Hospitalar. Análise dos Dados do Sistema de Vigilância Epidemiológica das Infecções Hospitalares do Estado de São Paulo - 2016. Disponível em: http://www.saude.sp.gov.br/cve-centro-devigilancia-epidemiologica-prof.-alexandre-vranjac/areas-de-vigilancia/infeccao-hospitalar/sistema-de-vigilanciaepidemiologica)

Cada GVE é responsável por coordenar a VE de um certo número de hospitais, o que varia entre as regiões. A notificação dos dados é mensal e realizada por meio de planilha do Microsoft Excel®. A informação notificada pelos hospitais é enviada ao órgão responsável na vigilância em saúde do município, que os repassa ao GVE responsável, que por sua vez encaminha à DIH/CVE, que realiza interface com o Centro de Vigilância Sanitária (SES, 2018). A notificação das planilhas deve seguir o fluxo apresentado na Figura 3. 
Figura 3. Representação esquemática do fluxo de informações de notificação de infecções relacionadas à assistência à saúde no Estado de São Paulo. São Paulo, 2018.

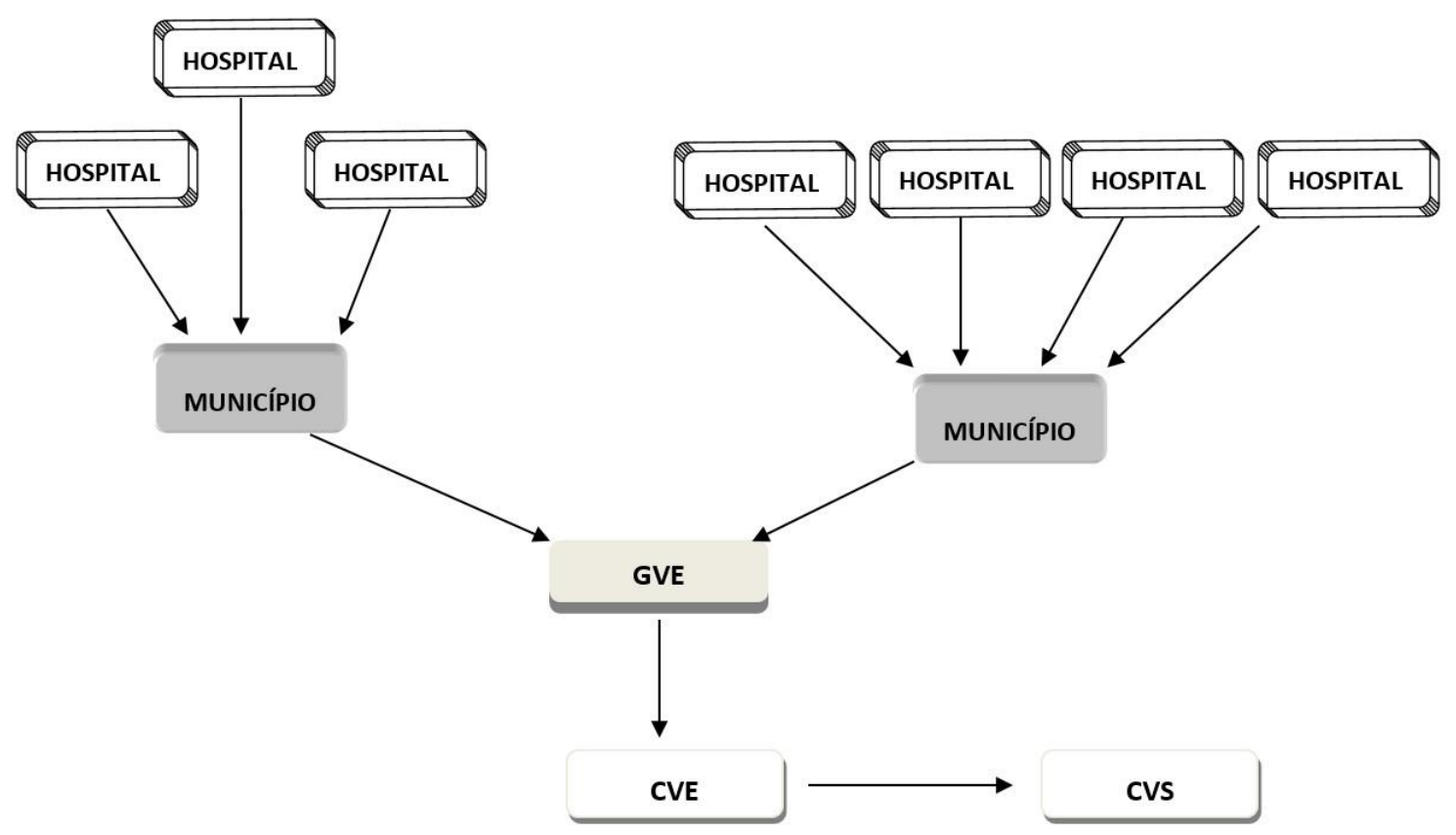

(Adaptado de: Divisão de Infecção Hospitalar. Análise dos Dados do Sistema de Vigilância Epidemiológica das Infecções Hospitalares do Estado de São Paulo - 2016. Disponível em: http://www.saude.sp.gov.br/cve-centro-devigilancia-epidemiologica-prof.-alexandre-vranjac/areas-de-vigilancia/infeccao-hospitalar/sistema-devigilanciaepidemiologica)

GVE: Grupo de Vigilância Epidemiológica.

CVE: Centro de Vigilância Epidemiológica.

CVS: Centro de Vigilância Sanitária

No que se refere às ISC há um manual de orientações e critérios diagnósticos para hospital geral, adotado pelo Estado de São Paulo, que se baseia nas recomendações da ANVISA e do CDC (SES, 2018).

Até o ano de 2012 a DIH/CVE realizava a VE apenas das cirurgias limpas, agrupadas por área topográfica. Reconhecendo a necessidade de um olhar mais detalhado sobre o fenômeno de ocorrência destes agravos, a DIH/CVE realizou um estudo em parceria com a Escola de Enfermagem da Universidade de São Paulo (EEUSP), no qual foram selecionados a partir de critérios científicos e implementados, os procedimentos específicos para a VE das ISC no estado de São Paulo. Este trabalho foi objeto de mestrado da pesquisadora responsável pelo presente estudo. 
Como resultado deste estudo, passaram então, a fazer parte da VE das IRAS no Estado, os seguintes procedimentos cirúrgicos:

- Apendicectomia laparoscópica.

- Artroplastia de joelho.

- Artroplastia total de quadril.

- Colectomia laparoscópica.

- Colecistectomia laparoscópica.

- Craniotomia.

- Herniorrafia/hernioplastia laparoscópica.

- Histerectomia laparoscópica.

- Mastectomia.

- Parto cesariano.

- Revascularização do miocárdio.

Cada hospital, por sua vez, realiza um certo número destes procedimentos cirúrgicos selecionados, o qual deve ser informado mensalmente à DIH/CVE, bem como o correspondente número ISC. Com estes dados é calculada a proporção de ISC dentre as cirurgias realizadas, para cada procedimento específico.

Os dados analisados pela DIH/CVE para o ano de 2016 apontaram para parto cesariano como o procedimento cirúrgico com maior de instituições notificantes (436), seguido por colecistectomia laparoscópica (379), artroplastia total de quadril (310), artroplastia de joelho (309), herniorrafia/hernioplastia laparoscópica (303), apendicectomia laparoscópica (263), craniotomia (254), mastectomia (250), histerectomia laparoscópica (240), colectomia laparoscópica (191) e revascularização do miocárdio (142).

Em 2016, parto cesariano foi o procedimento com o maior número de cirurgias notificadas (325.5569), seguido por colecistectomia laparoscópica (80.129), herniorrafia, hernioplastia laparoscópica (29.259), mastectomia (15.829), craniotomia (13.895), histerectomia laparoscópica (13.135), apendicectomia laparoscópica (12.609), artroplastia total de quadril (11.922), artroplastia de joelho (11.474), revascularização do miocárdio (11.007) e colectomia laparoscópica (2.648).

Exceto parto cesariano $(0,22 \%)$ e revascularização do miocárdio $(2,47 \%)$, os demais tipos de procedimentos cirúrgicos citados acima apresentaram taxa de ISC igual a zero para o percentil 50 (SES, 2017). 


\subsection{VALIDAÇÃO DOS DADOS DE ISC DE SISTEMAS GOVERNAMENTAIS}

A necessidade de garantia da qualidade dos dados reportados aos sistemas de vigilância de IRAS tem sido apontada como fundamental pela literatura científica (Wilson \& Kiernan, 2012; Passaretti et al, 2011; McCoubrey et al, 2005). Elemento essencial a estes sistemas, a validação assegura a qualidade dos dados reportados e possibilita a comparação entre os hospitais (McKibben et al., 2005), garantindo desta forma, credibilidade científica e identificação de problemas metodológicos do programa. Outrossim, contribui para o aumento da adesão e participação no programa (McCoubrey et al., 2005).

A validação de sistemas de vigilância de IRAS pode ocorrer em termos de estrutura, de processos ou de resultados. Em termos de estrutura, avaliou na instituição de saúde a disponibilidade de recursos considerados necessários para uma VE efetiva. A validação em termos de processo buscou uma descrição sobre a forma pela qual os dados de ISC são obtidos. E a validação em termos de resultados verificou a completitude do denominador e a acurácia dos dados de ISC reportados (McCoubrey et al. 2005).

Cardo, Falk \& Mayhall (1993) realizaram um estudo de validação para determinar a sensibilidade e a especificidade das técnicas de vigilância padrão utilizadas na identificação de casos de ISC. Tal estudo, conduzido na década de 90 comparou dados coletados por profissionais do controle de infecção, que utilizavam as técnicas padrão, com os dados de um observador considerado padrão-ouro, que utilizou outra técnica. O resultado apontou para a mesma sensibilidade entre os dois métodos.

Vários estudos de validação da vigilância de IRAS foram realizados desde a década de 80, geralmente focando em apenas um aspecto de avaliação, como por exemplo a coleta de dados e, em geral relacionados a uma ou poucas instituições (Fabry et al., 2007)

Fabry et al., (2007) já apontavam para a necessidade da garantia da qualidade dos dados notificados na Europa, sob pena de sistemas vigilância terem seu futuro ameaçado caso seus dados não pudessem ser comparados, correndo a possibilidade de se tornarem objeto de controvérsia pública. De acordo com estes autores, dados de vigilância de IRAS podem ser avaliados sob diferentes dimensões, entre estas, sua representatividade; validade intrínseca dos indicadores (incluindo aqui as medidas relativas ao valor preditivo positivo, valor preditivo negativo, sensibilidade e especificidade) e outros aspectos como custos relacionados à coleta e 
análise dos dados, relevância clínica dos indicadores, simplicidade, utilidade e aplicabilidade dos indicadores.

A validação de dados pode ser interna ou externa. A primeira é executada pelos próprios hospitais para autoavaliação do programa de vigilância e pode ser realizada por meio de comparação dos resultados de uma amostra de casos sob risco de infecção e os casos registrados pelo hospital. A partir dos resultados é possível estimar a sensibilidade e a especificidade do programa. Já a validação externa é realizada por um processo de auditoria externo ao hospital (Washington,s/d). Ambos os processos tem por finalidade verificar a qualidade dos dados notificados.

A conferência da entrada dos dados do sistema também pode fazer parte da avaliação da qualidade. O Estado de Washington (EUA), por exemplo, realiza esta conferência por meio de verificação da entrada de dados de todos os hospitais, avaliando tendências mês a mês, conferindo a atualização dos hospitais em relação à notificação de dados, entre outros. O programa de IRAS deste Estado considera que, embora os dados não necessitem serem perfeitos para serem uteis, a acurácia é importante para que sejam significativos (Washington,s/d).

O sistema holandês PREZIES (Preventie Ziekenhuisinfecties door Surveillance) realiza a validação dos dados de ISC periodicamente, a cada três anos. A Holanda é um país que possui um pequeno número de hospitais, o que torna a aplicação de um estudo de validação sistemas de vigilância das ISC praticável, necessitando realizar entre 20 e 30 visitas anualmente (Manniën et al, 2007).

Na Austrália, o sistema VICNNIS (Victorian Hospital Acquired Infection Surveillance System) avaliou registros médicos de ISC de revascularização do miocárdio e comparou os dados. As discordâncias encontradas levaram a recomendações de modificação na metodologia de vigilância das ISC relacionadas a este procedimento (Friedman et al, 2007).

Na Escócia foi realizado um estudo de validação do sistema de vigilância das ISC e quando identificados problemas no nível local medidas foram tomadas no sentido de auxiliar os hospitais a melhorarem a qualidade de seus dados (McCoubrey et al, 2005).

A validação de sistemas de vigilância em âmbito nacional é um desafio, pois, além dos custos envolvidos, o alto número de observações necessárias dificulta a metodologia. Gastmeier et al, (2007) em sua revisão sobre os estudos de validação de IRAS publicados até então, já apontava para diferenças entre as metodologias utilizadas, como cálculo do tamanho da amostra, por exemplo, levando estes autores a sugerir que poderia ser de grande utilidade o desenvolvimento de um protocolo que combinasse as diferentes experiências destes estudos. 
Embora a validação de sistemas de VE seja considerada um desafio (McBryde et al., 2009), é essencial para verificar a confiabilidade dos dados reportados (Rich et al., 2013). 


\section{JUSTIFICATIVA DO ESTUDO}

Até o presente momento desconhecemos a existência de protocolo de validação de dados de IRAS para quaisquer das esferas administrativas em âmbito governamental, no Brasil. Baseados na necessidade de qualificar os dados notificados pelas instituições de saúde para o sistema de vigilância das ISC no Estado de São Paulo, apontada pela análise dos resultados desde sua implementação, este projeto de pesquisa teve por objetivo elaborar um protocolo com esta finalidade, com base em critérios científicos, para ser disponibilizado para o Sistema Único de Saúde (SUS) no Estado de São Paulo. 


\section{OBJETIVO GERAL}

Elaborar um protocolo que possa ser utilizado pelo Sistema Único de Saúde (SUS) para validar os dados do sistema de vigilância epidemiológica (VE) das ISC no Estado de São Paulo, com base em critérios científicos.

\subsection{OBJETIVOS ESPECÍFICOS}

1. Identificar elementos dos métodos de validação de dados adotados por diferentes sistemas governamentais de VE das ISC.

2. Desenvolver um protocolo de validação de dados de ISC para a ser aplicado no Estado de São Paulo.

3. Realizar um estudo piloto de validação de dados de ISC em uma região do Estado de São Paulo, a fim de verificar sua exequibilidade, bem como recursos técnicos necessários para sua aplicação.

4. Obter dados preliminares por meio da aplicação do protocolo desenvolvido para validação de dados de ISC no Estado de São Paulo.

5. Identificar potenciais melhorias necessárias para o sistema de notificação de dados de ISC no Estado de São Paulo, a partir dos resultados obtidos com o piloto de validação. 


\section{METODOLOGIA}

Trata-se de estudo de realizado em três etapas:

I) Estudo de revisão de estratégias adotadas por sistemas governamentais para a validação de dados de sistemas de vigilância das ISC, na última década.

II) Piloto de validação de dados de ISC em uma região do Estado de São Paulo.

III) Elaboração do protocolo de validação de dados de ISC para o estado de São Paulo. 


\subsection{ESTUDO DE REVISÃO DE ESTRATÉGIAS ADOTADAS POR SISTEMAS GOVERNAMENTAIS PARA A VALIDAÇÃO DE DADOS DE SISTEMAS DE VIGILÂNCIA DAS ISC, NA ÚLTIMA DÉCADA.}

Esta fase teve como propósito identificar elementos utilizados para validação de dados de infecção de sítio (ISC) por autoridades de saúde em outros cenários. Esta etapa foi considerada importante para obter informações que auxiliassem na elaboração dos componentes estruturantes do protocolo de validação a ser proposto no presente estudo. A Figura 4 apresenta as estratégias utilizadas nesta fase.

Figura 4. Representação esquemática das estratégias utilizadas para identificar os elementos necessários ao protocolo de validação de dados de infecções de sítio cirúrgico, a ser estabelecido para o Estado de São Paulo. São Paulo, 2018.

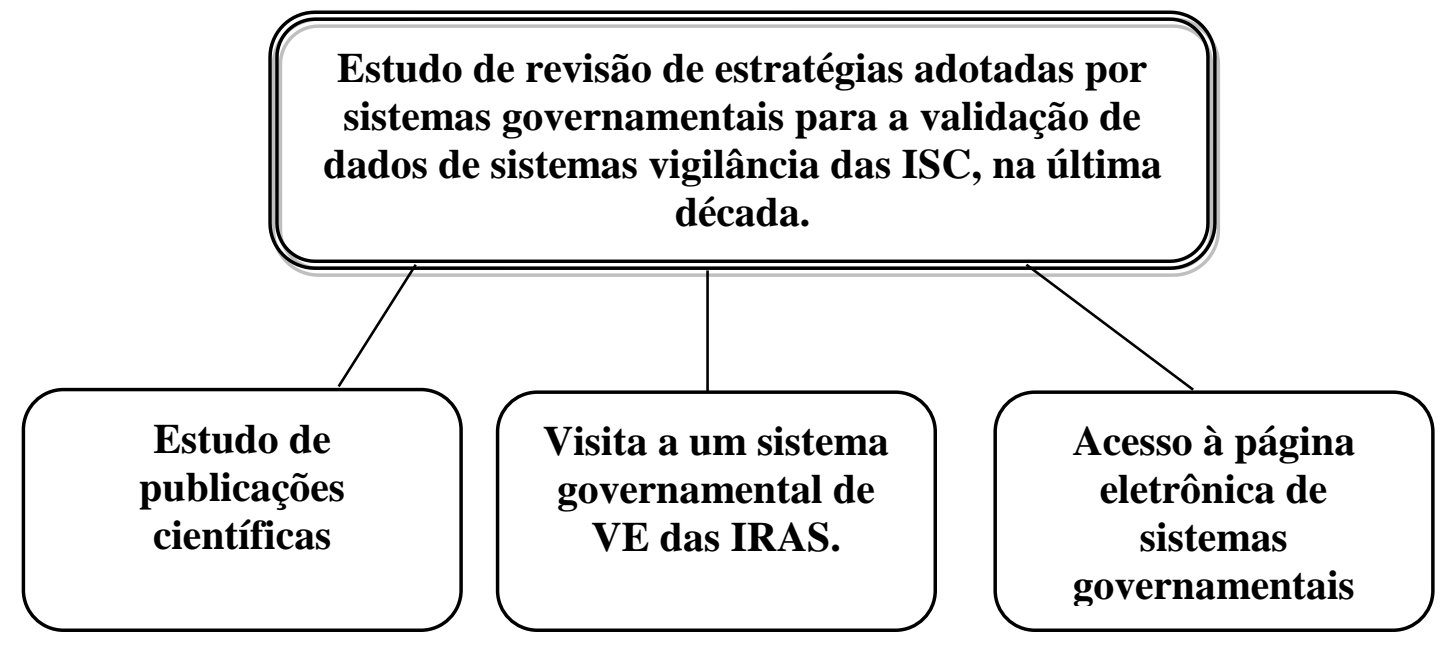

\subsubsection{Estudo de publicações científicas}

Optou-se por realizar uma revisão da literatura buscando conhecer as estratégias e os elementos de validação de dados de ISC utilizados por sistemas governamentais de outros países. O levantamento das publicações na literatura científica foi realizado por meio das bases de dados PubMed/Medline, SciELO e LILACS. Foram incluídos estudos publicados entre 01 de janeiro de 2005 e 31 de dezembro de 2016, nos idiomas português, inglês ou espanhol e excluídos aqueles que não se referiam a validação de dados de IRAS de sistemas governamentais de vigilância. Alguns artigos, já conhecidos pelas autoras e pertinentes ao tema foram utilizados inicialmente para a identificação de palavras-chave comuns à estas publicações. 
Os termos utilizados para busca no título ou resumo foram: healthcare associated infection $\underline{\mathbf{A N D}}$ validation $\underline{\mathbf{O R}}$ accuracy $\underline{\mathbf{O R}}$ auditing.

A revisão destes estudos buscou identificar as seguintes variáveis de interesse: nome do sistema governamental de vigilância para o qual o estudo foi validação foi realizado, o ano da publicação, país e a região para qual o estudo foi delimitado, objetivos da validação, período e tipos de IRAS validados, características qualitativas e quantitativas das equipes de revisores, método empregado para a seleção de hospitais e prontuários a serem validados, bem como cálculo do tamanho da amostra. Os aspectos operacionais e os resultados obtidos pelos estudos também foram identificados por esta revisão.

\subsubsection{Acesso à página de sistemas governamentais}

Para complementar o conhecimento acerca dos elementos e estratégias adotadas pelos sistemas governamentais de vigilância das IRAS para a validação de dados foram consultadas as páginas eletrônicas dos sistemas previamente identificados por meio do estudo das publicações científicas.

Buscou-se identificar a disponibilidade de protocolo de validação de dados de IRAS e informações referentes ao cálculo do tamanho da amostra de hospitais e dados a serem validados, periodicidade da validação, tipo de validação (prevalência ou outro), composição da equipe de validadores e se esta equipe é contratada ou própria do sistema.

\subsubsection{Visita a um sistema governamental de VE das IRAS}

O CDC foi escolhido como sistema governamental a ser visitado, por sua tradição e reconhecimento internacional no campo da prevenção e controle das infecções relacionadas à assistência à saúde (IRAS). Esta foi uma importante etapa para o desenvolvimento do projeto, uma vez que não se tem conhecimento de que no Brasil haja mecanismo similar de validação de um sistema governamental de vigilância das ISC.

A visita foi realizada no início de janeiro de 2016 e teve por objetivo conhecer detalhadamente os métodos utilizados para a validação dos dados de ISC, buscando identificar elementos de ordem prática e teórica que pudessem apoiar o desenvolvimento do presente estudo. 


\subsection{PILOTO DE VALIDAÇÃO DE DADOS DE ISC EM UMA REGIÃO DO ESTADO DE SÃO PAULO.}

Esta etapa teve por objetivo identificar recursos e estratégias necessários à realização de um estudo de validação desta natureza e testar sua exequibilidade e factibilidade para aplicação em larga escala. Os elementos por meio dela identificados possibilitaram a construção da versão final do protocolo a ser disponibilizado para a validação de dados do sistema de vigilância das ISC no Estado de São Paulo.

O planejamento e execução do piloto de validação são descritos detalhadamente a seguir:

\subsubsection{Operacionalização do piloto de validação}

\subsubsection{Seleção da região.}

A seleção da região convidada para a participação em caráter voluntário e confidencial no piloto de validação foi definida em conjunto com a equipe da DIH/CVE e levou em consideração os seguintes aspectos:

- Participação consistente no sistema estadual de notificação de dados de ISC.

- Representatividade: possuir hospitais nos três estratos definidos para este estudo, com base no número de leitos $(\leq 49 ; \geq 50$ e $\leq 199 ; \geq 200)$.

- Proximidade com o município de São Paulo para facilitar o deslocamento da equipe de validadores para a realização do projeto, considerando os recursos disponíveis.

Com base nestes critérios, a região administrativa correspondente ao Grupo de Vigilância Epidemiológica VII - Santo André foi a escolhida para ser convidada a participar do piloto de validação deste projeto de pesquisa. Esta região compreende os seguintes município: Diadema, Mauá, Ribeirão Pires, Rio Grande da Serra, São Bernardo do Campo, São Caetano do Sul e Santo André. 


\subsubsection{Definição dos procedimentos cirúrgicos selecionados para validação.}

Os critérios estabelecidos para a seleção dos procedimentos a serem validados foram:

- Ao menos um procedimento cirúrgico cuja manifestação da ISC possa ocorrer dentro do período de 30 dias após a realização da cirurgia, segundo os critérios adotados para o Estado de São Paulo.

- Ao menos um procedimento cirúrgico cuja ISC possa ocorrer dentro do período de 90 dias após a realização da cirurgia.

- Um procedimento realizado por via laparoscópica.

Desta forma, foram selecionados para a validação os seguintes procedimentos cirúrgicos:

- Artroplastia de joelho.

- Artroplastia total de quadril.

- Histerectomia laparoscópica.

- Parto cesariano.

\subsubsection{Período a ser validado.}

Optou-se por validar o período de um ano completo, buscando-se evitar desta forma vieses relacionados à sazonalidade. $\mathrm{O}$ ano de 2016 foi intencionalmente escolhido pelas pesquisadoras do estudo, por ser o último ano de notificação anterior à coleta de dados a ser realizada em 2017. Foram utilizados os dados recebidos até maio de 2017 pela DIH/CVE, provenientes dos hospitais notificantes. Desta forma, garantiu-se que ISC de procedimentos realizados até 31 de dezembro de 2016 e cuja manifestação tivesse ocorrido em até 90 dias após a cirurgia pudessem ter sido notificadas em tempo hábil (antes do início do piloto de validação) para a DIH/CVE.

\subsubsection{Elaboração de um formulário para coleta de dados.}

Para padronizar a coleta de dados foi elaborado um formulário em Microsoft Word ${ }^{\circledR}$ versão 2013 que permitiu o registro dos dados identificados por meio da revisão dos prontuários nos hospitais participantes.

Além de dados demográficos e de internação do paciente, este formulário elaborado em Microsoft $\operatorname{Word}{ }^{\circledR}$, possui também um campo para anotações do validador, no qual pode-se registrar informações que ajudem o validador a identificar a ocorrência ou não de ISC, bem 
como outras informações que julgar pertinente. $\mathrm{O}$ formulário contém também um campo para a classificação do validador em relação à ocorrência ou não de ISC desde sua interpretação realizada a partir dos critérios epidemiológicos vigentes no ano de 2016 (ANEXO 1), bem como sua classificação topográfica, quando do diagnóstico da ISC. O formulário inicialmente elaborado sofreu ajustes ao longo do piloto para permitir melhor captação dos dados a partir da revisão dos prontuários e sua versão final é apresentada no Apêndice A.

Foram revisados prontuários, resultados laboratoriais e registros de retornos ambulatoriais, quando disponíveis.

\subsubsection{Construção de um banco de dados}

Foi construído um banco de dados em Microsoft Excel® versão 2013 para inserção, armazenamento e análise dos dados coletados a partir da revisão dos prontuários.

\subsubsection{Estratégias operacionais para recrutamento de participantes e} desenvolvimento do piloto

Uma apresentação do projeto de pesquisa foi realizada inicialmente para os gestores do GVE selecionado para a participação no piloto. Após a anuência destes, foi realizada uma apresentação para os hospitais amostrados de acordo com a metodologia proposta por meio de consultoria da equipe do CEA/IME/USP.

Após esta apresentação, foi encaminhado um e-mail através da DIH/CVE aos hospitais amostrados, informando uma síntese do projeto de pesquisa e acompanhado dos seguintes documentos:

- Instrumento de coleta de dados (Apêndice A)

- Carta de autorização do responsável pelo hospital para participação voluntária e confidencial no projeto de pesquisa (Apêndice B)

- Termo de responsabilidade assinado pela pesquisadora responsável (Apêndice C).

Nos casos de recusa na participação do estudo, procedeu-se ao convite dos demais hospitais, seguindo-se o critério de seleção adotado.

A data e o horário para a revisão dos prontuários foi estabelecida em comum acordo entre a pesquisadora responsável e os profissionais designados para acompanhar o estudo no hospital. 
A revisão dos prontuários ocorreu na própria instituição participante. A coleta de dados foi realizada pela pesquisadora, com apoio de profissional enfermeiro contratado e treinado especificamente para a realização desta tarefa.

Foram mensuradas a distância total dos percursos de ida e volta até os hospitais participantes do piloto. Este levantamento permitiu o planejamento e a otimização dos recursos a serem utilizados com o transporte para realização desta etapa do projeto de pesquisa. A depender da distância entre duas instituições e do número de prontuários a serem revisados, quando possível, duas instituições foram visitadas em um mesmo dia.

\subsubsection{Cálculo da amostra de hospitais a serem validados.}

Buscou-se apoio estatístico do Centro de Estatística Aplicada do Instituto de Matemática e Estatística da Universidade de São Paulo (CEA/IME/USP) por meio de uma consultoria, para propor uma metodologia estatística que permitisse realizar um cálculo de amostra de hospitais e prontuários para a validação de dados de ISC no Estado de São Paulo e que pudesse ser disponibilizada no protocolo para estudos futuros.

As pesquisadoras deste estudo solicitaram à equipe do CEA/IME/USP que o planejamento do cálculo do tamanho da amostra levasse em consideração a exequibilidade do projeto, considerando os recursos disponíveis para sua realização, mas sem deixar de ser representativa. Desta forma, optou-se por privilegiar a coleta de dados de maior número de prontuários por hospitais, em detrimento do número de hospitais.

Foi solicitado à equipe de consultoria estatística do CEA/IME/USP que, em cada ano, para um determinado procedimento selecionado, a amostra de hospitais contemplasse hospitais de pequeno, médio e grande porte, definidos de acordo com os seguintes estratos:

- Estrato I: com até 49 leitos;

- Estrato II: de 50 até 199 leitos;

- Estrato III: com 200 ou mais leitos.

O relatório elaborado como resultado desta consultoria encontra-se no ANEXO 2 .

Com base na distribuição do número de hospitais que notificaram ter realizado no ano de 2016 ao menos 01 dos procedimentos selecionados e, utilizando a fórmula apresentada a seguir foi calculada a amostra de hospitais a serem validados no piloto. Este cálculo foi realizado para 
cada um dos três estratos e cada um dos procedimentos cirúrgicos selecionados para a validação.

$$
\mathbf{h}_{j}^{K}=\frac{\mathbf{n}}{\mathbf{1}+\frac{n-1}{H_{j}^{K}}},
$$

Onde:

- $H_{j}^{k}$ : número de hospitais do estrato k que realizaram o procedimento $\mathrm{j}$;

- $\boldsymbol{h}_{j}^{k}$ : número de hospitais a serem amostrados no estrato $\mathrm{k}$ para o procedimento $\mathrm{j}$.

- $n=z_{\alpha}^{2} /\left(4\left(E_{k}\right)^{2}\right)$,

- $E_{k}$ : erro escolhido entre a proporção estimada de infecções dos hospitais do estrato k e o valor verdadeiro (neste estudo foi utilizado o valor de 0,15 )

- $z_{a}$ é o valor obtido da tabela associado ao nível de confiança do intervalo na estimação da proporção (neste estudo foi utilizado o coeficiente de confiança igual a 95\%; $z_{\alpha}=1,96$ ).

(Extraído de: Reimann, Avidos \& Tamada, 2016)

A Tabela 1 apresenta o tamanho da amostra de hospitais a serem validados, calculada para cada procedimento, em cada estrato e, o número total de hospitais da região a ser validada que notificaram ter realizado ao menos 1 procedimento cirúrgico em 2016, dentre os selecionados.

Tabela 1. Número amostral de hospitais para participar do piloto de validação de dados de infecções de sítio cirúrgico no Estado de São Paulo e número total de hospitais notificantes no ano de 2016. Grupo de Vigilância Epidemiológica VII - Santo André. São Paulo, 2018.

\begin{tabular}{ccccc}
\hline Estrato & $\begin{array}{c}\text { Histerectomia } \\
\text { laparoscópica N amostral } \\
(\mathbf{N} \text { total*) }\end{array}$ & $\begin{array}{c}\text { Artroplastia do } \\
\text { joelho N amostral } \\
(\mathbf{N} \text { total*) }\end{array}$ & $\begin{array}{c}\text { Artroplastia do } \\
\text { quadril N amostral } \\
(\mathbf{N} \text { total*) }\end{array}$ & $\begin{array}{c}\text { Parto cesariano } \\
\text { N amostral } \\
\text { (N total*) }\end{array}$ \\
\hline I & $\mathbf{1}(1)$ & $\mathbf{2}(2)$ & & \\
II & $\mathbf{7}(8)$ & $\mathbf{8}(9)$ & $\mathbf{1}(1)$ & $\mathbf{1}(2)$ \\
III & $\mathbf{3}(3)$ & $\mathbf{5}(5)$ & $\mathbf{5}(11)$ & $\mathbf{1 0}(12)$ \\
\hline Total & $\mathbf{1 1}(12)$ & $\mathbf{1 5}(16)$ & $\mathbf{1 5}(17)$ & $\mathbf{4}(6)$ \\
\hline
\end{tabular}

* total de hospitais notificantes 
Após o cálculo do tamanho da amostra de hospitais, definiu-se uma ordem arbitrária para os procedimentos cirúrgicos selecionados. Para este estudo, o critério adotado para esta ordem foi o da magnitude do procedimento. Assim, parto cesariano foi o primeiro procedimento selecionado aleatoriamente, seguido de artroplastia total do quadril, artroplastia de joelho e histerectomia laparoscópica. Para artroplastia total de quadril considerou-se aqueles hospitais que também fizeram parto cesariano. E desta forma foi feito com os dois seguintes procedimentos, sempre priorizando a seleção de hospitais que realizaram os procedimentos anteriormente selecionados. Quando houve necessidade, a amostra foi complementada considerando os hospitais que realizaram somente o procedimento em questão, mas que não realizaram o (s) anterior (s). Esta estratégia permitiu otimizar os recursos disponíveis para realizar a validação de dados in loco.

\subsubsection{Cálculo da amostra de prontuários a serem validados.}

Após a anuência formal dos hospitais, que aceitaram participar do piloto sob caráter voluntário e confidencial, foi solicitado a estes o envio das seguintes informações para a pesquisadora responsável:

1) Lista com a identificação das cirurgias realizadas entre 01 de janeiro e 31 de dezembro de 2016, para cada um dos seguintes procedimentos cirúrgicos (quando realizado): artroplastia de joelho, artroplastia total de quadril, histerectomia laparoscópica e parto cesariano.

2) Identificação de quais pacientes foram notificados com ISC para o sistema estadual de vigilância das ISC. Para assegurar o anonimato, foi orientado aos hospitais que a lista com as informações solicitadas fosse encaminhada para a pesquisadora responsável sem o nome dos pacientes, apenas o número de registro.

A partir do número de cirurgias e de ISC informado pelo hospital, foi realizado o cálculo da amostra de prontuários a serem revisados. Para evitar dados inválidos na aplicação da fórmula para obtenção de amostras, foi necessário optar por um número diferente de zero, sempre que a taxa reportada pelo hospital fosse zero. Assim sendo, optou-se por utilizar o menor valor diferente de zero, identificado na distribuição de percentis para taxas de ISC em cada tipo de procedimento cirúrgico obtido pelo sistema de vigilância da DIH/CVE no ano de 2016. Para facilitar a compreensão deste recurso matemático, no Quadro1 é apresentada a distribuição dos percentis nos diferentes procedimentos no ano de referência. 
Quadro 1. Distribuição do número de hospitais notificantes, número de cirurgias e percentis das taxas de infecção de sítio cirúrgico em procedimentos cirúrgicos selecionados, referente ao ano de 2016. Centro de Vigilância Epidemiológica "Prof. Alexandre Vranjac". São Paulo, 2018.

\begin{tabular}{|c|c|c|c|c|c|c|c|}
\hline $\begin{array}{c}\text { Tipo de procedimento } \\
\text { cirúrgico }\end{array}$ & $\begin{array}{c}\text { Hospitais } \\
\text { notificantes } \\
(\mathbf{N})\end{array}$ & $\begin{array}{c}\text { Cirurgias } \\
(\mathbf{N})\end{array}$ & $\mathbf{p 1 0}$ & $\mathbf{p 2 5}$ & $\mathbf{p 5 0}$ & $\mathbf{p 7 5}$ & $\mathbf{p 9 0}$ \\
\hline Artroplastia de joelho & 309 & 11474 & 0 & 0 & 0 & $\underline{\mathbf{2 , 8}}$ & 7,54 \\
\hline $\begin{array}{c}\text { Artroplastia total de } \\
\text { quadril }\end{array}$ & 310 & 11922 & 0 & 0 & 0 & $\underline{\mathbf{3 , 1}}$ & 8,03 \\
\hline $\begin{array}{c}\text { Histerectomia } \\
\text { laparoscópica }\end{array}$ & 240 & 13135 & 0 & 0 & 0 & 0 & $\underline{\mathbf{2 , 0 4}}$ \\
\hline Parto cesariano & 436 & 325569 & 0 & 0 & $\underline{\mathbf{0 , 2}}$ & 1 & 2,22 \\
\hline
\end{tabular}

O cálculo da amostra de prontuários a serem revisados foi realizado utilizando-se a fórmula apresentada a seguir:

$$
\mathrm{a}_{\mathrm{i}}=\frac{\mathrm{m}_{\mathrm{j}}}{1+\frac{\mathrm{m}_{\mathrm{j}}-1}{\mathrm{C}_{\mathrm{j}}}},
$$

Onde:

$\mathbf{a}_{\mathrm{j}}=$ número de prontuários a serem amostrados.

$\mathrm{m}_{\mathrm{j}}=\frac{\mathrm{z}_{\mathrm{\alpha}}^{2} \hat{\mathrm{p}_{\mathrm{j}}}\left(1-\hat{\mathrm{p}_{\mathrm{j}}}\right)}{\mathrm{E}^{2}}$

$\mathbf{z}_{\alpha}=$ é determinada a partir do valor fixado para o coeficiente de confiança. Neste estudo foi utilizado o coeficiente igual a $95 \%\left(\mathrm{z}_{\alpha}^{2}=(\mathbf{1}, 96)^{2} \cong 3,842\right)$.

$\widehat{\mathbf{p}_{\mathfrak{j}}}=$ taxa de ISC informada pelo hospital, obtida a partir das informações levantadas junto aos hospitais, conforme descrito acima. Quando a taxa reportada pelo hospital foi igual a zero optou-se por utilizar o menor valor diferente de zero identificado na distribuição de percentis para taxas de ISC em cada tipo de procedimento cirúrgico obtido pelo sistema de vigilância da DIH/CVE no ano de 2016. 
$\mathbf{E}=$ é o quanto se aceita de erro entre a proporção estimada e o valor verdadeiro (que seria observado caso todos os prontuários fossem analisados), que deve ser um valor entre 0 e 1 . Neste estudo fixou-se o erro em 0,05 .

$\mathbf{C}_{\mathrm{j}}=\mathrm{o}$ número de cirurgias do procedimento escolhido no período considerado, que foram realizadas no hospital $\mathrm{j}$,

Quando, ${ }^{\mathbf{a}_{\mathfrak{j}}}$ não foi um número inteiro, ele deve foi arredondado para o valor inteiro mais próximo acima dele.

(Fonte: Reimann, Avidos \& Tamada, 2016. In: Mello DS, 2018)

\subsubsection{Análise dos resultados e retroalimentação para as instituições participantes} do piloto de validação.

O diagnóstico quanto à ocorrência ou não da ISC estabelecido pela equipe de revisores foi considerado como "padrão-ouro", neste estudo. A partir dos resultados obtidos, os dados foram analisados comparando-se o numerador, denominador e taxas notificados pelo hospital para o sistema de vigilância de ISC do estado de São Paulo com aqueles observados a partir da revisão da amostra de prontuários pela equipe de validadores. Para os casos em que houve dúvida por parte da equipe de validadores quanto ao diagnóstico de ISC a equipe da DIH/CVE foi consultada.

Cada hospital participante recebeu da DIH/CVE um relatório individualizado contendo além destas informações, recomendações relacionadas às divergências, quando identificadas. Também foram descritas as divergências entre a classificação das ISC de acordo com o plano acometido. O modelo de relatório enviado aos hospitais é apresentado no Apêndice D.

Para cada procedimento cirúrgico revisado foi elaborada uma tabela de contingência contendo os verdadeiros positivos (VP), os falsos positivos (FP), os verdadeiros negativos $(\mathrm{VN})$ e os falsos negativos (FN), considerando-se o diagnóstico estabelecido pelos validadores como "padrão-ouro" em relação ao conjunto de valores identificados por meio da validação de dados de ISC realizada com os hospitais participantes. Foram então, calculados o valor preditivo positivo (VPP), o valor preditivo negativo (VPN), a sensibilidade e a especificidade diretamente a partir destas tabelas. 
Os seguintes conceitos foram adotados:

- Verdadeiros positivos: casos notificados como ISC pelo hospital e confirmados pelo revisor como ISC.

- Falsos positivos: casos notificados como ISC pelo hospital e identificados pelo revisor como não ISC.

- Verdadeiros negativos: casos notificados como não ISC pelo hospital e confirmados pelo revisor como não ISC.

- Falsos negativos: casos notificados como não ISC pelo hospital e identificados pelo revisor como ISC.

- Valor preditivo positivo $($ VPP $)=$ proporção de pacientes notificados pelo hospital com ISC, que foram confirmados pelo revisor com ISC.

$\underline{\text { Cálculo }}=\mathrm{VP} /(\mathrm{VP}+\mathrm{FP})$

- Valor preditivo negativo $(\mathbf{V P N})=$ proporção de pacientes notificados pelo hospital como não ISC, que foram confirmados pelo revisor como não ISC.

$\underline{\text { Cálculo }}=\mathrm{VN} /(\mathrm{VN}+\mathrm{FN})$

- Sensibilidade: proporção de pacientes com ISC identificados pelo revisor, que foram notificados como ISC pelo hospital (VP).

$\underline{\text { Cálculo }}=\mathrm{VP} /(\mathrm{VP}+\mathrm{FN})$

- Especificidade: proporção de pacientes identificados pelo revisor como não ISC, que foram notificados como não ISC pelo hospital (VN).

$\underline{\text { Cálculo }}=\mathrm{VN} /(\mathrm{VN}+\mathrm{FP})$

(Benseñor \& Lotufo, 2011) 


\subsection{ELABORAÇÃO DO PROTOCOLO DE VALIDAÇÃO DE DADOS DE ISC PARA O ESTADO DE SÃO PAULO.}

Esta etapa final do projeto de pesquisa compreendeu a elaboração do protocolo propriamente dito, para a validação dos dados de ISC no Estado de São Paulo.

Para alcançar sua formatação final, utilizou-se do conjunto de informações identificadas por meio do estudo de revisão da literatura e do piloto de validação. Todos os recursos, elementos e estratégias identificados nas etapas anteriores possibilitaram a organização de um modelo norteador da técnica e dinâmica a serem adotadas durante um estudo de validação de dados de ISC no Estado de São Paulo. O resultado desta etapa compreende o protocolo a ser disponibilizado para o SUS no Estado de São Paulo.

A versão final do protocolo, resultante deste estudo, a ser disponibilizado para o SUS para o Estado de São Paulo é apresentada no Apêndice E. 


\section{ASPECTOS ÉTICOS}

Este projeto de pesquisa foi submetido e aprovado pelo Comitê de Ética em Pesquisa da Escola de Enfermagem da Universidade de São Paulo (CEP-EEUSP) CAAE: 64237917.9.0000.5392 (ANEXO 3).

A realização deste projeto recebeu autorização formal do Centro de Vigilância Epidemiológica "Prof. Alexandre Vranjac" (ANEXO 4).

A participação das instituições teve caráter voluntário e confidencial e foi solicitada autorização formal do responsável pelo hospital para participação no projeto de pesquisa por meio do documento denominado "CARTA DE AUTORIZAÇÃO DO SERVIÇO DE SAÚDE" (APÊNDICE B)

Todos os dados coletados por meio do piloto de validação de dados de ISC serão mantidos sob confidencialidade, estando em posse apenas da pesquisadora responsável pelo estudo, que realizou a análise. Sob nenhuma hipótese foram ou serão divulgadas por nenhum meio, informações que identifiquem o paciente ou a instituição participante. 


\section{RISCOS}

Por não se tratar de pesquisa de intervenção e sim de avaliação retrospectiva de dados, com consulta a prontuários, os riscos relacionaram-se ao possível desconforto pela necessidade de revisar dados institucionais, perda do anonimato e da confidencialidade, extravio, perda e rasura de documentos. Para minimizar estes riscos a pesquisadora responsável pelo estudo assinou um “TERMO DE RESPONSABILIDADE” (APÊNDICE C), que foi entregue à direção do hospital garantindo sigilo de todos os dados que identificassem o paciente e a instituição e de que não haveria dano moral, psicológico ou físico aos participantes do estudo. Os prontuários foram revisados em local pertencente ao serviço participante, indicado por seu responsável, com o objetivo de evitar o transporte destes documentos, o que poderia implicar em perda ou extravio ou mesmos rasuras aos prontuários. 


\section{BENEFÍCIOS}

O protocolo desenvolvido ficará disponível para sua utilização pelo Sistema Único de Saúde (SUS) para ser aplicado no estado de São Paulo, com vistas a avaliar a qualidade da informação notificada pelas instituições de saúde sobre suas taxas de infecção de sítio cirúrgico. Espera-se que sua aplicação possa identificar, quando houver falhas no processo de notificação destes dados, adoção de estratégias que promovam a melhoria deste processo e a possibilidade de que o Estado obtenha taxas acuradas deste tipo de agravo à saúde. 


\section{RESULTADOS}

\subsection{ESTUDO DE REVISÃO DE ESTRATÉGIAS ADOTADAS POR SISTEMAS GOVERNAMENTAIS PARA A VALIDAÇÃO DE DADOS DE SISTEMAS DE VIGILÂNCIA DAS ISC, NA ÚLTIMA DÉCADA.}

\subsubsection{Estudo de publicações científicas}

Foram localizados inicialmente PubMed/Medline: 1.835 artigos; SciELO: 143; LILACS: 17. Destes, 74 foram selecionados pelo título, 48 pelo resumo e 14 foram os artigos incluídos neste estudo após a leitura do texto na íntegra. O país com maior número de publicações $(\mathrm{N}=05)$ foram os Estados Unidos da América. Estes estudos referem à validação de dados de IRAS realizada por alguns de seus Estados. Dados de caracterização dos estudos são apresentados na Tabela 2.

Seis dentre os artigos $(\mathrm{N}=14)$ trataram da validação de dados de ISC, e os demais sobre infecção da corrente sanguínea relacionada ao cateter central (ICSRC), como apresentado na Tabela 3, que destaca o período e tipo de infecção relacionadas à assistência à saúde validado por cada estudo, o objetivo da validação, método empregado, composição da equipe de revisores e critérios adotados para a seleção de hospitais e prontuários incluídos nos estudos. São Paulo. Brasil, 2018. 
Tabela 2. Caracterização dos estudos identificados, de acordo com ano da publicação, país, região para a qual se delimita e nome do programa competente. São Paulo, 2018.

\begin{tabular}{|c|c|c|c|c|}
\hline Autores & $\begin{array}{c}\text { Ano } \\
\text { publicação }\end{array}$ & País & $\begin{array}{l}\text { Região/ } \\
\text { Estado }\end{array}$ & Nome do programa de vigilância \\
\hline Reilly et al., & 2015 & $\begin{array}{l}\text { Bulgaria, Finlandia, Alemanha, } \\
\text { Hungria, Italia, Letónia, Lituânia, } \\
\text { Polônia, Espanha, Reino Unido }\end{array}$ & $\begin{array}{l}\text { União } \\
\text { Européia }\end{array}$ & European Centre for Disease Prevention and Control (ECDC) \\
\hline Singh et al. & 2015 & Inglaterra & Sudeste & Public Health England (PHE) \\
\hline Rich et al., & 2013 & EUA & Colorado & National Healthcare Safety Network (NHSN) \\
\hline Hazamy et al., & 2013 & EUA & New York & NHSN \\
\hline Haley et al., & 2012 & EUA & New York & NHSN \\
\hline John et al., & 2012 & EUA & Oregon & NHSN \\
\hline Backman et al., & 2010 & EUA & Connecticut & NHSN \\
\hline Masia et al., & 2010 & Itália & - & $\begin{array}{l}\text { Italian Nosocomial Infections Surveillance in Intensive Care } \\
\text { Units Project (SPIN-UTI) }\end{array}$ \\
\hline Mannien et al., & 2007 & Holanda & & $\begin{array}{l}\text { Dutch National Nosocomial Infection Surveillance System } \\
\text { (Preventie Ziekenhuisinfecties door Surveillance [PREZIES]) }\end{array}$ \\
\hline Huotari et al.. & 2007 & Finlândia & - & Finnish Hospital Infection Program (SIRO) \\
\hline McCoubrey et al., & 2005 & Escócia & - & $\begin{array}{l}\text { Scottish Surveillance of Healthcare Associated Infection } \\
\text { Programme (SSHAIP) }\end{array}$ \\
\hline
\end{tabular}


Tabela 3. Descrição dos estudos selecionados segundo o período e tipo de infecção relacionadas à assistência à saúde validado, objetivo da validação, método empregado, equipe de revisores critérios adotados para a seleção de hospitais e prontuários incluídos nos estudos. São Paulo. Brasil, 2018.

\begin{tabular}{|c|c|c|c|c|c|}
\hline Autores & $\begin{array}{l}\text { Período } \\
\text { validado }\end{array}$ & Tipo de IRAS & Objetivos da validação & Método & Equipe de revisores \\
\hline Reilly et al., & 01 ano & $\begin{array}{l}\text { IRAS e uso de } \\
\text { antimicrobianos }\end{array}$ & $\begin{array}{l}\text { Testar a sensibilidade e a } \\
\text { especificidade da } \\
\text { notificação de IRAS e do } \\
\text { uso de antimicrobianos. }\end{array}$ & $\begin{array}{l}\text { Revisão de anotações de } \\
\text { pacientes, de enfermagem, } \\
\text { sistemas de informação dos } \\
\text { hospitais e enfermarias } \\
\text { clínicas. }\end{array}$ & $\begin{array}{l}\text { Ao menos } 01 \text { especialista do } \\
\text { programa e } 01 \text { membro da equipe } \\
\text { do hospital. }\end{array}$ \\
\hline Singh et al., & 05 anos & $\begin{array}{l}\text { ISC (prótese de } \\
\text { quadril e joelho, } \\
\text { incluindo } \\
\text { revisões) }\end{array}$ & $\begin{array}{l}\text { Avaliar a acurácia dos } \\
\text { dados reportados em dois } \\
\text { hospitais. }\end{array}$ & $\begin{array}{l}\text { Revisão de prontuários } \\
\text { eletrônicos, readmissão e } \\
\text { microbiologia. }\end{array}$ & Não descrito \\
\hline Rich et al., & $\begin{array}{c}04 \\
\text { meses }\end{array}$ & ICSRC & $\begin{array}{l}\text { Determinar a qualidade dos } \\
\text { dados notificados. }\end{array}$ & $\begin{array}{l}\text { Revisão de prontuários e } \\
\text { entrevista. }\end{array}$ & $\begin{array}{l}01 \text { enfermeira e } 01 \\
\text { epidemiologista treinado. }\end{array}$ \\
\hline López-Pueyo et al., & $\begin{array}{c}03 \\
\text { meses }\end{array}$ & $\begin{array}{l}\text { IRAS associadas } \\
\text { a dispositivos } \\
\text { invasivos. }\end{array}$ & $\begin{array}{l}\text { Avaliar a concordância } \\
\text { entre as informações dos } \\
\text { registros incluídos no } \\
\text { sistema e aquelas obtidas a } \\
\text { partir da revisão de } \\
\text { prontuários. }\end{array}$ & Revisão de prontuários. & $\begin{array}{l}02 \text { médicos especialistas em } \\
\text { cuidados intensivos, treinados e } \\
\text { não vinculados ao hospital } \\
\text { participante do estudo. }\end{array}$ \\
\hline Haley et al., & $\begin{array}{l}3 \text { anos e } \\
05 \\
\text { meses }\end{array}$ & ISC & $\begin{array}{l}\text { Validar a acurácia dos } \\
\text { dados notificados ao } \\
\text { sistema. }\end{array}$ & Revisão de prontuários. & Membros do programa. \\
\hline
\end{tabular}



Autores
Período
Tipo de IRAS
Objetivos da validação
Método
Equipe de revisores

\begin{tabular}{|c|c|c|c|c|c|}
\hline John et al., & 01 ano & ICSRC & $\begin{array}{l}\text { Validar os dados de ICSRC } \\
\text { notificados }\end{array}$ & Revisão de prontuários. & $\begin{array}{l}01 \text { médico intensivista, } 01 \\
\text { enfermeira de CIH e uma de saúde } \\
\text { pública, } 01 \text { epidemiologista e } 01 \\
\text { pesquisador analista principal; } 04 \\
\text { destes treinados pelo sistema. }\end{array}$ \\
\hline Backman et al., & $\begin{array}{c}03 \\
\text { meses }\end{array}$ & ICSRC & $\begin{array}{l}\text { Determinar a confiabilidade } \\
\text { e consistência da aplicação } \\
\text { dos critérios de definição } \\
\text { das ICSRC notificadas ao } \\
\text { Estado. }\end{array}$ & $\begin{array}{l}\text { Revisão de prontuários e } \\
\text { entrevista sobre o processo } \\
\text { de coleta de denominadores. }\end{array}$ & $\begin{array}{l}01 \text { enfermeira microbiologista, } \\
\text { com experiência, treinada pelo } \\
\text { programa e } 01 \text { epidemiologista } \\
\text { com experiência. }\end{array}$ \\
\hline Masia et al., & $\begin{array}{c}06 \\
\text { meses }\end{array}$ & $\begin{array}{l}\text { IRAS em } \\
\text { unidades de } \\
\text { cuidados } \\
\text { intensivos. }\end{array}$ & $\begin{array}{l}\text { Validar e determinar o } \\
\text { VPP, o VPN, a } \\
\text { sensibilidade e } \\
\text { especificidade dos dados } \\
\text { notificados ao projeto de } \\
\text { vigilância. }\end{array}$ & $\begin{array}{l}\text { Revisão de prontuários e } \\
\text { dados laboratoriais. }\end{array}$ & $\begin{array}{l}01 \text { médicos treinado para cada } \\
\text { UTI. }\end{array}$ \\
\hline Mannien et al., & 06 anos & ISC & $\begin{array}{l}\text { Investigar a qualidade da } \\
\text { coleta de dados e a } \\
\text { interpretação dos critérios } \\
\text { diagnósticos. }\end{array}$ & $\begin{array}{l}\text { Revisão de prontuários, } \\
\text { diagnósticos inconclusivos e } \\
\text { entrevista estruturada. }\end{array}$ & $\begin{array}{l}01 \text { membro do programa mais } 01 \\
\text { profissional do controle de } \\
\text { infecção de um hospital } \\
\text { previamente validado. }\end{array}$ \\
\hline
\end{tabular}




\begin{tabular}{ccclll} 
Autores & $\begin{array}{c}\text { Período } \\
\text { validado }\end{array}$ & Tipo de IRAS & Objetivos da validação & Método & Equipe de revisores \\
\hline \hline Huotari et al., & 5 anos & ISC & $\begin{array}{l}\text { Validação de dados de } \\
\text { vigilância de cirurgia } \\
\text { ortopédica } \\
\text { Validar os dados } \\
\text { notificados ao sistema. }\end{array}$ & $\begin{array}{l}\text { Revisão de prontuários e } \\
\text { entrevista. }\end{array}$ & $\begin{array}{l}\text { 0ntrevistas com mbros do programa. } \\
\text { profissionais da equipe de } \\
\text { controle de infecção da } \\
\text { instituição de saúde e, } \\
\text { revisão de casos. }\end{array}$ \\
\hline
\end{tabular}

A descrição dos métodos de seleção de hospitais e prontuários identificado nos estudos é apresentada na Tabela 4. 
Tabela 4. Descrição dos estudos selecionados segundo os métodos para seleção dos hospitais e seleção de prontuários descritos pelos estudos identificados por meio do estudo de publicações científicas. São Paulo, 2018.

\begin{tabular}{|c|c|c|}
\hline Variáveis & Seleção de hospitais & Seleção de prontuários \\
\hline \multicolumn{3}{|c|}{$\begin{array}{l}\text { Reilly et al., } 2015 \\
\end{array}$} \\
\hline População alvo: & Hospitais de cuidados agudos na Europa. & Pacientes internados (? Por ser de prevalência) \\
\hline Tipo de amostra: & "não informado" & "não informado" \\
\hline N amostra disponível: & 02 hospitais/país. & $100 \%$ da população alvo \\
\hline Base para cálculo da amostra: & $\begin{array}{l}\text { Calculada para produzir resultados sobre } \\
\text { toda a Europa e não para um país específico. }\end{array}$ & $\begin{array}{l}\text { Prevalência }=7 \% \text {; sensibilidade }=80 \% \text {; precisão }=+/- \\
5 \% \text {. }\end{array}$ \\
\hline N total validado: & 20 hospitais. & 1912 \\
\hline \multicolumn{3}{|c|}{ Singh et al., 2015} \\
\hline População alvo: & 02 hospitais no sudeste da Inglaterra & $\begin{array}{l}\text { Prontuários de pacientes submetidos a substituição do } \\
\text { quadril e joelho. }\end{array}$ \\
\hline Tipo de amostra: & "não informado" & $100 \%$ da população alvo \\
\hline N amostra disponível: & "não informado" & 8280 procedimentos \\
\hline Base para cálculo da amostra: & "não informado" & $\begin{array}{l}\text { Pacientes, cujo tempo de internação após a colocação da } \\
\text { prótese foi > } 7 \text { dias e aqueles que foram readmitidos no } \\
\text { hospital dentro de } 12 \text { meses após a colocação da prótese. } \\
\text { Foram analisados apenas os prontuários dos pacientes que } \\
\text { dentre estes tiveram tecido, swab de ferida e ou fluido } \\
\text { articular enviados para análise. }\end{array}$ \\
\hline N total validado: & 02 hospitais & 751 \\
\hline
\end{tabular}




\begin{tabular}{|c|c|c|}
\hline Variáveis & Seleção de hospitais & Seleção de prontuários \\
\hline \multicolumn{3}{|c|}{ Rich et al., 2013} \\
\hline População alvo: & $\begin{array}{l}\text { Todo hospital com UTI e hospitais de } \\
\text { cuidados agudos de longa permanência e } \\
\text { que tinham casos potenciais que preenchiam } \\
\text { os critérios do NHSN para ICSRC. }\end{array}$ & $\begin{array}{l}\text { Pacientes que tiveram cultura positiva enquanto estavam } \\
\text { na UTI ou com permanência de } 48 \mathrm{~h} \text { nesta unidade. }\end{array}$ \\
\hline Tipo de amostra: & $100 \%$ da população alvo & Amostra randomizada estratificada por serviço. \\
\hline N amostra disponível: & 60 & 650 \\
\hline Base para cálculo da amostra: & $\begin{array}{l}\text { Excluiram-se UTIs que não tiveram } \\
\text { pacientes com cateter central e/ou cultura de } \\
\text { sangue positiva e/ou tiveram cultura positiva } \\
\text { para cateter com menos de } 48 \mathrm{~h} \text { de } \\
\text { instalação. }\end{array}$ & $\begin{array}{l}\text { Considerou-se: o N de culturas positivas, o N de ICSRC } \\
\text { notificadas antes do início do projeto e a prevalência } \\
\text { resultante das ICSRC entre as culturas positivas. Quando } \\
\text { amostragem = } 0 \text { foi realizado um cálculo para chegar a um } \\
\text { valor de amostra positiva. Revisou-se ainda prontuários de } \\
\text { pacientes notificados com ICSRC, mas que não foram } \\
\text { incluídos na amostra estratificada. }\end{array}$ \\
\hline $\mathbf{N}$ total validado: & 35 & 519 \\
\hline \multicolumn{3}{|l|}{ López-Pueyo et al., 2013} \\
\hline População alvo: & UTIs adulto do país. & $\begin{array}{l}\text { Pacientes admitidos nas UTIs participantes por mais de } 24 \\
\text { horas no período considerado. }\end{array}$ \\
\hline Tipo de amostra: & Estratificada e randomizada. & Randomizada \\
\hline $\mathrm{N}$ amostra disponível: & 118 UTIs (de 109 hospitais) & 13324 \\
\hline Base para cálculo da amostra: & $\begin{array}{l}\text { Unidades de cuidados intensivos com menos } \\
\text { de } 50 \text { casos registrados foram excluídas. }\end{array}$ & $\begin{array}{l}\text { Sensibilidade }=66 \% \text {, especificidade }=99 \% \text {, precisão } \\
\text { arbitrária }=8 \%, \text { um } \mathrm{N} \text { intermediário entre } 5 \% \text { e } 10 \% \text {, com } \\
\text { intervalo de confiança de } 95 \% \text {. Apenas infecções } \\
\text { associadas a dispositivos incluídas no sistema foram } \\
\text { avaliadas. }\end{array}$ \\
\hline $\mathbf{N}$ total validado: & 20 UTIs & 1486 \\
\hline
\end{tabular}




\begin{tabular}{|c|c|c|}
\hline Variáveis & Seleção de hospitais & Seleção de prontuários \\
\hline \multicolumn{3}{|c|}{ Hazamy et al., 2013} \\
\hline População alvo: & Hospitais notificantes. & Pacientes de UTI com cultura de sangue positiva. \\
\hline Tipo de amostra: & "não informado" & "não informado" \\
\hline N amostra disponível: & Variou entre os anos: $172-183$. & Variou entre os anos: 5 - 20 por UTI. \\
\hline Base para cálculo da amostra: & "não informado" & "não informado" \\
\hline $\mathbf{N}$ total validado: & Variou entre os anos: $73-90 \%(127-183)$ & Variou entre os anos: 460-1196 prontuários \\
\hline \multicolumn{3}{|c|}{ Haley et al., 2012} \\
\hline População alvo: & Hospitais do estado & $\begin{array}{l}\text { Pacientes submetidos à cirurgia de revascularização do } \\
\text { miocárdio, procedimentos do quadril e cirurgia de cólon. }\end{array}$ \\
\hline Tipo de amostra: & $\begin{array}{l}\text { Amostra de hospitais selecionados segundo } \\
\text { critérios de interesse (taxas muito altas ou } \\
\text { muito baixas, tempo decorrido desde a } \\
\text { ultima auditoria, resultados da última } \\
\text { auditoria, mudanças no staff do hospital e } \\
\text { problemas com o envio de dados completos } \\
\text { e dentro dos prazos. }\end{array}$ & Amostra estratificada \\
\hline N amostra disponível: & 176 & 112.270 \\
\hline Base para cálculo da amostra: & $100 \%$ da população alvo & $\begin{array}{l}<80 \text { cirurgias }=9 \text { prontuários } ; \geq 80 \text { e }<299=12 ; \geq 300-999 \\
=15 ; \geq 1000=18 .\end{array}$ \\
\hline $\mathbf{N}$ total validado: & Em 2009: 160; em 2010: 130. & 7059 (6\% dos procedimentos notificados pelo hospital) \\
\hline
\end{tabular}




\begin{tabular}{|c|c|c|}
\hline Variáveis & Seleção de hospitais & Seleção de prontuários \\
\hline \multicolumn{3}{|c|}{ John et al., 2012} \\
\hline População alvo: & Hospitais com notificação obrigatória. & $\begin{array}{l}\text { Prontuários de todos os pacientes que tiveram notificação } \\
\text { de ICSRC e pacientes que tiveram bacteremia relacionada } \\
\text { à internação. }\end{array}$ \\
\hline Tipo de amostra: & $100 \%$ da população alvo & "não informado" \\
\hline N amostra disponível: & 44 & - \\
\hline Base para cálculo da amostra: & $100 \%$ da população alvo & $\begin{array}{l}100 \% \text { pacientes notificados com ICSRC; até } 60 \text { casos de } \\
\text { bacteremia não reportados como ICSRC e para hospitais } \\
\text { com mais de } 60 \text {, uma amostra de } 44 \text {. }\end{array}$ \\
\hline $\mathbf{N}$ total validado: & 44 & 817 \\
\hline \multicolumn{3}{|c|}{ Backman et al., 2010} \\
\hline População alvo: & $\begin{array}{l}\text { UTIs de hospitais de cuidados agudos de } \\
\text { notificação obrigatória. }\end{array}$ & $\begin{array}{l}\text { Pacientes destas UTIs com culturas positivas de sangue e } \\
\text { que possuíam cateter central na data do resultado da } \\
\text { cultura. }\end{array}$ \\
\hline Tipo de amostra: & $100 \%$ da população alvo & $100 \%$ da população alvo \\
\hline N amostra disponível: & 33 UTIs & 410 \\
\hline Base para cálculo da amostra: & $100 \%$ da população alvo & $100 \%$ da população alvo \\
\hline $\mathrm{N}$ total validado: & 30 UTIs adulto e 03 pediátricas. & 770 culturas positivas de sangue de 410 pacientes. \\
\hline
\end{tabular}




\begin{tabular}{|c|c|c|}
\hline Variáveis & Seleção de hospitais & Seleção de prontuários \\
\hline \multicolumn{3}{|c|}{ Masia et al., 2010} \\
\hline População alvo: & $\begin{array}{l}\text { Unidades de cuidados intensivos que } \\
\text { participaram da vigilância por ao menos } 3 \\
\text { meses. }\end{array}$ & $\begin{array}{l}\text { Pacientes que permaneceram na UTI por mais de } 48 \mathrm{~h} \text { e } \\
\text { que fizeram parte do estudo de vigilância. }\end{array}$ \\
\hline Tipo de amostra: & Randomizada & Não randomizada \\
\hline N amostra disponível: & 49 UTI & $27,3 \%$ dos pacientes \\
\hline Base para cálculo da amostra: & $\begin{array}{l}\text { A listagem dos hospitais para randomização } \\
\text { foi feita em ordem decrescente de numero } \\
\text { de pacientes-dia a fim de melhor representar } \\
\text { o tamanho e a carga de trabalho das UTI. }\end{array}$ & $100 \%$ da população alvo \\
\hline N total validado: & $08 \mathrm{UTI}$ & $832(27,3 \%$ dos pacientes $)$ \\
\hline \multicolumn{3}{|c|}{ McBryde et al., 2009} \\
\hline População alvo: & $\begin{array}{l}\text { Hospitais que participaram da notificação } \\
\text { ativamente. }\end{array}$ & $\begin{array}{l}\text { Pacientes notificados com ICSRC e pacientes de UTI com } \\
\text { bacteremia, que não foram reportados com ICSRC. }\end{array}$ \\
\hline Tipo de amostra: & Randomizada & "não informado" \\
\hline N amostra disponível: & 18 hospitais & 398 \\
\hline Base para cálculo da amostra: & "não informado" & $\begin{array}{l}\text { Até } 10 \text { resultados notificados como positivos e até } 10 \\
\text { negativos para hospitais com até } 100 \text { casos de bacteremia } \\
\text { notificados. Até } 20 \text { resultados notificados como positivos } \\
\text { e até } 20 \text { negativos para hospitais com mais de } 100 \text { casos } \\
\text { de bacteremia. }\end{array}$ \\
\hline N total validado: & 6 hospitais & 108 \\
\hline
\end{tabular}




\begin{tabular}{|c|c|c|}
\hline Variáveis & Seleção de hospitais & Seleção de prontuários \\
\hline \multicolumn{3}{|c|}{ Friedman et al., 2007} \\
\hline População alvo: & $\begin{array}{l}\text { Hospitais participantes da vigilância no } \\
\text { período. }\end{array}$ & $\begin{array}{l}\text { Pacientes submetidos à cirurgia de revascularização de } \\
\text { miocárdio. }\end{array}$ \\
\hline Tipo de amostra: & $100 \%$ da população alvo & Uma parte randomizada e todos os 48 pacientes com ISC \\
\hline N amostra disponível: & 6 hospitais & 1203 \\
\hline Base para cálculo da amostra: & $100 \%$ da população alvo & entre 15 a 72 pacientes. \\
\hline N total validado: & 6 hospitais & 169 \\
\hline \multicolumn{3}{|c|}{ Mannien et al., 2007} \\
\hline População alvo: & Todos os hospitais participantes do sistema & Procedimentos cirúrgicos (não especificados) \\
\hline Tipo de amostra: & Não randomizada & Não randomizada \\
\hline N amostra disponível: & "não informado" & "não informado" \\
\hline Base para cálculo da amostra: & "não informado" & $\begin{array}{l}20 \text { prontuários mais recentes (independente do status de } \\
\text { ISC), } 05 \text { prontuários mais recentes, de casos notificados } \\
\text { como ISC pela equipe de CIH e } 05 \text { casos selecionados } \\
\text { pela equipe de CIH como duvidosos. }\end{array}$ \\
\hline $\mathbf{N}$ total validado: & 40 hospitais & 859 \\
\hline \multicolumn{3}{|c|}{ Huotari et al., 2007} \\
\hline População alvo: & Hospitais que realizaram vigilância. & $\begin{array}{l}\text { Pacientes submetidos à artroplastia de joelho e quadril e } \\
\text { redução aberta de fratura de fêmur. }\end{array}$ \\
\hline Tipo de amostra: & $\begin{array}{l}100 \% \text { dos hospitais (participação } \\
\text { voluntária) }\end{array}$ & "não informado" \\
\hline N amostra disponível: & 9 & 15143 \\
\hline Base para cálculo da amostra: & $100 \%$ dos hospitais & 10 cirurgias notificadas como ISC e 40 sem. \\
\hline N total validado: & 8 hospitais & 397 \\
\hline
\end{tabular}


Variáveis

McCoubrey et al., 2005

População alvo:

Tipo de amostra:

N amostra disponível:

Base para cálculo da amostra:

$\mathrm{N}$ total validado:
Seleção de hospitais

Hospitais de "Divisões de cuidados agudos" e Serviços Especializados.

Amostra de hospitais selecionados segundo critérios de interesse (hospitais para os quais era mandatória a vigilância de SSIS). Foram excluídos 3 hospitais com pequeno conjunto de dados. Hospitais que tinham vigilância de ortopedia estes foram os procedimentos de escolha; nos demais hospitais foi escolhido um procedimento alternativo para validar.

18 "Divisões de cuidados agudos" e one special health board in Scotland.

\section{-} agudos" e one special health board in Scotland.

\section{Seleção de prontuários}

Dois tipos de procedimentos, sendo a primeira opção por um ortopédico, quando realizado.

Randomizada para cirurgias realizadas em um período específico de 03 meses e um número pré estabelecido de casos notificados como ISC .

\section{3}

20 case notes disponíveis, dentre 60 casos escolhidos aleatóriamente, no período(que excluíam os últimos 15 casos notificados como ISC) e 15 ISC.

602 


\section{- Amostra de hospitais e de prontuários}

Observa-se que as estratégias foram as mais diferentes entre os estudos tanto para definição da amostra dos hospitais quanto dos prontuários a serem validados. Alguns estudos de validação incluíram todas as instituições que possuíam UTI (unidades de cuidados intensivos) (Rich et al., 2013), enquanto outros utilizaram como critérios de inclusão um número pré-definido de pacientes notificados para o sistema de vigilância.

O mesmo ocorre em relação ao número de prontuários verificados pelos estudos, alguns optaram por verificar registros de casos de IRAS notificados ao sistema em determinado período (McCoubrey et al., 2005), outros utilizaram-se desta estratégia e verificaram ainda um número determinado de prontuários de pacientes que não foram notificados com a ocorrência de IRA (Mannien et al.,2007; Huotari et al., 2007).

Friedman et al.; (2007) utilizaram valores de VPP e VPN de estudos prévios para calcular o tamanho da amostra de pacientes e consideraram que a validação poderia ter melhor qualidade se o tamanho da amostra fosse maior.

John et al.,2012 estimaram que cada prontuário médico levou uma média de 30 minutos para ser revisado. Já Manniën et al (2007) referiram em sua discussão que a experiência da validação de dados do sistema demonstrou que para um dia de visita é possível revisar cerca de 25 prontuários (Manniën et al, 2007). Entretanto, como a taxa na Holanda é baixa (em torno de $3,2 \%$ ), a avaliação de 25 registros iria incluir apenas um ISC. Isto resultaria em um intervalo de confiança muito largo para os valores de sensibilidade, especificidade, VPP e VPN. Por este motivo, estes autores entenderam que seria melhor incluir 5 registros que tivessem sido notificados pelos profissionais.

\section{- Aspectos operacionais da validação}

As revisões de prontuários foram realizadas localmente na instituição participante do estudo e para a coleta de dados foram utilizados formulários padronizados (Jonh et al.,2012). Os dados coletados dos estudos incluíram além de dados demográficos, duração do procedimento, classificação ASA (Friedman et al. 2007), data da admissão no hospital, data da alta da unidade, se óbito ou não entre outros (López-Pueyo et al.,2013).

O período escolhido para a validação dos dados foram os mais diversos, conforme observamos anteriormente na tabela 1. Masia et al., 2010 optaram realizar a validação após o final do período de vigilância. 
A validação em termos de processo e estrutura foi realizada por meio de entrevista telefônica com o coordenador da vigilância de cada hospital (McCoubrey et al., 2005).

Quando realizada a validação em termos de processo envolveu entrevista estruturada (Mannien et al.,2007), onde eram abordadas questões relativas ao processo de coleta de dados, métodos de vigilância pós alta, e interpretação de acordo com a definição de caso (Huotari et al.,2007)

Não é de rotina que o mesmo prontuário seja avaliado por mais de um revisor. Quando necessário, outros revisores foram consultados (John et al.,2012). No caso de discordância entre os resultados obtidos pela equipe de validação e aqueles notificados ao sistema o prontuário foi revisado por um segundo revisor com 15 anos de experiência (Friedman et al. 2007) ou discutida com o profissional de prevenção de IRAS registrando-se as possíveis razões para a discordância na classificação (Backman et al., 2010).

Após a validação a equipe de validação discutiu com a equipe de vigilância da instituição para esclarecer possíveis fatores para a inconsistências (Masia et al., 2010).

\section{- Resultados obtidos pelos estudos}

Huotari et al., 2005 revisaram um total de 397 prontuários; Haley et al., 20127.059 correspondentes a $6 \%$ dos procedimentos notificados pelos hospitais. Um estudo piloto de validação realizado em 10 países da Europa envolveu a participação de 20 hospitais e 1.950 prontuários de um total de 3.958, conforme cálculo do tamanho da amostra (Reilly et al., 2015). Foi observada variação na qualidade dos dados entre os hospitais (McCoubrey et al., 2005), bem como na prática da vigilância e da aplicação dos critérios de definição (Rich et al., 2013).

Alguns procedimentos tiveram maior número de erros no diagnóstico da IRAS, como é o caso dos dados de cirurgia de colón que após resultado final teve uma elevação em sua taxa de ISC no hospital validado (Haley et al., 2012). Também houve aumento das taxas estaduais ocasionada por sua correção, após a validação dos dados (John et al.,2012). Foi identificada taxa de subnotificação superior a 50\%, apontando para a necessidade de validação continua e treinamento sobre os critérios de definição (Backman et al., 2010). Houve diferença significante entre as taxas notificadas e aquelas obtidas pelos revisores (Singh et al., 2015).

Os resultados obtidos permitiram a identificação de problemas metodológicos que desencadearam ações como novo treinamento dos profissionais que realizam a vigilância (Masia et al., 2010). Além disto, a padronização de processos de auditoria foi considerada 
relevante para melhorar a qualificação dos dados reportados (Hazamy et al., 2013). As discordâncias identificadas, muitas vezes estavam relacionadas à classificação anatômica da ISC (profunda e órgão espaço), sobretudo quando se trata em parte anatômica na qual essa diferenciação torna-se bastante complexa.

Os estudos utilizaram-se do cálculo dos valores preditivo positivo (VPP) e negativo (VPN), bem como a sensibilidade e especificidade como resultados da validação de dados. Os resultados identificados são apresentados na Tabela 5. 
Tabela 5. Valor preditivo positivo, valor preditivo negativo, sensibilidade e especificidade identificados pelos estudos, com intervalo de confiança de 95\% . São Paulo, 2018.

\begin{tabular}{|c|c|c|c|c|}
\hline AUTORES & VPP \% (IC 95\%) & VPN \% (IC 95\%) & SENSIBILIDADE \% (IC 95\%) & ESPECIFICIDADE \% (IC 95\%) \\
\hline Reilly et al., & 0,828 & 0,983 & $83(79-87)$ & $98(98-99)$ \\
\hline Singh et al., & Não realizado* & Não realizado* & Não realizado* & Não realizado* \\
\hline López-Pueyo et al., & $87,9(82,19-93,6)$ & $98,5(97,8-99,2)$ & $86(80,0-92,0)$ & $98,7(98,1-99,4)$ \\
\hline Hazamy et al., & Não realizado* & Não realizado* & 71 & 97 \\
\hline Backman et al., & 85 & 94 & 48 & 99 \\
\hline Masia et al., & $\begin{array}{l}\quad 83,5 \\
\text { (mediana: } 31,5 \text {; variação: } \\
0-98,1)\end{array}$ & $\begin{array}{c}97.3 \\
\text { (mediana: } 98,3 ; \\
\text { variação: } 0-100 \text { ) }\end{array}$ & $\begin{array}{c}82.3 \% \\
\text { (mediana: } 32.1 \text { variação: } 0-100 \text { ) }\end{array}$ & $\begin{array}{c}97.2 \\
\text { (mediana: 98,9\%; variação: 86,2 - } \\
\text { 100\%). }\end{array}$ \\
\hline McBryde et al., & $59(43-73)$ & $73(60-83)$ & $35(23-48)$, & 87 (IC 95, 82-92). \\
\hline McCoubrey et al., & $94,6 \%(87,9-98,2)$ & $99,4(98-99,9)$ & $96,7(90,7-99,3)$ & $9997,7-99,7)$ \\
\hline
\end{tabular}

*Calculou outras proporções que não VPP, VPN, sensibilidade e especificidade. 
De acordo com López-Pueyo, et al., 2013 as diferentes metodologias aplicadas pelos estudos tornam a comparação destes resultados limitada.

\subsubsection{Acesso à página de sistemas governamentais}

Não foram encontradas todas as informações na língua inglesa para os sistemas da Finlândia e do Holanda. Desta forma, foi possível identificar protocolos de validação para apenas 03 dentre os 07 programas de VE das IRAS. O Quadro 2 apresenta uma descrição das variáveis de interesse buscadas nas páginas eletrônicas acessadas. 
Quadro 2. Descrição das variáveis identificadas por meio do acesso à página eletrônica de sistemas governamentais de vigilância epidemiológica das infecções relacionadas à assistência à saúde identificadas pelo estudo de publicações científicas. São Paulo, 2018.

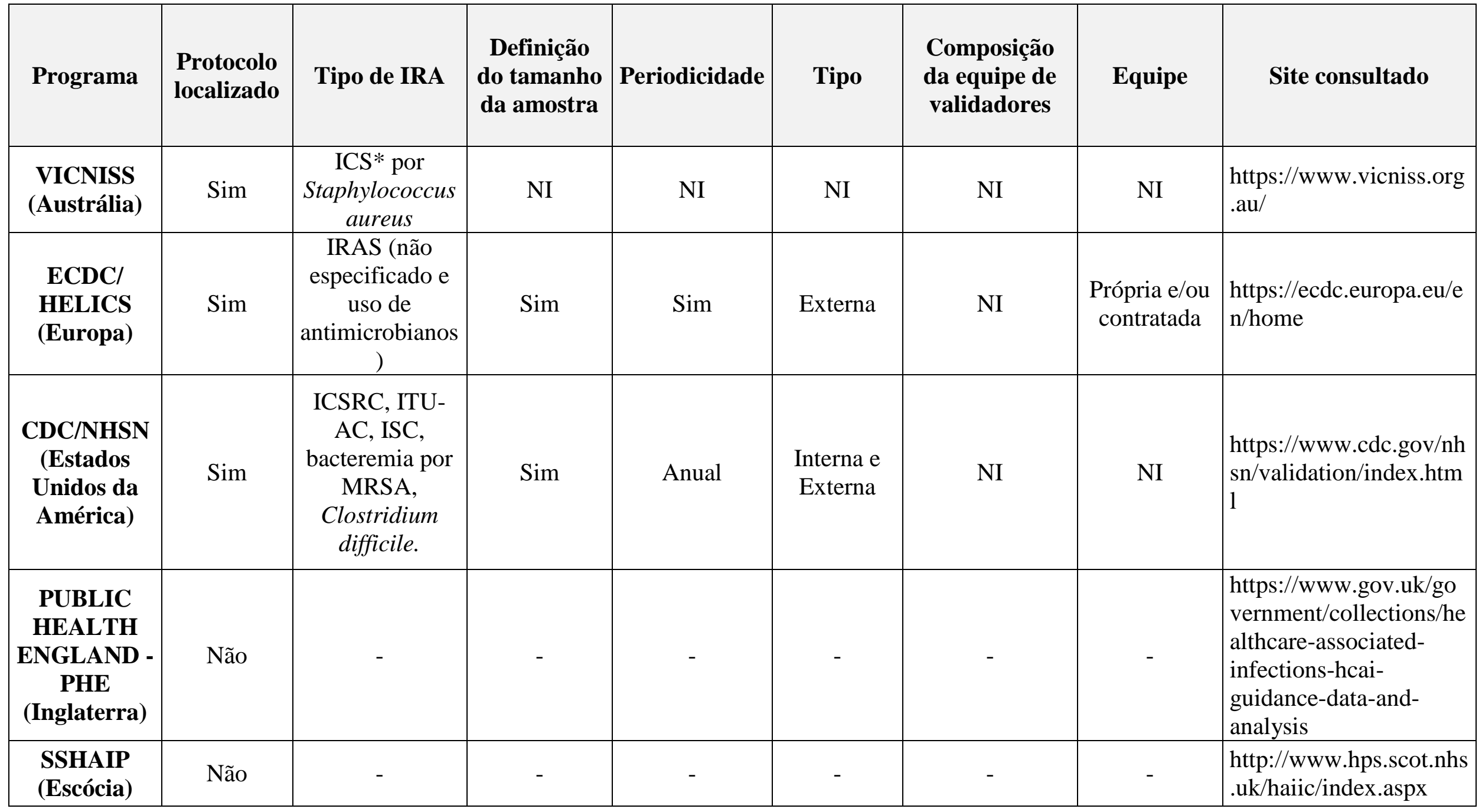

*NI. Não informado 


\subsubsection{Visita técnica à sistema governamental de VE das IRAS}

\section{Local: "Centers for Disease Control and Prevention, Division of healthcare quality promotion", Atlanta, Geórgia, EUA.}

Período: 10 a 14 de janeiro de 2016

A visita teve por objetivo conhecer as técnicas e estratégias utilizadas pelo CDC para validação de dados do sistema de vigilância das infecções de sitio cirúrgico (ISC) e identificar potenciais elementos adaptáveis para o sistema de vigilância epidemiológica (VE) das ISC do estado de São Paulo.

A atividade com foco na validação dos dados de ISC envolveu reuniões e discussões técnicas com membros das equipes componentes "Division of Healthcare Quality Promotion" (DHQP), divisão que está inserida no "National Center for Emerging and Zoonotic Infectious Disease" do "Centers for Disease Control and Prevention" (CDC) dirigida pela Dra Denise Mary Cardo.

Durante a visita técnica foi possível apreender um panorama geral das equipes relacionadas a este setor, bem como as atividades por elas desenvolvidas. Outras reuniões foram realizadas com diversos profissionais da DHQP, envolvidos em diferentes etapas do processo de vigilância. Estas reuniões favoreceram a compreensão do que representa o processo de validação dentro de um contexto mais amplo do sistema de vigilância, em relação as metas propostas. Além disto, oportunizou o debate com os profissionais sobre aspectos teóricos e práticos envolvendo o sistema de vigilância e o processo de validação. Foram discutidas as principais barreiras para a realização de um processo de validação ideal e potenciais formas de superá-la.

A validação como proposta pelo CDC tem como propósito assegurar a qualidade dos dados de vigilância, identificando e corrigindo problemas na notificação dos dados. A instituição elaborou um protocolo que tem como foco a validação externa de instituições que reportam dados ao NHSN conduzida por departamentos de saúde estaduais ou agências de fiscalização. O documento que contempla métodos padronizados para a condução da validação, incluindo um formulário padronizado para coleta de dados, encontra-se disponível na internet em: http://www.cdc.gov/nhsn/pdfs/validation/2014/2014-nhsn-ev-guidance.pdf . 
O protocolo padronizado contém um modelo de carta a ser enviado para os hospitais do estado antes da efetivação do processo de validação. O modelo pode ser customizado de acordo com a necessidade de cada estado e encontra-se no Appendix 1.2 do protocolo.

Os procedimentos cirúrgicos selecionados para a validação dos dados de ISC são preferencialmente histerectomia abdominal e cirurgia de cólon, já que estes são procedimentos alvos da vigilância de ISC nos EUA e são menos susceptíveis de sofrerem influência relacionada à vigilância pós alta, considerando que é esperado que pessoas acometidas por ISC relacionadas a estes procedimentos retornem para seguimento pós-operatório ou tratamento da infecção na instituição de origem.

A amostra de hospitais selecionados para a validação, bem como o número de prontuários a serem avaliados foi definida por conveniência, de acordo com o tempo que se tem disponível para que os profissionais realizem o processo. Desta forma, foi estabelecido um número fixo de hospitais a terem seus dados validados de acordo com o número mínimo e máximo de hospitais no estado. Uma amostra randomizada de 5\% de prontuários é recomendada de acordo com as características de cada instituição.

A avaliação da completitude do denominador é recomendada e deve ser realizada por meio de comparação entre os dados notificados ao National Healthcare Safety Network (NHSN) e o código de procedimentos ICD-9-CM gerados pelo hospital. No entanto, em discussão com membros da equipe fomos informadas de que atualmente a completitude do denominador não é um procedimento avaliado no momento, embora seja considerada como muito importante e está em foco para ser realizada.

A validação não é obrigatória, sendo realizada de forma voluntária pelos estados. Os Centers for Medicare \& Medicaid Services” (CMS), órgão responsável pelo financiamento das instituições de saúde, o qual subordina o repasse de verba, entre outras aspectos, à qualidade das informações notificadas e executa o processo de validação dos dados para que as instituições possam receber o benefício.

$\mathrm{O}$ treinamento para as equipes que realizam a validação é ministrado pelo CDC de acordo com a necessidade; não há periodicidade. O número de profissionais envolvidos na validação é variável de acordo com a equipe, uma vez que é realizado de maneira independente ou por agências de saúde estaduais, ou ainda pelo próprio CMS.

Não há um período específico que seja recomendado pelo CDC para a realização do processo de validação dos dados de ISC. 


\subsection{DESENVOLVIMENTO DO PROTOCOLO DE VALIDAÇÃO DE DADOS DE ISC PARA O ESTADO DE SÃO PAULO.}

\subsubsection{Resultados relativos aos aspectos operacionais}

Todos os 27 que notificaram ter realizado ao menos um procedimento cirúrgico, dentre os selecionados, no período validado foram convidados a participar do piloto, porém apenas 5 $(18,5 \%)$ aceitaram. De acordo com a esfera administrativa, 03 (60\%) hospitais são privados e $02(40 \%)$ públicos. A distribuição dos hospitais participantes de acordo com a estratificação estabelecida pelo número de leitos é apresentada a Tabela 6 .

Tabela 6. Distribuição dos hospitais participantes de acordo com o estrato estabelecido segundo número de leitos. Grupo de Vigilância Epidemiológica VII - Santo André. São Paulo, 2018.

\begin{tabular}{ccc}
\cline { 2 - 3 } & N hospitais participantes & N hospitais convidados (\%) \\
\hline Estrato I* & 1 & $4(100 \%)$ \\
Estrato II** & 3 & $16(100 \%)$ \\
Estrato III*** & 1 & $7(100 \%)$ \\
\hline
\end{tabular}

$\leq 49 * ; \geq 50 * * \mathrm{e} \leq 199 ; \geq 200 * * *$

Foram revisados 168 prontuários referentes aos seguintes procedimentos cirúrgicos: artroplastia de joelho, artroplastia total de quadril e histerectomia laparoscópica. A Tabela 7 descreve o número total de prontuários revisados por procedimento cirúrgico.

Infelizmente, a despeito do parto cesariano ter sido um dos critérios de priorização para a seleção de hospitais, não foi possível recrutar instituições para a participação voluntária no estudo e que realizassem este tipo de cirurgia. 
Tabela 7. Distribuição do número de prontuários revisados de acordo com o tipo de procedimento cirúrgico. Grupo de Vigilância Epidemiológica VII - Santo André. São Paulo, 2018.

\begin{tabular}{lc}
\hline \multicolumn{1}{c}{ Procedimento cirúrgico } & N prontuários revisados \\
\hline Artroplastia de joelho & 60 \\
Artroplastia total de quadril & 91 \\
Histerectomia laparoscópica & 17 \\
Parto cesariano & 0 \\
\hline TOTAL & $\mathbf{1 6 8}$ \\
\hline
\end{tabular}

Apenas 03 prontuários (referentes à artroplastia total de quadril) dentre os planejados para revisão não estavam disponíveis no momento da visita dos validadores.

Foram necessárias 42 horas e 09 minutos para sua revisão. O tempo médio gasto na revisão de cada prontuário foi de 15,05 minutos. A Figura 5 apresenta o tempo empregado com a revisão dos prontuários de acordo com o procedimento cirúrgico realizado.

Figura 5. Tempo empregado para revisão de prontuários de acordo com o procedimento cirúrgico realizado. $\mathbf{N}$ prontuários revisados = 168. Grupo de Vigilância Epidemiológica VII - Santo André. São Paulo, 2018.

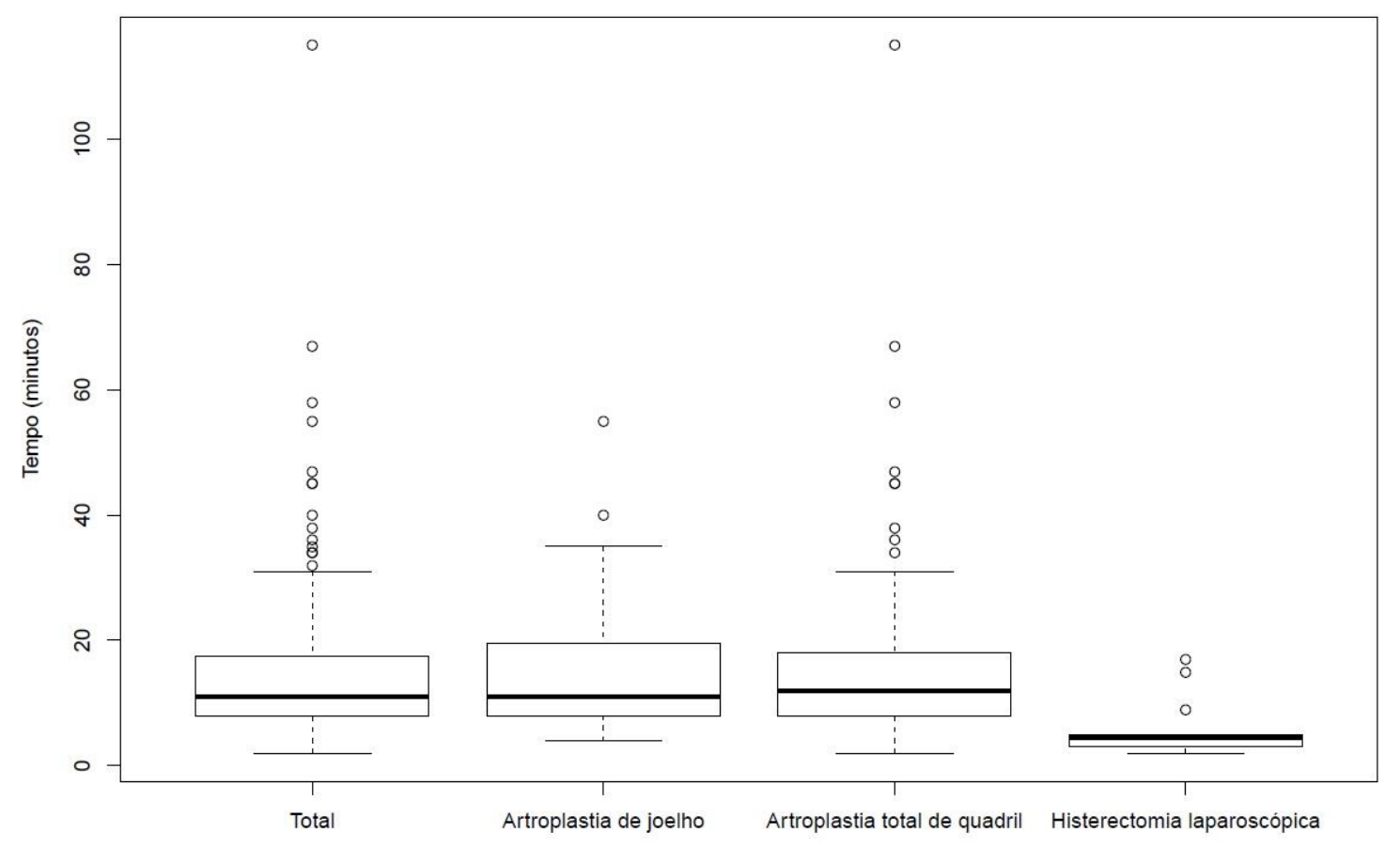


A validação consumiu 8 dias para visitas aos hospitais participantes e $394 \mathrm{~km}$ de deslocamento, a partir do município de São Paulo.

O custo médio total diário, por validador, incluindo meio período de treinamento, pagamento de diária, transporte e impressos foi de $\mathrm{R} \$ 212,56$. A Tabela 8 apresenta uma média de valores gasto por dia de validação e realizada por apenas 01 validador.

Tabela 8. Média de custos diários por validador e valor total estimado* do custo com o piloto de validação de dados de infecção de sítio cirúrgico realizado em uma região do Estado de São Paulo**. São Paulo, 2018.

\begin{tabular}{ccc}
\hline Custos & Valor médio diário (R\$) & Valor total (R\$) \\
\hline $\begin{array}{c}\text { Honorários } \\
\text { (Inclui treinamento e auxílio alimentação) }\end{array}$ & 170,00 & $2.210,00$ \\
Transporte & 40,00 & 520,00 \\
Impressos & 2,56 & 33.28 \\
\hline TOTAL & $\mathbf{2 1 2 , 5 6}$ & $\mathbf{2 . 7 6 3 . 2 8}$ \\
*Apenas um profissional foi contratado neste estudo, no entanto, os valores apresentados foram estimados \\
supondo-se que todos os 03 profissionais tivessem sido remunerados para o estudo. \\
**valores aplicados para 13 diárias.
\end{tabular}

Em 05 dentre os 08 dias dois validadores realizaram a revisão dos prontuários. Em três dos 08 dias apenas 01 validador realizou a revisão. Assim sendo, para a realização de validação em 5 hospitais e 168 prontuários, utilizou-se 13 diárias no total.

Os custos acima são apresentados para a situação efetivamente praticada neste projeto. pois apenas um dos validadores foi contratado com verba disponibilizada pelo CNPq para o desenvolvimento deste projeto de pesquisa. As duas outras validadoras são a pesquisadora principal e a orientadora, cujo atividade não foi remunerada. Contudo, tendo em vista o tempo requerido para a validação neste piloto, uma projeção de custos para 13 diárias, como neste caso, seria de $\mathrm{R} \$ 2.975,84$. 


\subsubsection{Acurácia dos dados de ISC}

\subsubsection{Numerador e denominador}

O número de prontuários a serem revisados, de acordo com o cálculo da amostra baseado no número de prontuários informados pelos hospitais, foi igual 171. No entanto, 03 prontuários não estavam disponíveis no dia da visita e, portanto, não puderam ser revisados. Dentre os 168 prontuários revisados, 17 foram excluídos, por não preencherem os critérios de notificação do procedimento cirúrgico selecionado (03 prontuários referentes à artroplastia de joelho, 10 à artroplastia total de quadril e 04 à histerectomia laparoscópica). Desta forma o denominador final da amostra foi de 151 prontuários (procedimentos cirúrgicos revisados e que preenchiam os critérios de inclusão previamente definido)

Dados notificados pelo hospital para o sistema estadual de vigilância das ISC foram comparados com aqueles identificados pelo validador após a revisão dos prontuários. O quadro 3 apresenta os resultados gerais em relação aos numeradores (número total de infecções) e denominadores (número total de cirurgias) notificados e observados durante a revisão de prontuários realizada por este projeto. 
Quadro 3. Resultados gerais em relação ao numerador e denominador, notificados e observados pela validação de dados. Grupo de Vigilância Epidemiológica VII - Santo André. São Paulo, 2018.

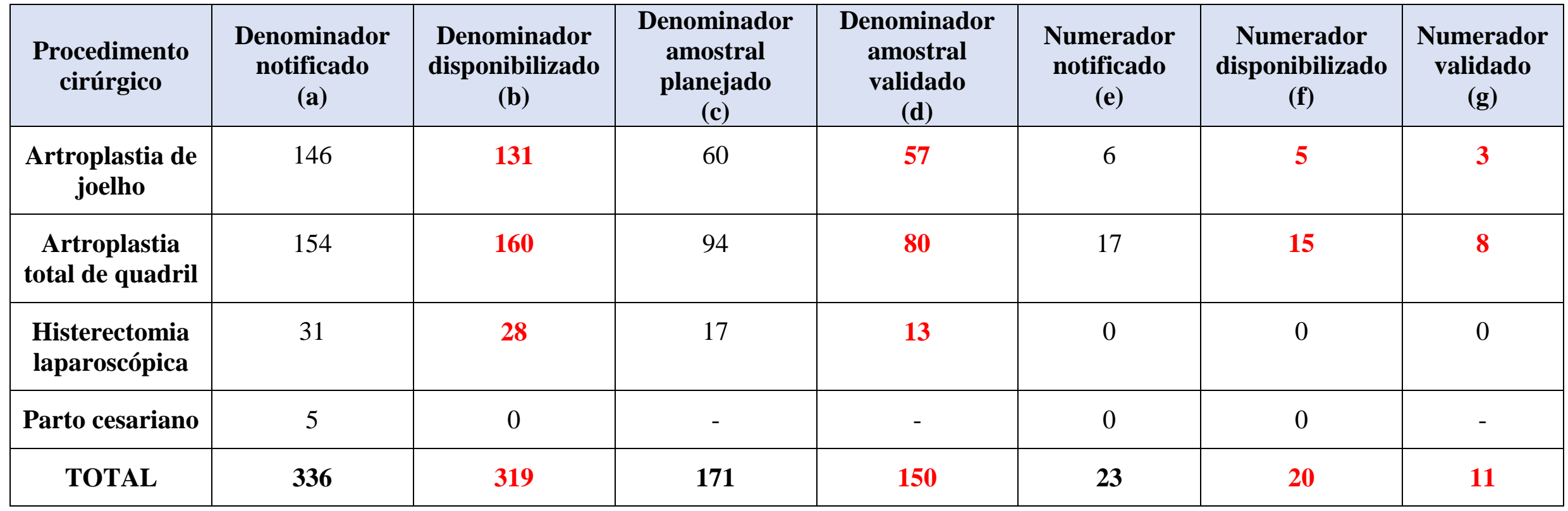

(a) = denominador notificado pelo hospital para o Estado, referente ao ano validado (2016)

(b) = denominador disponibilizado pelo hospital para o cálculo do tamanho da amostra e sorteio aleatório de prontuários a serem revisados; observa-se que este número difere de "a" para alguns procedimentos.

(c) = amostra de prontuários a serem revisados referentes ao denominador, calculada com base em "b".

d) = amostra final de prontuários revisados e que preenchiam critério de inclusão definido previamente no projeto.

(e) = numerador notificado pelo hospital para o estado, referente ao ano validado (2016).

(f) = numerador disponibilizado pelo hospital para o cálculo do tamanho da amostra de prontuários a serem revisados para a validação de dados; observa-se que este número difere de "e" para alguns procedimentos.

(g) = numerador identificado pelo validador. 
9.2.3. Avaliação da concordância de acordo com o critério diagnóstico das ISC

\subsubsection{Verdadeiros e falsos positivos e negativos}

Foi analisada a concordância entre os casos de ISC notificados pelo hospital para o sistema estadual de vigilância das ISC e aquele estabelecido pelo validador após a revisão do prontuário, considerado padrão-ouro. Os resultados são apresentados para cada procedimento cirúrgico analisado, na Tabela 9.

Tabela 9. Acurácia quanto ao diagnóstico de infecção de sítio cirúrgico entre os dados notificados para o sistema de vigilância estadual, em 2016 e aquele estabelecido pelo revisor, no piloto de validação, segundo o tipo de procedimento cirúrgico. Grupo de Vigilância Epidemiológica VII - Santo André. São Paulo, 2018.

\begin{tabular}{ccccc} 
& \multicolumn{3}{c}{ Avaliação do validador } \\
\cline { 2 - 5 } Procedimento cirúrgico & Notificação do hospital & Com ISC & Sem ISC & TOTAL \\
\hline \multirow{2}{*}{ Artroplastia de joelho } & ISC & 3 & 2 & $\mathbf{5}$ \\
& Não ISC & 0 & 52 & $\mathbf{5 2}$ \\
\cline { 2 - 5 } & Total & $\mathbf{3}$ & $\mathbf{5 4}$ & $\mathbf{5 7}$ \\
\hline \multirow{2}{*}{ Artroplastia total de } & ISC & 8 & 7 & $\mathbf{1 5}$ \\
quadril & Não ISC & 0 & 65 & $\mathbf{6 5}$ \\
\cline { 2 - 5 } & Total & $\mathbf{8}$ & $\mathbf{7 2}$ & $\mathbf{8 0}$ \\
\hline \multirow{2}{*}{ Histerectomia } & ISC & 0 & 1 & $\mathbf{1}$ \\
laparoscópica & Não ISC & 0 & 12 & $\mathbf{1 2}$ \\
\cline { 2 - 5 } & Total & $\mathbf{0}$ & $\mathbf{1 3}$ & $\mathbf{1 3}$ \\
\hline
\end{tabular}


9.2.3.2. Valor preditivo positivo, valor preditivo negativo, sensibilidade e especificidade

Para cada hospital e para cada procedimento foram calculados o valor preditivo positivo, o valor preditivo negativo, a sensibilidade e a especificidade. Um dos hospitais não teve este cálculo realizado porque verificou-se que o procedimento cirúrgico notificado não preenchia o critério de inclusão. Não foi possível calcular o VPP para os hospitais que informaram para o piloto de validação não haver casos de ISC (3). Também não foi possível calcular a sensibilidade para os hospitais para os quais não foram identificados casos de ISC por meio do estudo de validação (3 hospitais). Os valores de VPP, VPN, sensibilidade e especificidade calculados para cada um dos quatro hospitais são apresentados no Quadro 4.

Quadro 4. Valor preditivo positivo, valor preditivo negativo, sensibilidade e especificidade calculados para cada hospital e procedimento cirúrgico validado. Grupo de Vigilância Epidemiológica VII - Santo André. São Paulo, 2018.

\begin{tabular}{|c|c|c|c|c|c|}
\hline $\begin{array}{l}\text { Procedimento } \\
\text { cirúrgico }\end{array}$ & HOSPITAL & $\operatorname{VPP}(\%)$ & VPN (\%) & SENS (\%) & $\operatorname{ESPEC}(\%)$ \\
\hline \multirow{4}{*}{$\begin{array}{l}\text { Artroplastia de } \\
\text { joelho }\end{array}$} & $\mathrm{A}$ & $*$ & 100 & $* *$ & 100 \\
\hline & $\mathrm{B}$ & $*$ & 100 & $* *$ & 66,7 \\
\hline & $\mathrm{C}$ & 60 & 100 & 100 & 95,3 \\
\hline & $\mathrm{D}$ & NA & NA & NA & NA \\
\hline \multirow{4}{*}{$\begin{array}{l}\text { Artroplastia total de } \\
\text { quadril }\end{array}$} & $\mathrm{A}$ & $*$ & 100 & $* *$ & 100 \\
\hline & $\mathrm{B}$ & $*$ & 100 & $* *$ & 100 \\
\hline & $\mathrm{C}$ & 53,3 & 100 & 100 & 88,9 \\
\hline & $\mathrm{D}$ & $*$ & 100 & $* *$ & 100 \\
\hline \multirow{4}{*}{ Histerectomia } & $\mathrm{A}$ & NA & NA & NA & NA \\
\hline & $\mathrm{B}$ & $*$ & 100 & $* *$ & 100 \\
\hline & $\mathrm{C}$ & 0 & 100 & $* *$ & 50 \\
\hline & $\mathrm{D}$ & NA & NA & NA & NA \\
\hline
\end{tabular}

* NA: não se aplica, pois o hospital não realizou este procedimento cirúrgico. 


\subsubsection{Classificação de acordo com o plano tecidual acometido}

Houve discordância em relação à classificação de acordo com o plano tecidual acometido para $02(66,7 \%)$, dentre os 03 casos confirmados de ISC relacionados à artroplastia de joelho. Em relação às ISC relacionadas à artroplastia total de quadril essa discordância ocorreu para 05 $(62,5 \%)$ entre 08 casos confirmados. A Tabela 13 apresenta os resultados em relação a esta classificação, por procedimento.

Tabela 10. Acurária quanto à classificação em relação ao plano tecidual acometido realizada pelos hospitais e aquela identificada pelos validadores. Grupo de Vigilância Epidemiológica VII - Santo André. São Paulo, 2018.

\begin{tabular}{ccccc}
\hline Procedimento cirúrgico & $\begin{array}{c}\text { Casos } \\
\text { notificado } \\
\text { pelo hospital }\end{array}$ & Superficial & $\begin{array}{c}\text { Avaliação do } \\
\text { validador }\end{array}$ & Profunda \\
\hline \hline \multirow{2}{*}{ Artroplastia de joelho } & $\begin{array}{c}\text { Órgão/ } \\
\text { Espaço }\end{array}$ \\
\hline \multirow{3}{*}{ Artroplastia total de quadril } & Superficial & 1 & 1 & 0 \\
& Profunda & 0 & 0 & 1 \\
& Órgão/Espaço & 0 & 0 & 0 \\
\hline & Superficial & 0 & 1 & 1 \\
& Orofunda & 2 & 0 & 3 \\
\hline
\end{tabular}

Os resultados apontaram para uma dificuldade na aplicação de critérios tanto para a inclusão de procedimentos a serem notificados, quanto para a definição de ISC. 
9.3. ELABORAÇÃO DO PROTOCOLO DE VALIDAÇÃO DE DADOS DE ISC PARA O ESTADO DE SÃO PAULO.

O protocolo resultante deste estudo, a ser disponibilizado para o SUS para o Estado de São Paulo é apresentado no Apêndice E. 


\section{DISCUSSÃO}

Os resultados do estudo de revisão da literatura apoiaram o desenvolvimento do protocolo de validação, ao permitir identificar alguns elementos e estratégias comuns utilizados em estudos desta natureza. A opção pelo de método de revisão retrospectiva dos prontuários para a identificação dos casos de ISC, bem como a realização desta revisão por profissionais externos foi adotada pelos estudos revisados. No entanto, não se observou um método padrão para cálculo da amostra de hospitais e prontuários. Considerando a necessidade de um método de cálculo de amostra, que fosse representativo da população estudada e cuja fórmula pudesse ser disponibilizada no protocolo elaborado para estudos futuros, optou-se por solicitar apoio estatístico.

Analisando os estudos também foi possível identificar elementos estratégicos imprescindíveis à operacionalização de estudos desta natureza. É de extrema importância que os profissionais atuantes na revisão dos prontuários sejam capacitados e que, recursos materiais e de deslocamento sejam previstos. É necessário um planejamento junto ao hospital para que os prontuários estejam disponíveis no dia da visita in loco para a revisão. Um instrumento padronizado facilita na coleta e armazenamento das informações levantadas e otimiza o tempo de revisão. Observou-se que o país com maior número de publicações $(\mathrm{N}=05)$ foram os Estados Unidos da América, pioneiro na implantação de sistemas de notificação das IRAS denominado National Health Safety Network (NHSN) mantido há mais de quatro décadas (Backman et al., 2010; Rich et al., 2013; Hazamy et al., 2013; Haley et al., 2012; John et al., 2012).

A análise dos resultados pelos estudos também apresentou-se variada do ponto de vista do método empregado. Alguns estudos não informaram as razões que levaram a adotar determinar critério para a seleção dos hospitais e dos prontuários (Reilly et al.; 2015; Singh et al. 2015), o que gera uma lacuna para o entendimento sobre o tipo de amostra utilizado. No que tange à análise, vários estudos calcularam os valores preditivo positivo e negativo, a sensibilidade e a especificidade (McBryde et al.,2009; Friedman et al., 2007; Mannien et al., 2007; Huotari et al., 2007; McCoubrey et al., 2005; Backman et al., 2010).

O piloto de validação de dados de ISC em uma região do Estado de São Paulo permitiu identificar elementos e recursos necessários à implementação do arcabouço estruturado com base na etapa I. Além disto, puderam ser observadas as facilidades e dificuldades práticas na realização de estudos desta natureza, os quais serão discutidos a seguir. 
Conforme apontado por Friedman et al., 2007, por tratar-se estudo retrospectivo há que se contar com os registros das informações nos prontuários, diferentemente da vigilância prospectiva, na qual a comunicação com a equipe assistencial apoia positivamente para a identificação dos casos de ISC. Entretanto, a avaliação retrospectiva é uma limitação inerente ao processo de validação.

A disponibilidade de prontuário eletrônico foi considerada aspecto facilitador para o processo de validação. Além de facilitar a identificação de informações sobre a ocorrência das ISC evita-se maior dispêndio de trabalho por parte da instituição participante como seleção e transporte dos prontuários a serem revisados, bem como a eventual ocorrência de danos físicos aos mesmos. Além disto, torna mais ágil a busca das informações. Em contrapartida, o número de computadores disponível para a revisão dos prontuários pelos validadores em algumas instituições foi fator limitante, que contribuiu para a necessidade de um maior número de dias de visitas aos hospitais.

Dada a especificidade do diagnóstico, considera-se imprescindível a experiência do validador na vigilância de IRAS, já que este profissional tem habilidade na identificação de casos de ISC, o que contribui para menor tempo dispensado na revisão de prontuários e para a maior confiabilidade dos resultados identificados. No entanto, considerando o número de profissionais com esta competência e, por tratar-se de estudo pontual, é necessário um planejamento com tempo suficiente para a identificação, seleção e garantia de disponibilidade destes profissionais nas datas da revisão in loco. Neste piloto, a experiência dos validadores contribuiu positivamente para a facilidade da busca pelas informações que pudessem identificar a ocorrência da ISC. Como em outros estudos, o diagnóstico obtido pela equipe de validadores foi considerado padrão-ouro e foi revisão retrospectiva de prontuários foi o método adotado (Huotari et al., 2007; McBryde et al., 2010; Mannien et al., 2007)

Este primeiro estudo piloto de validação de dados de ISC realizado no Estado de São Paulo identificou um tempo médio de 15,05 minutos para revisão de um prontuário. Este tempo pode variar a depender da experiência do profissional validador, bem como da facilidade em se identificar as informações no sistema disponível. A experiência do sistema nacional de vigilância holandês, PREZIES, que realiza validação continuamente, considerou que, em um dia de visita é possível validar 25 prontuários (Manniën et al. 2007). Os resultados do presente estudo demonstraram que este tempo pode variar de acordo com o procedimento cirúrgico a ser revisado; por exemplo, a histerectomia laparoscópica de modo geral consumiu menor tempo de revisão. 
A análise do denominador neste estudo limitou-se à comparação entre os dados notificados e aqueles disponíveis para revisão, não tendo sido estudados os métodos empregados na vigilância para a identificação dos dados de ISC (validação em termos de processo). Outras informações relacionadas à vigilância das ISC, como por exemplo recursos disponíveis e métodos empregados para a identificação dos casos de ISC podem ser obtidas para auxiliar na identificação da necessidade de possíveis melhorias (McCoubrey et al., 2005), sobretudo daquelas instituições que apresentaram maiores inconsistências entre os dados notificados ao sistema de vigilância e aqueles obtidos por meio do estudo de validação.

Os resultados obtidos por meio do piloto de validação deste projeto de pesquisa referem-se à primeira análise desta natureza em âmbito governamental, realizada no Brasil, não tendo sido identificada na literatura ou por meios informais nenhuma outra semelhante e reforçaram a necessidade da certificação dos dados notificados ao sistema estadual.

Haley et al., (2012) identificaram que, 4,3\% de todos os casos reportados como não ISC foram identificados como ISC pela validação, considerando esta taxa alta quando comparados aos resultados de outros estudos. Estes autores constataram que alguns procedimentos tiveram maior número de erros no diagnóstico de IRAS, como é o caso dos dados de cirurgia de colón, que após resultado final teve elevação em sua taxa de ISC, no hospital validado. No grupo de hospitais participantes piloto de validação do presente estudo não foi identificado nenhum caso de falso negativo, no entanto houve casos de falsos positivos. Ao contrário da expectativa inicial, identificou-se uma "super notificação" e não uma subnotificação. Entretanto, este achado pode estar subordinado ao perfil dos hospitais que aceitaram a participação no estudo e pode não representar o comportamento generalizado das demais instituições.

Além disto, foram observadas diferenças entre o denominador notificado ao sistema e aquele disponível para a revisão dos prontuários, sugerindo uma possível correção nos dados internos dos hospitais, referentes à vigilância, sem que isto, no entanto, ocorra em relação aos dados notificados ao sistema estadual. Os resultados e recomendações foram enviados individualmente para cada hospital participante. Inconsistências encontradas no denominador podem produzir taxas super ou subestimadas (Arnold KE, Thompson, 2012).

Concordando com Haley et al., (2012) a visita in loco ao hospital é componente fundamental da validação de dados de IRAS, promovendo uma oportunidade quanto ao esclarecimento de dúvidas por parte das equipes dos hospitais, favorecendo desta forma a comunicação entre os profissionais da instituição e a equipe do sistema de vigilância.

López-Pueyo et al., (2013) destacaram como objetivos da validação de dados em âmbito nacional, melhorar a qualidade dos registros. Estes autores apontaram para as dificuldades 
identificadas na classificação de determinado tipo de IRAS e bem como Masia et al., (2010) e Hazamy et al., (2013) enfatizaram para a necessidade de treinamento continuo de todas as pessoas envolvidas sobre a utilização dos critérios diagnósticos.

A comparação entre os dados obtidos por meio deste piloto de validação e os resultados de outros estudos tem sua limitação pautada nos diferentes métodos utilizados pelos estudos, como demonstrado nos resultados da etapa I deste projeto. Observação semelhante foi feita por Lopez-Pueyo et al., (2013) ao discutir os resultados obtidos. Huotari et al., (2007) já haviam apontado que ao se comparar resultados como o VPP, o VPN, sensibilidade e especificidade deve-se considerar os métodos empregados para tal.

Sobre este aspecto Hazamy et al., 2013 discutem que embora programas de validação não encontrem $100 \%$ da acurácia esperada, a validação assegura comparações com taxas mais reais e provê dados consistentes para medidas de sucesso de práticas de prevenção que resultam na redução das IRAS. Iniciativas de estudos de validação melhoram a qualidade dos dados notificados ao sistema (Arnold KE, Thompson, 2012).

Similar aos dados publicados por Rich et al., 2013, este estudo teve por limitação a participação de um pequeno número de hospitais, devido ao caráter voluntário. Entretanto, tomando-se em conta que se trata de um piloto com foco maior na identificação da aplicabilidade do protocolo, esta amostra está aceitável. Considera-se que o número de instituições participantes será diferente na medida em que o estudo de validação se tornar uma atividade do sistema de vigilância.

Faz-se necessário destacar a complexidade envolvida no presente estudo, que reuniu um conjunto de métodos para chegar a uma proposta de validação de dados de ISC para o Estado de São Paulo. Buscou-se considerar, na definição dos métodos, fatores que pudessem gerar algum tipo de viés aos resultados, como por exemplo, a estratificação das instituições de acordo com o número de leitos, cálculo de amostra de hospitais e prontuários que seja representativo da população estudada e sua seleção aleatória, bem como a experiência dos validadores. $\mathrm{O}$ número de instituições participantes, bem como a execução do piloto incluindo apenas alguns dos procedimentos cirúrgicos monitorados no Estado de São Paulo, podem ter limitado a identificação de outros ajustes necessários à ferramenta. Portanto, considera-se fundamental a revisão periódica do protocolo aqui proposto, no que tange a melhorias e atualizações como necessárias. 


\section{CONCLUSÕES}

O protocolo elaborado mostrou-se ser exequível e factível e os resultados do piloto reforçaram a necessidade de verificar a acurácia dos dados de ISC reportados no Estado de São Paulo. A ferramenta elaborada por este estudo possui potencial para ser utilizada por outros sistemas governamentais que possuam metodologia semelhante à adotada para a vigilância das ISC no Estado de São Paulo, desde que ajustada para o sistema a ser validado.

Considera-se necessária atualização do protocolo apresentado, à medida em que forem observadas durante sua execução para estudos de validação à que se propõe. 


\section{REFERÊNCIAS}

Agência Nacional de Vigilância Sanitária [ANVISA]. Informe técnico $n^{\circ}$ 01/09 princípios básicos para limpeza de instrumental cirúrgico em serviços de saúde. Unidade de Investigação e Prevenção das Infecções e dos Eventos Adversos - Uipea Gerência Geral de Tecnologia em Serviços de Saúde 107 - GGTES [Internet]. Brasília-DF; 2009. [citado 2013 jul. 25] Disponível em: http://www.anvisa.gov.br/servicosaude/controle/Alertas/2009/informe_tecnico_1.pdf

Nacional de Vigilância Sanitária. Sítio Cirúrgico. Critérios nacionais de infecções relacionadas à assistência à saúde [Internet] Brasília-DF; 2009. p. 1-19. . [citado 2016 fev. 8]. Disponível:

http://www.anvisa.gov.br/servicosaude/manuais/criterios_nacionais_ISC.pdf. [Acesso: 08/02/2016].

Agência Nacional de Vigilância Sanitária [ANVISA]. RDC nº 8, DE 27 de fevereiro de 2009. Dispõe sobre as medidas para redução da ocorrência de infecções por Micobactérias de Crescimento Rápido - MCR em serviços de saúde [Internet]. Brasília-DF; 2009. [citado 2013 jul. 25].

Disponível em: http://www.anvisa.gov.br/hotsite/segurancadopaciente/documentos/rdcs/RDC\%20N\%C2\%BA \%2008-2009.pdf [Acesso: 08/02/2016

Agência Nacional de Vigilância Sanitária. Nota Técnica $N^{0}$ 01/2014. Vigilância e Monitoramento das Infecções Relacionadas à Assistência à Saúde (IRAS) e Resistência Microbiana (RM) em serviços de saúde. Brasília, 24 de fevereiro de 2014. Acesso [08/02/2016]. Disponível em:

http://portal.anvisa.gov.br/wps/wcm/connect/d6ec0e00433a3bd7b799ff5afd5e7b35/NOTA+TE $\mathrm{CNICA}+\mathrm{IRAS}+\mathrm{E}+\mathrm{RM}+-+\mathrm{FEV}+2014+\mathrm{II}+(2) \cdot \mathrm{pdf}$ ?MOD=AJPERES

Agência Nacional de Vigilância Sanitária. Nota Técnica GVIMS/GGTes n n 05/2017REVISADA. Orientações para a notificação nacional das Infecções Relacionadas à Assistência à Saúde (IRAS), Resistência Microbiana (RM) e monitoramento do consumo de antimicrobianos - 2018 Brasília: 2018.

Agência Nacional de Vigilância Sanitária. Critérios Diagnósticos de Infecção Relacionada à Assistência à Saúde. Série: Segurança do Paciente e Qualidade em Serviços de Saúde. Brasília: 2017.

Agência Nacional de Vigilância Sanitária. Unidade de Investigação e Prevenção das Infecções e dos Eventos Adversos - UIPEA Gerência Geral de Tecnologia em Serviços de Saúde Cirurgias- GGTES [Internet]. Cirurgias com implantes/próteses: Critérios Nacionais de Infecções relacionadas à Assistência à Saúde Brasília-DF; 2011. . [citado 2016 fev. 8]. Disponível em:

http://portal.anvisa.gov.br/wps/wcm/connect/74cea28047458b949565d53fbc4c6735/criterios_n acionais_de_inf_implantes_e_proteses_mar_2011.pdf?MOD=AJPERES

].

Agência Nacional de Vigilância Sanitária [ANVISA]. RDC no 15, de 15 de março de 2012. Dispõe sobre requisitos de boas práticas para o processamento de produtos para saúde e dá outras providências. [Internet]. Brasília-DF; 2012. [citado 2016 fev. 8]. Disponível em: 
http://www.prefeitura.sp.gov.br/cidade/secretarias/upload/chamadas/rdc_cme_2012processamento_de_produtos_para_saude_1333025561.pdf

Allegranzi B, Nejad SB, Combescure C, Graafmans W, Attar H, Donaldson L, et al. Burden of endemic health-care-associated infection in developing countries: Systematic review and metaanalysis. Lancet 2011;377(9761):228-241.

Anderson DJ, Kaye KS, Classen D, Arias KM, Podgorny K, Burstin H, et al. Strategies to prevent surgical site infections in acute care hospitals. Infection control and hospital epidemiology : the official journal of the Society of Hospital Epidemiologists of America. 2008;29 Suppl 1:S51-61.

Arnold KE, Thompson ND. Building data quality and confidence in data reported to the national healthcare safety network. Infect Control Hosp Epidemiol 2012;33(5):446-448.

Associação Paulista de Epidemiologia e Controle de Infecção Relacionada à Assistência à Saúde- APECIH. Prevenção de Infecção do Sítio Cirúrgico. $3^{a}$ Edição Revisada e Ampliada. São Paulo, 2009; pg 1-2

Astagneau P, LHériteau F. Surveillance of surgical-site infections: Impact on quality of care and reporting dilemmas. Curr Opin Infect Dis. 2010;23(4):306-10.

Backman LA, Melchreit R, Rodriguez R. Validation of the surveillance and reporting of central line-associated bloodstream infection data to a state health department. Am J Infect Control 2010;38(10):832-838

Bärwolff S, Sohr D, Geffers C, Brandt C, Vonberg R, Halle H, et al. Reduction of surgical site infections after caesarean delivery using surveillance. J Hosp Infect. 2006;64(2):156-61.

Bensenor, I. M. ; Lotufo, P.A. Epidemiologia, abordagem prática. São Paulo: Sarvier. 2011. 400p. Benseñor, I.M, Lotufo, P.A.

Bolfarine, H. Bussab, W.O. (2005). Elementos de Amostragem. 1.ed., São Paulo: Edgard Blucer, 290p.

Bratzler DW, Dellinger EP, Olsen KM, Perl TM, Auwaerter PG, Bolon MK, et al. Clinical practice guidelines for antimicrobial prophylaxis in surgery. American Journal of HealthSystem Pharmacy. 2013;70(3):195-283.

BRASIL. Ministério da Saúde. Lei Orgânica 8080. Dispõe sobre as condições para a promoção, proteção e recuperação da saúde, a organização e o funcionamento dos serviços correspondentes e dá outras providências. Diário Oficial da União. 1990, 19 setembro.

Burke JP. Infection control - A problem for patient safety. N Engl J Med. 2003;348(7):651-6.

Cardo DM, Mayhall CG, Mayhall CG. Validation of surgical wound surveillance. Infect Control Hosp Epidemiol 1993;14(4):211-215. 
Centers for Disease Control and Prevention. National Healthcare Safety Network. About NHSN. What is NHSN. Georgia. Atlanta. EUA, outubro 2015. Acesso [08/02/2015]. Disponível em: http://www.cdc.gov/nhsn/about-nhsn/index.html

Díaz-Agero-Pérez C, Pita-López MJ, Robustillo-Rodela A, Figuerola-Tejerina A, Monge Jodrá V. Assessment of the surgical site infection in 14 hospitals of the madrid region: An incidence study. Enferm Infecc Microbiol Clin. 2011; 29(4):257-62.

Fabry J, Morales I, Metzger M-, Russell I, Gastmeier P. Quality of information: a European challenge. J Hosp Infect 2007;65(SUPPL. 2):155-158.

Friedman ND, Russo PL, Bull AL, Richards MJ, Kelly H. Validation of coronary artery bypass graft surgical site infection surveillance data from a statewide surveillance system in Australia. Infect Control Hosp Epidemiol 2007;28(7):812-817.

Gastmeier P, Geffers C, Brandt C, Zuschneid I, Sohr D, Schwab F, et al. Effectiveness of a nationwide nosocomial infection surveillance system for reducing nosocomial infections. $\mathbf{J}$ Hosp Infect. 2006;64(1):16-22.

Gastmeier P, Sohr D, Schwab F, Behnke M, Zuschneid I, Brandt C, et al. Ten years of KISS: The most important requirements for success. J Hosp Infect. 2008;70(SUPPL. 1):11-6.

Geubbels ELPE, Nagelkerke NJD, Mintjes-De Groot AJ, Vandenbroucke-Grauls CMJE, Grobbee DE, De Boer AS. Reduced risk of surgical site infections through surveillance in a network. International Journal for Quality in Health Care. 2006;18(2):127-33

Haley VB, van Antwerpen C, Tserenpuntsag B, Gase KA, Hazamy P, Doughty D, et al. Use of administrative data in efficient auditing of hospital- acquired surgical site infections, New York State 2009-2010. Infect Control Hosp Epidemiol 2012;33(6):565-571.

Haley RW, Meade Morgan W, Culver DH, White JW, Grace Emori T, Mosser J, et al. Update from the SENIC project. Hospital infection control: Recent progress and opportunities under prospective payment. Am J Infect Control 1985;13(3):97-108.

Hazamy PA, Van Antwerpen C, Tserenpuntsag B, Haley VB, Tsivitis M, Doughty D, et al. Trends in validity of central line-associated bloodstream infection surveillance data, New York State, 2007-2010. Am J Infect Control 2013;41(12):1200-1204.

Horan TC, Andrus M, Dudeck MA. CDC/NHSN surveillance definition of health careassociated infection and criteria for specific types of infections in the acute care setting. Am $\mathbf{J}$ Infect Control 2008;36(5):309-332.

Huotari K, Agthe N, Lyytikäinen O. Validation of surgical site infection surveillance in orthopedic procedures. Am J Infect Control 2007;35(4):216-221.

Jodrá VM, Pérez CDA, Soler LST, Requejo CMS, Ballesteros DD and Quality Control Indicator Working Group Madrid Spain. Results of the Spanish national nosocomial infection surveillance network (VICONOS) for surgery patients from January 1997 through December 2003. Am J Infect Control, 2006 (34) 3, 134-141 
Alterar no text John Y, Cunningham MC, Beldavs ZG, Tujo J, Moore SW, Thomas AR, et al. Statewide validation of hospital-reported central line-associated bloodstream infections: Oregon, 2009. Infect Control Hosp Epidemiol 2012;33(5):439-445.

Kirkland KB, Briggs JP, Trivette SL, Wilkinson WE, Sexton DJ. The impact of surgical-site infections in the 1990s: Attributable mortality, excess length of hospitalization, and extra costs. Infection Control and Hospital Epidemiology. 1999;20(11):725-30.

López-Pueyo MJ, Olaechea-Astigarraga P, Palomar-Martínez M, Insausti-Ordeñana J, ÁlvarezLerma F. Quality control of the surveillance programme of ICU-acquired infection (ENVINHELICS registry) in Spain. J Hosp Infect 2013;84(2):126-131.

Mangram AJ; Horan TC; Pearson ML; Silver LC; Jarvis WR. Guideline for prevention of surgical site infection, 1999. Hospital Infection Control Practices 112 Advisory Committee. Infection Control and Hospital Epidemiology. 1999; 20(4):250-78.

McCoubrey J, Reilly J, Mullings A, Pollock KGJ, Johnston F. Validation of surgical site infection surveillance data in scotland. J Hosp Infect. 2005;61(3):194-200.

Manniën J, Van Der Zeeuw AE, Wille JC, Van Den Hof S. Validation of surgical site infection surveillance in The Netherlands. Infect Control Hosp Epidemiol 2007;28(1):36-41.

Manniën J, van den Hof S, Brandt C, Behnke M, Wille JC, Gastmeier P. Comparison of the national surgical site infection surveillance data between the Netherlands and Germany: PREZIES versus KISS. J Hosp Infect. 2007;66(3):224-31. Conferir se cito no texto.

Masia MD, Barchitta M, Liperi G, Cantù AP, Alliata E, Auxilia F, et al. Validation of intensive care unit-acquired infection surveillance in the Italian SPIN-UTI network. J Hosp Infect 2010;76(2):139-142.

McBryde ES, Brett J, Russo PL, Worth LJ, Bull AL, Richards MJ. Validation of statewide surveillance system data on central line-associated bloodstream infection in intensive care units in Australia. Infect Control Hosp Epidemiol 2009;30(11):1045-1049.

McKibben L, Horan TC, Tokars JI, Fowler G, Cardo DM, Pearson ML, et al. Guidance on public reporting of healthcare-associated infections: Recommendations of the healthcare infection control practices advisory committee. Infect Control Hosp Epidemiol 2005;26(6):580587.

Mello, Débora Silva de. Monitoramento das infecções de sítio cirúrgico no estado de São Paulo: seleção e implementação de indicadores [dissertação]. São Paulo: Universidade de São Paulo, Escola de Enfermagem; 2013 [acesso 2016-03-15]. Disponível em: http://www.teses.usp.br/teses/disponiveis/7/7141/tde-18072014-121004/

National Institute for Health and Clinical Excellence: Guidance. National Collaborating Centre for Women's and Children's Health (UK). Surgical Site Infection: Prevention and Treatment of Surgical Site Infection. London: RCOG Press; 2008 Oct. 
Nogueira Junior C, de Mello DS, Padoveze MC, Boszczowski I, Levin AS, Lacerda RA. Characterization of epidemiological surveillance systems for healthcare-associated infections (HAI) in the world and challenges for Brazil. Cad Saude Publica 2014;30(1):11-20.

Organización Mundial de La Salud. Prevención de lãs infecciones nosocomiales. Guía Practica. $2^{a} \quad$ edición, 2003.2 Disponível em: http://www.who.int/csr/resources/publications/ES_WHO_CDS_CSR_EPH_2002_12.pdf [acesso: 08/02/2016]

Padoveze MC, Assis DB, Freire MP, Madalosso G, Ferreira SA, Valente MG, et al. Surveillance programme for healthcare associated infections in the state of são paulo, brazil. implementation and the first three years' results. J Hosp Infect. 2010;76(4):311-5.

Passaretti CL, Barclay P, Pronovost P, Perl TM. Public reporting of health care-associated infections (HAIs): Approach to choosing HAI measures. Infection Control and Hospital Epidemiology. 2011;32(8):768-74.

Reimann B.F., Avidos I., Tamada T.D.T. Relatório de consulta: "Desenvolvimento de uma ferramenta que permita a validação periódica do sistema de vigilância das infecções de sítio cirúrgico no estado de São Paulo”. São Paulo, IME-USP, 2016.

Reilly JS, Price L, Godwin J, Cairns S, Hopkins S, Cookson B, et al. A pilot validation in 10 European Union member states of a point prevalence survey of healthcare-associated infections and antimicrobial use in acute hospitals in Europe, 2011. Eurosurveillance 2015;20(8).

Rich KL, Reese SM, Bol KA, Gilmartin HM, Janosz T. Assessment of the quality of publicly reported central line-associated bloodstream infection data in Colorado, 2010. Am J Infect Control 2013;41(10):874-879.

Rioux C, Grandbastien B, Astagneau P. Impact of a six-year control programme on surgical site infections in france: Results of the INCISO surveillance. J Hosp Infect. 2007;66(3):217-23.

Secretaria da Saúde do Estado de São Paulo. Coordenadoria de Controle de Doenças. Centro de Vigilância Epidemiológica "Prof. Alexandre Vranjac". Instituição. Sobre o CVE [internet]. São Paulo, SP, s/d [citado 2016 jul. 19]. Disponível em: http://www.cve.saude.sp.gov.br/htm/cve_apres.htm

Secretaria de Estado da Saúde de São Paulo. Coordenadoria de Controle de Doenças. Centro de Vigilância Epidemiológica "Prof. Alexandre Vranjac”. Divisão de Infecção Hospitalar. Análise dos dados do Sistema de Vigilância Epidemiológica das Infecções Hospitalares do Estado de São Paulo - 2016 [Internet]. São Paulo, 2017. Disponível em: http://www.saude.sp.gov.br/cvecentro-de-vigilancia-epidemiologica-prof.-alexandre-vranjac/areas-de-vigilancia/infeccaohospitalar/sistema-de-vigilancia-epidemiologica

Secretaria da Saúde do Estado de São Paulo. Coordenadoria de Controle de Doenças. Centro de Vigilância Epidemiológica "Prof. Alexandre Vranjac". Divisão de Infecção Hospitalar DIH/CVE. Manual de orientações e critérios diagnósticos. Hospital Geral. Sistema de vigilância epidemiológica das infecções hospitalares do Estado de São Paulo. São Paulo, 2016. 
(SES, 2018) Secretaria da Saúde do Estado de São Paulo. Coordenadoria de Controle de Doenças. Centro de Vigilância Epidemiológica "Prof. Alexandre Vranjac". Divisão de Infecção Hospitalar - DIH/CVE. Manual de orientações e critérios diagnósticos. Hospital Geral. Sistema de vigilância epidemiológica das infecções hospitalares do Estado de São Paulo [Internet]. São Paulo, 2018. Disponível em: http://www.saude.sp.gov.br/resources/cve-centro-de-vigilanciaepidemiologica/areas-de-vigilancia/infeccao-

hospitalar/2018/ih18_manualcriteriosdiagnosticos_hospitalgeral2018.pdf

Singh S, Davies J, Sabou S, Shrivastava R, Reddy S. Challenges in reporting surgical site infections to the national surgical site infection surveillance and suggestions for improvement. Ann R Coll Surg Engl 2015;97(6):460-465.

Wilson APR, Kiernan M. Recommendations for surveillance priorities for healthcareassociated infections and criteria for their conduct. J Antimicrob Chemother. 2012; 67(SUPPL.1): i23-8.

World Health Organization. Core components for infection prevention and control programmes. Report of the Second Meeting Informal Network on Infection Prevention and Control in Health Care. Geneva, Switzerland, June 2008.

Umscheid CA, Mitchell MD, Doshi JA, Agarwal R, Williams K, Brennan PJ. Estimating the proportion of healthcare-associated infections that are reasonably preventable and the related mortality and costs. Infection Control and Hospital Epidemiology. 2011; 32(2):101-14.

Washington State Department of Health [Internet]. Washington. [s.d.] Disponível em: https://www.doh.wa.gov/youandyourfamily/illnessanddisease/healthcareassociatedinfections/an nualreports/reportingaccuracy 


\section{APÊNDICE A}

\section{Validação de dados de infecção de sítio cirúrgico (ISC), ano 2016. Formulário de revisão de prontuário}

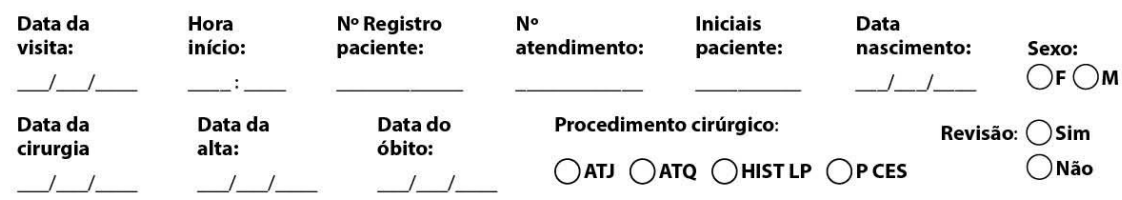

DESCRIÇÃO DO PROCEDIMENTO NO PRONTUÁRIO:

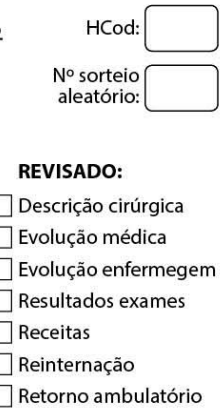

Excluir do denominador - Motivo:

OBSERVAÇõES DO VALIDADOR: (se o espaço for insuficiente, utilizar o verso)

\begin{tabular}{|c|c|}
\hline \multicolumn{2}{|c|}{$\begin{array}{l}\text { CRITÉRIOS DIAGNÓSTICOS DE INFECÇÃO DE SÍTIO CIRÚRGICO (ISC) - CVE, } 2016 \\
\text { Validador, sublinhar os achados e apontar data de ocorrência para cada um: }\end{array}$} \\
\hline \multicolumn{2}{|l|}{$\square$ NÄOHOUVE ISC: } \\
\hline \multicolumn{2}{|c|}{$\begin{array}{l}\text { INCISIONAL SUPERFICIAL: ocorreu nos primeiros } 30 \text { dias e envolveu apenas pele e subcutâneo, COM PELO MENOS UM dos seguintes: } \\
\text { a) Drenagem purulenta da incisão superficial; } \\
\text { b) Cultura positiva de secreção ou tecido da incisão superficial obtido assepticamente (não são considerados resultados de culturas colhidas por swab); } \\
\text { c) A incisão superficial é deliberadamente aberta pelo cirurgião na vigência de pelo menos um dos seguintes sinais ou sintomas: dor, aumento da sensibili- } \\
\text { dade, edema local, hiperemia ou calor, EXCETO se a cultura for negativa; } \\
\text { d) Diagnóstico de infecção superficial pelo médico assistente. }\end{array}$} \\
\hline \multicolumn{2}{|c|}{$\begin{array}{l}\square \text { INCISIONAL PROFUNDA: ocorreu nos primeiros } 30 \text { ou } 90 \text { dias (VER QUADRO 3) após a cirurgia, e envolveu tecidos moles profundos à incisão (ex: fáscia e/ } \\
\text { ou músculos), COM PELO MENOS um dos seguintes: }\end{array}$} \\
\hline $\begin{array}{l}\text { a) Drenagem purulenta da incisão profunda, mas não de órgão/cavidade; } \\
\text { b) Deiscência parcial ou total da parede abdominal ou abertura da ferida pelo cirurgião, } \\
\text { ou sintomas: febre }>38^{\circ} \mathrm{C} \text {, dor ou aumento da sensibilidade local, exceto se a cultura for } \\
\text { c) Presença de abscesso ou outra evidência que a infecção envolva os planos profundos } \\
\text { co ou exame de imagem; } \\
\text { d) Diagnóstico de infecção incisional profunda pelo médico assistente. }\end{array}$ & $\begin{array}{l}\text { guintes sinais } \\
\text { nistopatológi- }\end{array}$ \\
\hline \multicolumn{2}{|c|}{$\begin{array}{l}\square \text { ÓRGÄO/CAVIDADE: ocorreu nOs primeiros } 30 \text { ou } 90 \text { dias (VER QUADRO 3) após a cirurgia, e envolveu qualquer órgão ou cavidade que tenha sido aberta ou } \\
\text { manipulada durante a cirurgia, COM PELO MENOS um dos seguintes: }\end{array}$} \\
\hline $\begin{array}{l}\text { a) Cultura positiva de secreção ou tecido do órgão/cavidade obtido assepticamente; } \\
\text { b) Presença de abscesso ou outra evidência que a infecção envolva os planos profundos } \\
\text { co ou exame de imagem; } \\
\text { d) Diagnóstico de infecção de órgão/cavidade pelo médico assistente. }\end{array}$ & histopatológi- \\
\hline $\begin{array}{l}\text { Notificação de ISC pelo hospital para GVE: } \\
\square \text { Năo ISC. } \square \text { Incisional superficial. } \square \text { Incisional profunda. } \square \text { Incisional órgão/cavidad }\end{array}$ & Hora término \\
\hline
\end{tabular}




\section{APÊNDICE B}

\section{CARTA DE AUTORIZAÇÃO DO SERVIÇO DE SAÚDE}

Prezado senhor (a) responsável pelo Serviço de Saúde

Vimos, por meio desta, solicitar formalmente a autorização deste serviço para realização da pesquisa intitulada "Desenvolvimento de um protocolo para a validação do sistema de vigilância das infecções de sítio cirúrgico (SVISC) no Estado de São Paulo”. Este estudo está sendo realizado pela Divisão de Infecção Hospitalar do Centro de Vigilância Epidemiológica "Prof. Alexandre Vranjac" (DIH/CVE) em parceria com a Escola de Enfermagem da Universidade de São Paulo e tem por objetivo desenvolver um protocolo para a validação dos dados de infecções de sítio cirúrgico no estado de São Paulo. Está sendo desenvolvido pela doutoranda Débora Silva de Mello (COREN-SP 169622), sob orientação da Prof $^{a}$. Dra ${ }^{\mathrm{a}}$. Maria Clara Padoveze COREN 36542 e foi aprovado pelo Comitê de Ética em Pesquisa da Escola de Enfermagem da Universidade de São Paulo (CEP-EEUSP) CAAE: 64237917.9 .0000 .5392$.

Para a participação da instituição no estudo, solicitamos sua autorização para análise de prontuários de pacientes submetidos aos seguintes procedimentos cirúrgicos que o hospital tenha realizado no ano de 2016: artroplastia de joelho, artroplastia total de quadril, histerectomia laparoscópica e parto cesariano. Os dados serão coletados por meio de um formulário com o objetivo de identificar a ocorrência ou não de infecção de sítio cirúrgico. Os pacientes e a instituição serão mantidos em anonimato, sendo estes dados de acesso apenas aos pesquisadores do estudo.

A coleta de dados será realizada in loco, por uma equipe treinada especificamente para este procedimento, sob supervisão das pesquisadoras supracitadas. Para tanto, os pesquisadores participantes do estudo irão até a instituição em dia e horário pré-estabelecidos acordados entre a equipe de pesquisa e o responsável pelo serviço de saúde ou outro membro designado de sua equipe.

Não haverá nenhum custo financeiro para instituição em participar do estudo, uma vez que todos os recursos necessários serão financiados pelas pesquisadoras do estudo.

Esclarecemos que a participação no estudo não está relacionada a nenhuma ação de auditoria ou avaliação de vigilância sanitária. Após o estudo, caso seja de interesse da instituição, será encaminhado um relatório individualizado sobre o resultado dos dados obtidos no serviço de saúde participante. 
Como benefícios, espera-se que este projeto de pesquisa disponibilize para utilização pelo Sistema Único de Saúde (SUS) um instrumento que permita avaliar a qualidade da informação notificada pelas instituições de saúde em relação às infecções de sítio cirúrgico e desta formar identificar potenciais falhas no processo de vigilância epidemiológica deste agravo; quando pertinente, apontar necessidades de implementação de estratégias que promovam a melhoria deste processo, permitindo ao estado e aos serviços de saúde identificar taxas acuradas de infecção do sítio cirúrgico.

Anexamos a este documento uma síntese do projeto de pesquisa, bem como a aprovação do CEP-EEUSP e um "Termo de Responsabilidade" o qual deverá ser assinado e rubricado pela pesquisadora principal e pelo responsável pelo serviço.

Em qualquer etapa do estudo, o senhor terá acesso ao (s) pesquisador (es) responsável(eis) pela investigação para esclarecimento de dúvidas. O principal pesquisador é a Sra Débora Silva de Mello que pode ser encontrada no endereço: Av. Dr. Enéas de Carvalho Aguiar, 419 - Cerqueira Cesar - São Paulo/SP CEP - 05403-000 Telefone: xxxxxx e-mail deborasm@usp.br.

Caso aceite, necessito de sua autorização formal e rubrica em todas as páginas, nas duas vias.

$\mathrm{Eu}$ $\mathrm{RG}$ , abaixo assinado, tendo recebido as informações acima, autorizo a participação da instituição na pesquisa, ciente de meus direitos relacionados a seguir:

- A liberdade de deixar de participar no estudo, em qualquer fase da pesquisa, sem que isso me traga algum prejuízo;

- A garantia por parte dos pesquisadores de que os dados pessoais dos pacientes, bem como de identificação da instituição serão mantidos sob sigilo durante todas as fases da pesquisa;

- A garantia por parte dos pesquisadores de que as informações coletadas serão transformadas em trabalho científico e apresentado em congressos e revistas da área da saúde, e que em nenhum momento o nome da instituição e de pacientes será mencionado.

- O acesso ao (s) pesquisador (es) responsável(eis) para esclarecimento de dúvidas em qualquer etapa do estudo.

Esta pesquisa atende todas as especificações da Resolução 466, de 12 de dezembro de 2012 que aprova as diretrizes e normas regulamentadoras de pesquisas envolvendo seres humanos. 
Este documento contém duas vias assinadas e rubricadas em todas as páginas também pela pesquisadora, sendo que uma ficará em seu poder e a outra conosco, garantindo as condições citadas acima.

São Paulo, de de 2017.

Assinatura do responsável pela instituição

Assinatura do pesquisador

Assinatura da diretora da Divisão de Infecção Hospitalar do

Centro de Vigilância Epidemiológica "Prof. Alexandre Vranjac".

Agradecendo sua colaboração, colocamo-nos à disposição para os esclarecimentos necessários pelo telefone da DIH/CVE: (11) 3066-8759. Endereço: Av. Dr. Arnaldo, 351, Pacaembu São Paulo/SP CEP: 01246-000.

Caso você tenha alguma consideração ou dúvida sobre a ética da pesquisa, entre em contato com o Comitê de Ética em Pesquisa (CEP) - Endereço: Av. Dr. Enéas de Carvalho Aguiar, 419 - Cerqueira Cesar - São Paulo/SP CEP - 05403-000 Telefone- (11) 30618858 e-mail cepee@usp.br. 


\section{APÊNDICE C}

\section{TERMO DE RESPONSABILIDADE}

O projeto de pesquisa intitulado "Desenvolvimento de um protocolo para a validação do sistema de vigilância das infecções de sítio cirúrgico (SVISC) no Estado de São Paulo tem como pesquisadora responsável Débora Silva de Mello, enfermeira, doutoranda do Programa de Pós-Graduação em Enfermagem da Escola de Enfermagem da Universidade de São Paulo (EEUSP). COREN-SP 169622. Este projeto é realizado em parceria com o Centro de Vigilância Epidemiológica "Prof. Alexandre Vranjac", esta sob orientação da Prof a $^{\mathrm{a}}$ Dra $^{\mathrm{a}}$. Maria Clara Padoveze do Departamento de Enfermagem em Saúde Coletiva da Escola de Enfermagem da Universidade de São Paulo (EEUSP). COREN 36542 e foi aprovado pelo Comitê de Ética em Pesquisa da Escola de Enfermagem da Universidade de São Paulo (CEPEEUSP) CAAE: 64237917.9.0000.5392.

As pesquisadoras acima assumem os seguintes compromissos perante o serviço de saúde participante da pesquisa:

- A pesquisa respeita os preceitos da Resolução no 466 de 12 de dezembro de 2012, do Conselho Nacional de Saúde.

- Serão coletados dados de pacientes submetidos aos seguintes procedimentos cirúrgicos que o hospital tenha realizado no ano de 2016: artroplastia de joelho, artroplastia total de quadril, histerectomia laparoscópica e parto cesariano.

-Os prontuários dos pacientes serão selecionados por meio de critério de aleatoriedade.

-Serão coletados dados registrados nos prontuários dos pacientes que permitam identificar a ocorrência ou não de infecção de sítio cirúrgico, de acordo com o critério para diagnóstico epidemiológico utilizado pelo Centro de Vigilância Epidemiológica "Prof. Alexandre Vranjac". Estado de São Paulo no ano de 2016.

-Serão coletados pelos pesquisadores dados que identifiquem o paciente como nome completo, nome da mãe, data de nascimento e número do prontuário. Estes dados serão inseridos e armazenados no aplicativo Epi Info ${ }^{\mathrm{TM}} 7.1 .5$ sob responsabilidade da pesquisadora principal, que os utilizará na análise final unicamente para verificar se os casos de infecção de sítio cirúrgico reportados pelo serviço de saúde ao serviço de vigilância são os mesmos identificados pela equipe de validadores. 
- As pesquisadoras manterão sigilo de todos os dados que identifiquem o paciente e a instituição.

- As pesquisadoras garantem que não haverá dano moral, psicológico ou físico aos participantes do estudo.

- Os prontuários serão avaliados em local pertencente ao serviço participante, indicado por seu responsável, com o objetivo de evitar o transporte destes documentos, evitando-se desta forma risco de perda, extravio ou mesmo rasuras aos prontuários.

- Caso seja de interesse da instituição participante da pesquisa, seu responsável receberá relatório dos resultados referente à aplicação do protocolo da pesquisa na instituição.

- Os resultados obtidos serão divulgados por meio de publicações científicas, sem identificação da instituição ou de pacientes.

Cientes e de acordo, as partes assinam este documento em duas vias, com rubricadas em todas as páginas. Uma via ficará com o responsável pelo serviço de saúde e outra com a pesquisadora principal do projeto.

São Paulo, de de 2017.

Assinatura do responsável pelo serviço de saúde

Assinatura do pesquisador responsável

Agradecendo sua colaboração, colocamo-nos à disposição para os esclarecimentos necessários pelo telefone (11) 9 8898-3287. Endereço: Av. Dr. Enéas de Carvalho Aguiar, 419 - Cerqueira Cesar - São Paulo/SP CEP - 05403-000. E-mail deborasm@usp.br. 


\section{APÊNDICE D \\ Modelo de relatório enviado aos hospitais participantes do piloto de validação de dados de ISC, no Estado de São Paulo.}

PROJETO DE PESQUISA:

"Desenvolvimento de um protocolo para a validação de dados do sistema de vigilância das infecções de sítio cirúrgico no Estado de São Paulo"..

Orientadora: Profa. Dra Maria Clara Padoveze Doutoranda: Débora Silva de Mello Parceira de pesquisa: Divisão de Infecção Hospitalar/ Centro de Vigilância Epidemiológica "Prof. Alexandre Vranjac" e Grupo de Vigilância Epidemiológica de Santo André

São Paulo, de de 2018. 


\section{RESULTADOS}

Neste estudo foram considerados para a revisão, prontuários referentes aos seguintes procedimentos cirúrgicos (quando realizados) notificados para o sistema estadual de vigilância das ISC, no ano de 2016: artroplastia de joelho, artroplastia total de quadril, histerectomia laparoscópica e parto cesariano. O Quadro 1 apresenta os resultados gerais em relação ao numerador (número total de infecções), denominador (número total de cirurgias) e taxas de ISC (numerador/denominador*100), notificados e observados durante a revisão de prontuários realizada por este projeto.

QUADRO 1. Resultados gerais em relação ao numerador, denominador e taxas de ISC, notificados e observados pela validação de dados. São Paulo, 2017.

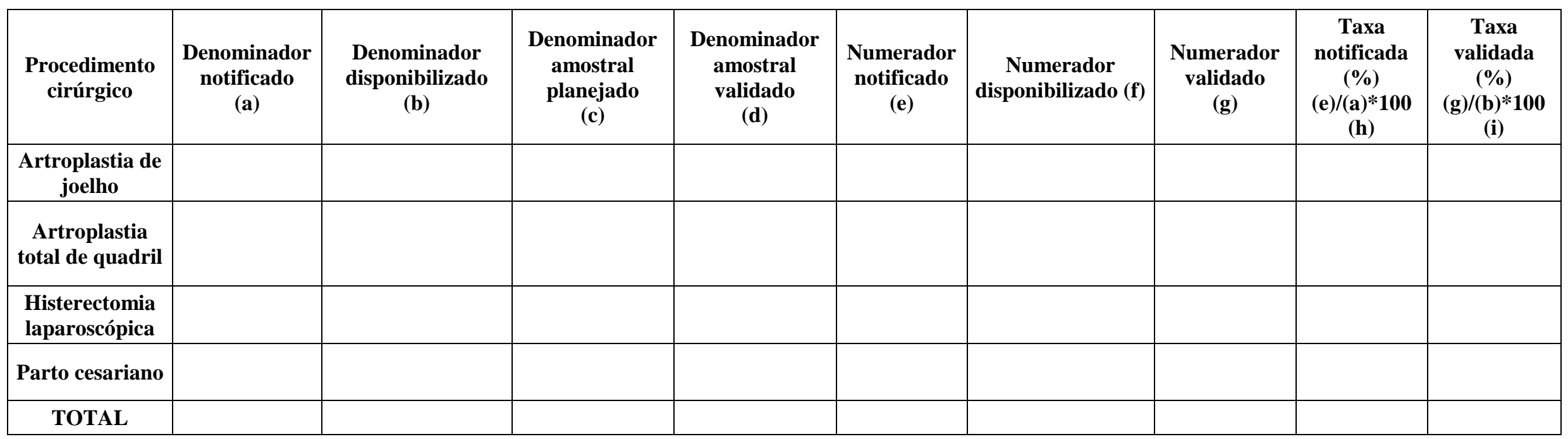

(a) = denominador notificado pelo hospital para o Estado, referente ao ano validado (2016). 
(b) = denominador disponibilizado pelo hospital para o cálculo do tamanho da amostra e sorteio aleatório de prontuário a serem revisadas; observa-se que este número difere de "a" para alguns procedimentos. $(\mathrm{c})=$ amostra de prontuários a serem revisados referentes ao denominador, calculada com base em "b".

(d) = amostra final de prontuários revisados, após a exclusão de cirurgias que não preenchiam critério de inclusão definido previamente no projeto.

(e) = numerador notificado pelo hospital para o estado, referente ao ano validado (2016).

(f) = numerador disponibilizado pelo hospital para o cálculo do tamanho da amostra de prontuários a serem revisados para a validação de dados; observa-se que este número difere de "e" para alguns procedimentos.

$(\mathrm{g})=$ numerador identificado pelo validador.

(h) $=$ taxa notificada $(\mathrm{e} / \mathrm{a}) * 100$

(i) = taxa identificada pelo validador na amostra (g / b) * 100; observa-se que para este cálculo assume-se que o resultado encontrado na amostra é representativo da totalidade das cirurgias realizadas.

Cada caso excluído do denominador está justificado no quadro anexo.

Foi analisada a concordância e a discordância entre os casos de ISC notificados pelo hospital para o sistema estadual de vigilância das ISC e aquele estabelecido pelo validador após a revisão do prontuário, considerado padrão-ouro neste estudo. Os resultados são apresentados na Tabela 1.

TABELA 1. Concordância entre o critério diagnóstico epidemiológico dos casos de ISC notificados pelo hospital para o sistema de vigilância estadual e o diagnóstico estabelecido pela equipe de validadores para artroplastia de joelho e artroplastia total do quadril período analisado: 2016. São Paulo, 2018.

\begin{tabular}{ccccc}
\hline Procedimento cirúrgico & $\begin{array}{c}\text { Casos notificado pelo } \\
\text { hospital }\end{array}$ & $\begin{array}{c}\text { Com } \\
\text { ISC }\end{array}$ & Sem ISC & Total \\
\hline \hline Artroplastia de joelho & ISC & \\
\hline Artroplastia total de quadril & Não ISC & \\
\hline
\end{tabular}

A avaliação quanto à concordância ou discordância para a classificação em relação ao plano tecidual acometido é apresentada na Tabela 2. 
TABELA 2. Concordância e discordância quanto à classificação em relação ao plano tecidual acometido realizada pelos hospitais e aquela identificada pelos validadores. São Paulo, 2017.

\begin{tabular}{ccc}
\hline Procedimento cirúrgico & $\begin{array}{c}\text { Casos notificado } \\
\text { pelo hospital }\end{array}$ & Superficial Profunda Órgão/Cavidade \\
\hline \hline & Superficial \\
Artroplastia de joelho & Profunda \\
& Órgão/ \\
\hline \multirow{3}{*}{ Artroplastia total de quadril } & Superficial \\
& Profunda \\
& Órgão/ \\
\hline
\end{tabular}

COMENTÁRIOS:

RECOMENDAÇÕES:

Quadro 2. Justificativa da exclusão do procedimento cirúrgico notificado como artroplastia de joelho. Projeto piloto de validação de dados de ISC. São Paulo, 2017.

\begin{tabular}{|l|l|l|l|}
\hline ARTROPLASTIA DE JOELHO \\
\hline ID prontuário/atendimento & Data da cirurgia & $\begin{array}{l}\text { Notificada } \\
\text { como ISC }\end{array}$ & Motivo da exclusão \\
\hline & & & \\
\hline & & & \\
\hline
\end{tabular}

Quadro 3. Justificativa da exclusão do procedimento cirúrgico notificado como artroplastia total de quadril. Projeto piloto de validação de dados de ISC. São Paulo, 2017.

\begin{tabular}{|l|l|l|l|}
\hline ARTROPLASTIA TOTAL DE QUADRIL \\
\hline ID prontuário/atendimento & Data da cirurgia & $\begin{array}{l}\text { Notificada } \\
\text { como ISC }\end{array}$ & Justificativa da exclusão \\
\hline & & & \\
\hline & & & \\
\hline
\end{tabular}




\section{APÊNDICE E}

Secretaria de Estado da Saúde de São Paulo Coordenadoria de Controle de Doenças-CCD

Centro de Vigilância Epidemiológica "Prof. Alexandre Vranjac" Divisão de Infecção Hospitalar

\section{PROTOCOLO PARA VALIDAÇÃO DE DADOS DO SISTEMA DE VIGILÂNCIA DE INFECÇÕES DO SIITIO CIRÚRGICO (ISC) NO ESTADO DE SÃO PAULO.}

Projeto em parceria com a

Escola de Enfermagem da Universidade de São Paulo
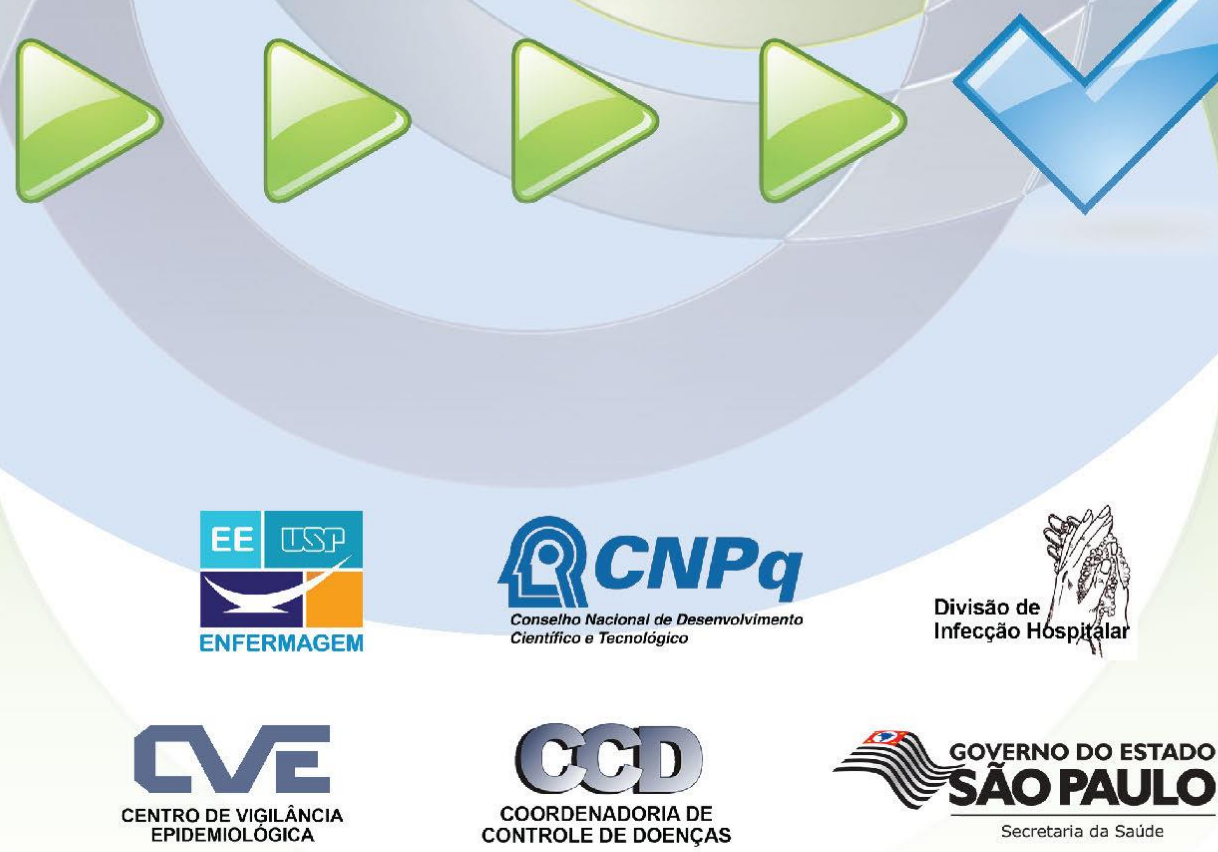

São Paulo

2018 


\begin{abstract}
APOIOS
Escola de Enfermagem da Universidade de São Paulo

Instituição-Sede
\end{abstract}

Divisão de Infecção Hospitalar do Centro de Vigilância Epidemiológica da Secretaria Estadual de Saúde de São Paulo

Instituição Parceira

Grupo de Vigilância Epidemiológica de Santo André VII - Santo André

Secretaria Estadual de Saúde de São Paulo

Centro de Estatística Aplicada da Universidade de São Paulo

Instituições colaboradoras

Conselho Nacional de Desenvolvimento Científico e Tecnológico

Financiamento 


\section{PARTICIPANTES}

\section{COORDENAÇÃO GERAL}

Maria Clara Padoveze. Enfermeira. Professora Doutora2. Escola de Enfermagem. Bolsista de Produtividade em Pesquisa do CNPq.

\section{PESQUISADORA RESPONSÁVEL}

Débora Silva de Mello. Enfermeira. Mestra em Ciências. Doutoranda. Escola de Enfermagem, Universidade de São Paulo.

\section{INSTITUIÇÃO PARCEIRA}

Denise Brandão de Assis. Diretora Técnica. Divisão de Infecção Hospitalar. Centro de Vigilância Epidemiológica "Prof. Alexandre Vranjac". Secretaria Estadual da Saúde de São Paulo.

Geraldine Madalosso. Médica Infectologista. Divisão de Infecção Hospitalar. Centro de Vigilância Epidemiológica "Prof. Alexandre Vranjac". Secretaria Estadual da Saúde de São Paulo.

\section{ASSESSORIA ESTATÍSTICA}

\section{Alunos}

Bruno Franco Reimann. Centro de Estatística Aplicada, Universidade de São Paulo.

Isadora Avidos. Centro de Estatística Aplicada, Universidade de São Paulo.

Tales Dan Taira Tamada. Centro de Estatística Aplicada, Universidade de São Paulo.

\section{Orientadores}

Prof $^{a}$. Dr ${ }^{a}$. Gisela Tunes da Silva. Centro de Estatística Aplicada, Universidade de São Paulo.

Prof $^{\circ}$. Dro ${ }^{\circ}$ Antonio Carlos Pedroso de Lima. Centro de Estatística Aplicada, Universidade de São Paulo.

Prof $^{\circ}$. Dr ${ }^{\circ}$. Carlos Alberto de Bragança Pereira. Centro de Estatística Aplicada, Universidade de São Paulo. 


\section{CONTEÚDO}

APRESENTAÇÃO.

OPERACIONALIZAÇÃO DO ESTUDO DE VALIDAÇÃO DE DADOS DE ISC...

- Definindo os procedimentos cirúrgicos a serem validados.

- Definindo o período a ser validado.

- Conferência e organização dos dados notificados pelas instituições de saúde para o sistema estadual de vigilância das ISC.

- Amostra de hospitais e prontuários

- Amostragem em único estágio.

○ Realizar contato com o hospital

○ Conferir as informações obtidas

○ Proceder ao cálculo da amostra de prontuários.

○ Seleção aleatória de prontuários

- Amostragem em dois estágios.

- Amostra de hospitais a serem visitados ( $1^{\circ}$ estágio)

- Seleção de hospitais quando mais de um procedimentos cirúrgico for validado

RECURSOS NECESSÁRIOS.

- Formulário para a coleta de dados

- Banco de dados

- Confirmar data, horário e local da visita para revisão dos prontuários.

- Recursos humanos.

- Recursos materiais necessários para a visita aos hospitais

- Dispositivos móveis

ANÁLISE DOS RESULTADOS.

- Resultados gerais

- Avaliação da concordância de acordo com o critério diagnóstico das ISC.

- Classificação de acordo com o plano tecidual acometido.

RELATÓRIO PARA OS HOSPITAIS VISITADOS

REFERÊNCIAS 


\section{APRESENTAÇÃO}

A magnitude e o comportamento das infecções relacionadas a assistência a saúde (IRAS) podem ser estimados pelas instituições de saúde e órgãos governamentais por meio da vigilância epidemiológica (VE). Os dados obtidos podem apoiar os hospitais indicando o comportamento da ocorrência destes agravos, bem como a efetividade das intervenções adotadas para sua redução ${ }^{1(M c B r y d e ~ e t ~ a l ., ~ 2009), ~ e ~ a s s i m ~ d i r e c i o n a n d o ~ a s ~ e s t r a t e ́ g i a s ~ d e ~ p r e v e n c ̧ a ̃ o ~ e ~}$ controle que devem ser priorizadas.

Sistemas governamentais tem utilizado a VE como parte da estratégia de prevenção das infecções de sitio cirúrgico (ISC) e os resultados tem demonstrado redução das taxas destes agravos ao longo do tempo entre as instituições participantes2, 3, 4 (Rioux, Grandbastien \& Astagneau, 2007; Geubbels et al., 2006; Gastmeier et al., 2008). Um importante aspecto a ser considerado em relação a estes sistemas refere-se a sua validação no sentido de assegurar a qualidade das informações notificadas5 (Manniën et al, 2007).

A necessidade de garantia da qualidade dos dados notificados aos sistemas de vigilância de IRAS tem sido apontada como fundamental pela literatura científica (Wilson \& Kiernan, 2012; Passaretti et al, 2011; McCoubrey et al, 2005). Além disto, possibilita a comparação entre os hospitais (McKibben et al., 2005), garantindo, desta forma, credibilidade científica, identificação de problemas metodológicos do programa, aumento da adesão e adequada participação no programa (McCoubrey et al. 2005). Além disto, a validação pode promover oportunidade para o esclarecimento de dúvidas por parte das equipes dos hospitais, favorecendo a comunicação entre estes profissionais e aqueles que atuam no sistema de vigilância das IRAS (Haley et al., 2012).

O Estado de São Paulo adotou critérios diagnósticos padronizados para a notificação das IRAS que é periodicamente atualizada pela Divisão de Infecção Hospitalar do Centro de Vigilância Epidemiológica "Prof. Alexandre Vranjac" da Secretaria de Estado da Saúde de São Paulo (DIH/CVE/SES). Estes critérios encontram-se disponíveis em um manual de orientações e critérios diagnósticos e são baseados nas recomendações da Agência Nacional de Vigilância Sanitária (ANVISA) e do Centro de Controle de Doenças/EUA (CDC) (SES, 2018).

Os resultados obtidos desde a implantação do sistema de VE das ISC no Estado de São Paulo em 2004 e sua revisão em 2012, tem apontado para a necessidade de avaliação dos dados notificados, buscando conhecer possíveis divergências na aplicação dos critérios diagnósticos adotados. Para tanto, o projeto de pesquisa realizado em parceria entre a Escola de Enfermagem da Universidade de São Paulo (EEUSP) e a DIH/CVE/SES teve por objetivo a elaboração do 
presente protocolo cuja finalidade é a padronização do processo de validação de dados de infecções de sítio cirúrgico (ISC) do sistema de vigilância epidemiológica (VE) no Estado.

O Centro de Vigilância Epidemiológica coordena as ações de VE no estado de São Paulo e, no nível regional, estrutura-se a partir de 28 Grupos de Vigilância Epidemiológica (GVE), que são responsáveis por realizar a interlocução do sistema de VE das IRAS, entre outras atribuições. Sendo assim, o presente protocolo foi elaborado para ser aplicado para as regiões administrativas, os GVE.

A Figura 1 apresenta a distribuição administrativa atual dos GVE no Estado.

Figura 1. Divisão administrativa para as ações de vigilância epidemiológico no Estado de São Paulo, de acordo com os Grupos de Vigilância Epidemiológica (GVE). São Paulo, 2018.

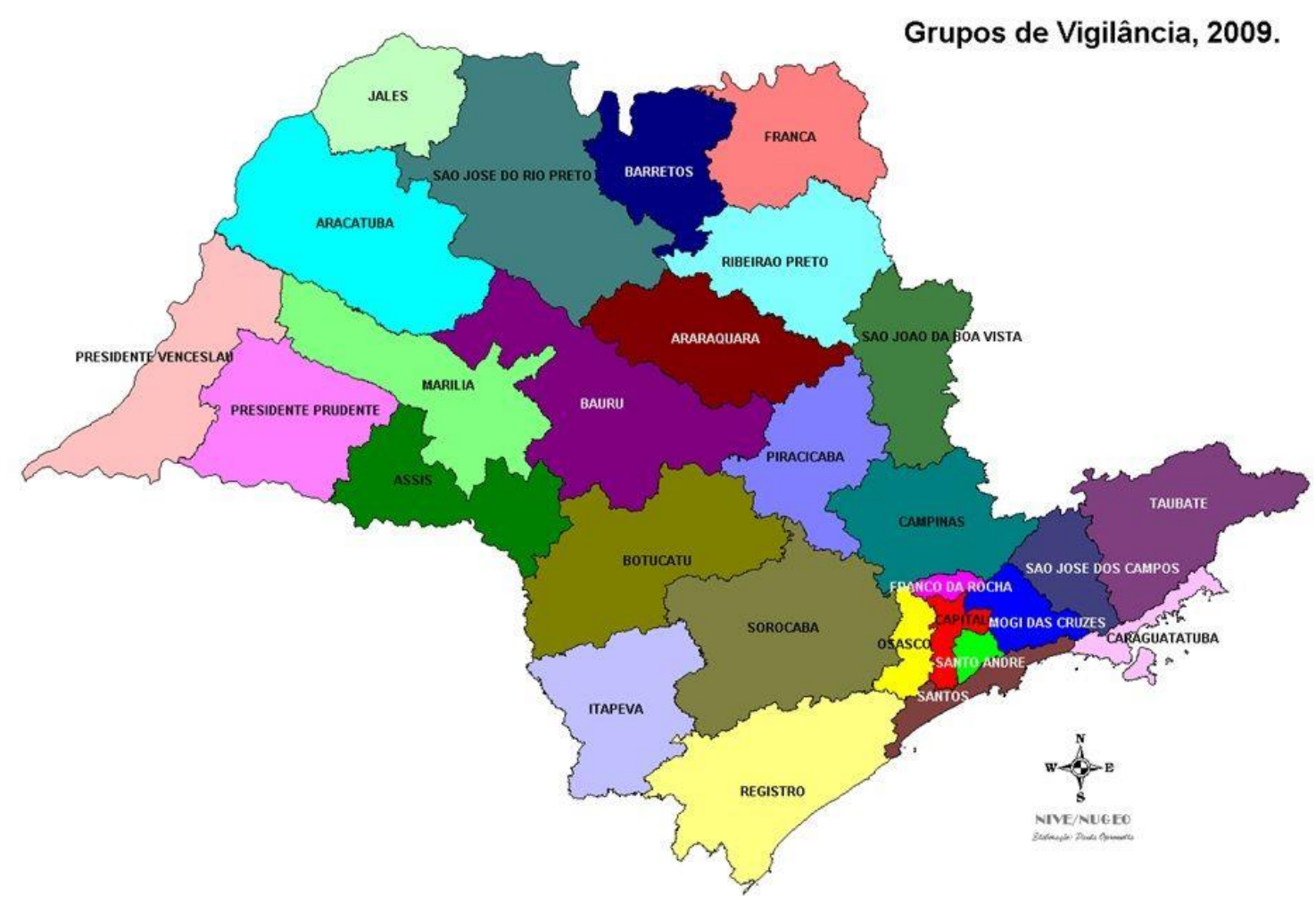

(Fonte: Divisão de Infecção Hospitalar. Análise dos Dados do Sistema de Vigilância Epidemiológica das Infecções Hospitalares do Estado de São Paulo - 2016. Disponível em: http://www.saude.sp.gov.br/cve-centro-de-vigilancia-epidemiologica-prof.-alexandrevranjac/areas-de-vigilancia/infeccao-hospitalar/sistema-de-vigilancia-epidemiologica) 
O processo proposto para a validação de dados de ISC no Estado de São Paulo é apresentado a seguir, de forma estruturada, a fim de facilitar seu planejamento e execução. As etapas aqui apresentadas foram executadas em um estudo piloto, em uma região de São Paulo, de tal modo que sua exequibilidade já foi demonstrada (Mello DS, 2018). 


\section{OPERACIONALIZAÇÃO DO ESTUDO DE VALIDAÇÃO DE DADOS DE ISC}

A revisão retrospectiva de prontuários é o método a ser utilizado para a identificação dos casos de ISC pelos validadores. A determinação da ocorrência ou não da ISC deve ser baseada no manual de orientações e critérios do sistema de vigilância epidemiológica das infecções hospitalares, adotado pelo Estado de São Paulo, referente ao ano que será validado. O cálculo da amostragem considera uma estratificação por número de leitos de cada instituição para assegurar que a validação ocorra de modo mais homogêneo possível entre instituições com diferentes características.

É importante considerar que algumas instituições possuem prontuários eletrônicos. Neste caso, a disponibilização dos prontuários é realizada de forma mais ágil, no entanto, é necessário computador disponível na instituição para sua revisão. Dessa forma, é importante planejar com a equipe do hospital que a data da revisão - preveja a disponibilidade de acesso a esta ferramenta por parte da equipe de validadores e que funcionários com permissão de acesso ao sistema acompanhem o processo de revisão dos prontuários.

\subsection{Definindo os procedimentos cirúrgicos a serem validados}

A seleção dos procedimentos cirúrgicos a serem validados deve contemplar os seguintes aspectos:

- Estar entre os procedimentos cirúrgicos sob vigilância pelo sistema de vigilância epidemiológica das IRAS no Estado de São Paulo.

- Considerar a disponibilidade de recursos humanos capacitados e de infra-estrutura como materiais (impressos, canetas, pastas e computador com recurso para armazenamento e análise dos dados) e transporte, para a definição dos tipos de procedimentos cirúrgicos a serem validados.

\subsection{Definindo o período a ser validado}

A fim de evitar viés de ordem sazonal que possa interferir nos resultados do estudo, recomenda-se que o período validado contemple um ano de notificação.

Para o planejamento da execução da validação deve-se considerar o tempo preconizado para a definição de caso de ISC após a data da cirurgia. Assim sendo, o início da revisão dos prontuários por parte dos validadores só pode ocorrer após o término deste período de acordo com o procedimento selecionado. Por exemplo, na validação para os procedimentos cirúrgicos 
cujos critérios diagnósticos consideram a manifestação da ISC ocorrida em até 90 dias após a data da cirurgia. Neste caso, se o período selecionado para a validação for de janeiro a dezembro, os procedimentos de validação só poderão ser iniciados a partir de abril do ano subsequente. Isto porque, há que se considerar o tempo necessário para a notificação dos dados pela instituição de saúde para a equipe da vigilância regional, bem como a definição de tempo preconizada para o diagnóstico atribuído a ISC.

\subsection{Conferência e organização dos dados notificados pelas instituições de saúde para o sistema estadual de vigilância das ISC}

Primeiramente deve-se proceder à conferência dos dados de IRAS notificados pelas instituições de saúde referentes ao GVE a ser validado. Lembrar que esta conferência deve ser realizada apenas após o final do período de rotina para a notificação dos dados e deve contemplar os seguintes elementos:

- conferir o recebimento de todas as planilhas de notificação de dados de ISC enviadas pelas instituições de saúde referentes ao GVE selecionado no período estabelecido;

- conferir o preenchimento de todos os campos das planilhas, com vistas a garantir que não haja campos em branco;

- certificar o correto preenchimento dos campos para cada procedimento cirúrgico (planilha 1B), buscando identificar a ocorrência de erros. Entre os erros comuns temos como exemplo, o número de ISC maior que número de procedimentos cirúgicos. Solicitar à instituição notificante a correção dos erros eventualmente identificados.

- Após a consolidação dos dados de todas as instituições, fazer uma cópia adicional da planilha, para uso no cálculo da amostragem. Cada linha deve corresponder aos dados de uma única instituição. A primeira coluna de cada instituição deve informar o número de leitos da instituição.

- Na planilha de amostragem excluir dados e informações das instituições de saúde que notificaram ter realizado 0 (zero) procedimento cirúrgico no período a ser validado. Nesta etapa devem ser incluídos no grupo de hospitais a serem sorteados para a validação apenas as instituições que tenham realizado pelo menos 01 
procedimento cirúrgico no período a ser validado, para determinado procedimento selecionado.

- Ordenar os dados da planilha por número de leitos dos hospitais.

- Agrupar os hospitais segundo o número de leitos de acordo com a estratificação a seguir:

Estrato I: até 49 leitos

Estrato II: de 50 a 199 leitos

Estrato III: de 200 ou mais leitos

- Calcular o número (N) total de instituições para cada um dos 03 estratos.

\subsection{Amostra de hospitais e prontuários.}

Para cada um dos estratos apresentados acima deve ser calculada uma amostra de hospitais. Desta forma, a amostra será representativa de hospitais de todos os estratos.

Em seguida serão selecionados os prontuários a serem revisados em cada hospital selecionado.

Duas situações podem ocorrer em relação ao planejamento amostral, a saber:

1. O número de hospitais na região_permite visitar todos os hospitais que notificaram o (s) procedimento (s) cirúrgico (s) selecionado (s). Neste caso, deve-se proceder diretamente à seleção dos prontuários utilizando o método denominado amostragem em único estágio.

2. O número de hospitais é tal que não é possível visitar todos os hospitais. Neste caso, será necessário realizar o cálculo da amostra e a seleção dos hospitais que serão visitados para posteriormente proceder ao cálculo da amostra e seleção dos prontuários a serem revisados. Neste caso, será realizada amostragem em dois estágios.

O método a ser utilizado em cada uma das situações descritas acima será apresentado a seguir. 


\subsubsection{Amostragem em único estágio}

Nesta situação, todos os hospitais serão visitados, portanto, deve-se proceder diretamente ao cálculo da amostra e à seleção dos prontuários a serem revisados para a validação em cada hospital, para cada procedimento cirúrgico selecionado. Este cálculo será realizado a partir do número de cirurgias e e do número de ISC informados pelo hospital, portanto, antes de realizar o cálculo da amostra de hospitais faz-se necessário confirmar as informações notificadas junto ao hospital que será visitado. As etapas do procedimento de amostragem um único estágio são detalhadas a seguir:

\subsubsection{Realizar contato com o hospital}

É de extrema importância que seja realizado um contato formal e oficial por parte do profissional responsável pela vigilância das IRAS no âmbito municipal com os hospitas selecionados para a validação. Esta comunicação deve incluir:

- Equipe responsável pela validação e seus contatos (e-mail e telefone institucionais);

- Objetivos do estudo de validação;

- Procedimento (s) cirúrgico (s) selecionado (s) para validação;

- Ano selecionado validação;

- Critérios para a seleção dos hospitais e prontuários;

- O que se espera com os resultados obtidos;

- Data prevista para a revisão dos prontuários in loco (recomendamos que esta visita seja realizada a partir de 02 meses após o envio do comunicado para que haja tempo suficiente de preparo dos recursos necessários);

- Solicitação para envio de uma lista com a identificação das cirurgias realizadas entre 01 de janeiro e 31 de dezembro do ano selecionado para a validação, para cada um dos procedimentos cirúrgicos selecionados. Esta lista deve conter as seguintes informações:

o data do procedimento cirúrgico;

o número do atendimento e/ou do prontuário (que permita identificar o prontuário referente à cirurgia realizada), porém sem o nome do paciente ${ }^{1}$;

o tipo de procedimento cirúrgico.

o identificação de quais dentre estes procedimentos foram notificados como casos de ISC para o sistema estadual de vigilância. Informar apenas o número de

${ }^{1}$ A não inclusão de nomes de pacientes é importante para evitar o tráfego desnecessário de informações confidenciais de pacientes. 
registro do paciente referente ao procedimento cirúrgico para o qual foi atribuída a ocorrência da ISC.

Deve-se indicar um prazo para o envio desta lista pelos hospitais.

\subsubsection{Conferir as informações obtidas}

Após o recebimento, realizar a conferência das seguintes informações:

- Todas as cirurgias referem-se ao ano selecionado para a validação?

- As informações referem-se aos procedimentos cirúrgicos selecionados?

- Há repetição de dados referentes a um mesmo paciente?

Conferir na identificação dos tipos de procedimentos cirúrgicos realizados se foram incluídas somente as cirurgias do sistema de vigilância epidemiológica das IRAS do Estado de São Paulo, de acordo com as orientações do manual de orientações e critérios diagnósticos vigente no ano a ser validado.

$\mathrm{Na}$ planilha de trabalho, ordenar a coluna que identifica o prontuário referente ao procedimento cirúrgico e verificar se há repetição de informações (duplicidade de dados). Neste caso, verificar se ambas as informações referem-se a procedimentos cirúrgicos diferentes realizados no mesmo paciente, ou ainda a diferentes atendimentos do mesmo paciente, o que não é considerado como duplicidade. É importante que as duplicidades sejam eliminadas e a informação seja conferida com o hospital antes de realizar o cálculo da amostra de prontuários.

\subsubsection{Proceder ao cálculo de amostra de prontuários}

Com a lista conferida de cirurgias e casos notificados como ISC, o cálculo da amostra de prontuários a serem revisados pode ser então realizado, utilizado-se a fórmula apresentada a seguir:

$$
\mathrm{a}_{\mathrm{j}}=\frac{\mathrm{m}_{\mathrm{j}}}{1+\frac{\mathrm{m}_{\mathrm{j}}-1}{\mathrm{C}_{\mathrm{j}}}},
$$

Onde:

$\mathbf{a}_{\mathrm{j}}=$ número de prontuários a serem amostrados. 
$\mathrm{m}_{\mathrm{j}}=\frac{\mathrm{z}_{\alpha}^{2} \hat{\mathrm{p}_{\mathrm{j}}}\left(1-\hat{\mathrm{p}_{\mathrm{j}}}\right)}{\mathrm{E}^{2}}$

$\mathbf{z}_{\boldsymbol{\alpha}}=$ é determinada a partir do valor fixado para o coeficiente de confiança. Usualmente, utiliza-se um coeficiente igual a $95 \%$ (que produz $z_{\alpha}^{2}=(1,96)^{2} \cong 3,842$ ).

$\widehat{\mathbf{p}_{\mathrm{j}}} \quad=$ taxa de ISC informada pelo hospital, obtida a partir das informações levantadas junto aos hospitais, conforme descrito acima. Caso a taxa seja menor do que 0,001, ela será fixada em 0,001 e, neste caso deverá ser revisado pelo menos $50 \%$ a mais de prontuários para aumentar a margem de probabilidade de encontrar falhas que eventualemente existam.

$\mathbf{E}$ = é o quanto se aceita de erro entre a proporção estimada e o valor verdadeiro (que seria observado caso todos os prontuários fossem analisados), que deve ser um valor entre 0 e 1.

$\mathbf{C}_{\mathrm{j}}=\mathrm{o}$ número de cirurgias do procedimento escolhido no período considerado, que foram realizadas no hospital $\mathrm{j}$,

Caso $\mathbf{a}_{\mathfrak{j}}$ não seja um número inteiro, ele deve ser arredondado para o valor inteiro mais próximo acima dele.

(Fonte: Reimann, Avidos \& Tamada, 2016. In: Mello DS, 2018)

A Figura 2 ilustra uma sugestão para calcular no Microsoft Excel® , o tamanho da amostra de prontuários a serem revisados para um determinado procedimento utilizando a fórmula apresentada acima.

Figura 2. Ilustração da fórmula para cálculo da amostra de prontuários, por procedimento para $95 \%$ de confiança, utilizando uma planilha do Microsoft Excel. São Paulo, 2018.

\begin{tabular}{|c|c|c|c|c|c|c|c|}
\hline & $\mathrm{A}$ & $\mathrm{B}$ & $\mathrm{C}$ & $\mathrm{D}$ & $\mathrm{E}$ & $\mathrm{F}$ & $\mathrm{G}$ \\
\hline 1 & Procedimento cirúrgico & $m_{j}$ & $(\widehat{p})$ & $\mathrm{z}_{\alpha}^{2}$ & $\mathrm{C}_{\mathbf{j}}$ & $\mathrm{E}$ & $a_{j}$ \\
\hline 2 & Histerectomia LP & $=\mathrm{D} 2 *(\mathrm{C} 2)^{*}(1-\mathrm{C} 2) /\left(\mathrm{F} 2^{\wedge} 2\right)$ & 0,019 & 3,842 & 18 & 0,05 & $=(\mathrm{B} 2) /(1+((\mathrm{B} 2-1) / \mathrm{E} 2))$ \\
\hline 3 & Artroplastia Total quadril & $=\mathrm{D} 3^{*}(\mathrm{C} 3)^{*}(1-\mathrm{C} 3) /\left(\mathrm{F} 3^{\wedge} 2\right)$ & 0,235 & 3,842 & 423 & 0,05 & $=(\mathrm{B} 3) /(1+((\mathrm{B} 3-1) / \mathrm{E} 3))$ \\
\hline 4 & Artroplastia de joelho & $=\mathrm{D} 4 *(\mathrm{C} 4)^{*}(1-\mathrm{C} 4) /\left(\mathrm{F} 4{ }^{\wedge} 2\right)$ & 0,074 & 3,842 & 115 & 0,05 & $=(\mathrm{B} 4) /(1+((\mathrm{B} 4-1) / \mathrm{E} 4))$ \\
\hline
\end{tabular}

*Na figura acima, a coluna "E" traz números hipotéticos de total de cirurgias de cada tipo de procedimento cirúrgico selecionado para a validação, apenas como exemplo para esta ilustração. 


\subsubsection{Seleção aleatória de prontuários}

Para garantir que todos os prontuários tenham a mesma probabilidade de serem incluídos na amostra deve-se proceder à seleção aleatória dos mesmos. A seguir é apresentado um método para realizar a seleção aleatória utilizando-se o Microsoft Excel®:

- Para cada hospital, utilizar uma aba diferente da planilha.

- A função de aleatorização deve ser feito de modo separado para cada tipo de procedimento.

- Em seguida, criar uma coluna com a função aleatório. Utilizando-se o exemplo da Tabela 1, supondo que seja 17 o número total de prontuários de um determinado procedimento cirúrgico realizado em um determinado hospital, podemos na coluna " $\mathrm{A}$ " dispor todos estes hospitais e na coluna "B", utilizar a função "aleatório" para gerar um número aleatório para cada um dos hospitais, conforme exemplo da Tabela 1.

TABELA 1. Exemplo de número aleatório gerado em Microsoft Excel® para determinar os prontuários que serão revisados para cada hospital a ser visitado e relactivo a cada procedimento cirúrgico selecionado para a validação. São Paulo, 2018.

\begin{tabular}{|c|c|}
\hline $\begin{array}{l}\text { COLUNA } \\
\text { (A) }\end{array}$ & COLUNA (B) \\
\hline $\begin{array}{c}\text { ID } \\
\text { prontuário }\end{array}$ & $\begin{array}{c}\text { Número } \\
\text { aleatório }\end{array}$ \\
\hline Pront A & 0,55612 \\
\hline Pront B & 0,57495 \\
\hline Pront C & 0,52199 \\
\hline Pront D & 0,28287 \\
\hline Pront F & 0,03015 \\
\hline Pront G & 0,03983 \\
\hline Pront $\mathrm{H}$ & 0,88567 \\
\hline Pront I & 0,70802 \\
\hline Pront J & 0,20880 \\
\hline Pront L & 0,48570 \\
\hline Pront M & 0,48883 \\
\hline Pront N & 0,21951 \\
\hline Pront $O$ & 0,26155 \\
\hline Pront P & 0,47821 \\
\hline Pront Q & 0,35296 \\
\hline Pront R & 0,97597 \\
\hline Pront S & 0,33036 \\
\hline
\end{tabular}

Note que, após gerar os números aleatórios é

necessário copiar e colar somente os valores para depois, então ordenar os hospitais de acordo com o 
O segundo passo é ordenar os valores gerados, em ordem decrescente, conforme apresentado na Tabela 2. A

TABELA 2. Exemplo da ordem de prontuários a serem revisados segundo cálculo da amostra e sorteio aleatório. São Paulo, 2018.

\begin{tabular}{c|c|c}
\hline $\begin{array}{c}\text { COLUNA } \\
(\mathrm{A})\end{array}$ & COLUNA (B) & COLUNA (C) \\
\hline $\begin{array}{c}\text { ID } \\
\text { prontuário }\end{array}$ & $\begin{array}{c}\text { Número } \\
\text { aleatório }\end{array}$ & $\begin{array}{c}\text { Ordem } \\
\text { aleatória }\end{array}$ \\
\hline Pront $\mathbf{R}$ & 0,97597 & $1^{\circ}$ \\
\hline Pront $\mathbf{H}$ & 0,88567 & $2^{\circ}$ \\
\hline Pront I & 0,70802 & $3^{\circ}$ \\
\hline Pront B & 0,57495 & $4^{\circ}$ \\
\hline Pront $\mathbf{A}$ & 0,55612 & $5^{\circ}$ \\
\hline Pront $\mathbf{C}$ & 0,52199 & $6^{\circ}$ \\
\hline Pront $\mathbf{M}$ & 0,48883 & $7^{\circ}$ \\
\hline Pront $\mathbf{L}$ & 0,4857 & $8^{\circ}$ \\
\hline Pront P & 0,47821 & $9^{\circ}$ \\
\hline Pront $\mathbf{Q}$ & 0,35296 & $10^{\circ}$ \\
\hline Pront S & 0,33036 & $11^{\circ}$ \\
\hline Pront D & 0,28287 & $12^{\circ}$ \\
\hline Pront $\mathbf{O}$ & 0,26155 & $13^{\circ}$ \\
\hline Pront N & 0,21951 & $14^{\circ}$ \\
\hline Pront J & 0,2088 & $15^{\circ}$ \\
\hline Pront G & 0,03983 & $16^{\circ}$ \\
\hline Pront F & 0,03015 & $17^{\circ}$ \\
\hline
\end{tabular}

Em seguida, selecionar os prontuários a serem revisados na ordem em que se apresentam.

\subsubsection{Amostragem em dois estágios}

Nas situações em que não seja possível visitar todos os hospitais de um determinado GVE deve-se utilizar uma amostragem em dois estágios (tecnicamente denonimada "amostragem por conglomerados em dois estágios") (Bolfarine e Bussab, 2005) conforme descrito a seguir:

$1^{\text {0 }}$ estágio: para cada estrato, selecionar os hospitais que realizaram o procedimento cirúrgico escolhido para a validação (aqui, cada hospital representa um conglomerado). A amostra de hospitais a serem visitados será calculada para cada estrato. 
$2^{\mathbf{o}}$ estágio: para cada hospital, calcular a amostra de prontuários do procedimento cirúrgico selecionado.

A Figura 3 contém um organograma que estrutura esta proposta

FIGURA 3. Organograma do planejamento amostral em dois estágios. São Paulo, 2018.

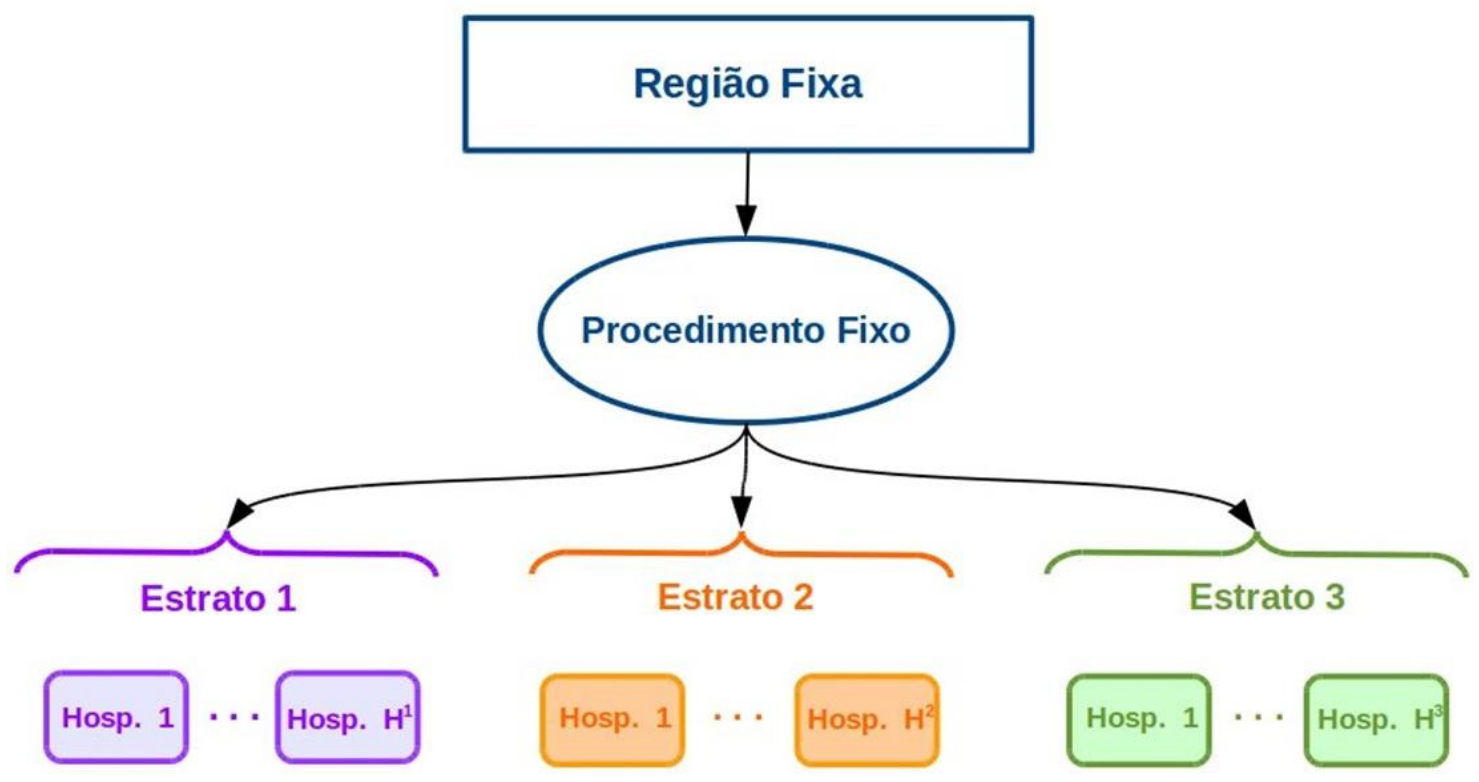

(Fonte: Reimann, Avidos \& Tamada, 2016. In: Mello, DS, 2018)

*Considerar como região fixa, um determinado GVE.

**Considerar como procedimento fixo o procedimento selecionado para a validação.

\subsubsection{Amostra de hospitais a serem visitados ( $1^{\circ}$ estágio $)$}

A fórmula a seguir deve ser utilizada para cálculo da amostra de hospitais a serem visitados. Este cálculo deve ser realizado para cada um dos três estratos e cada um dos procedimentos cirúrgicos selecionados para a validação.

$$
\mathbf{h}_{j}^{k}=\frac{\mathbf{n}}{\mathbf{1}+\frac{n-1}{H_{j}^{k}}},
$$

Onde: 
- $H_{j}^{k}$ : número de hospitais do estrato k que realizaram o procedimento j;

- $\boldsymbol{h}_{j}^{k}$ : número de hospitais a serem amostrados no estrato $\mathrm{k}$ para o procedimento $\mathrm{j}$.

$n=z_{\alpha}^{2} /\left(4\left(E_{k}\right)^{2}\right)$,

- $E_{k}$ : erro escolhido entre a proporção estimada de infecções dos hospitais do estrato k e o valor verdadeiro (não são recomendados erros abaixo de 0,15 , pois estes exigem tamanhos grandes de amostra de hospitais),

- $z_{\alpha}$ é o valor obtido da tabela associado ao nível de confiança do intervalo na estimação da proporção (será utilizado o coeficiente de confiança igual a 95\%; considerar $\left.z_{\alpha}=1,96\right)$.

(Extraído de Reimann, Avidos \& Tamada, 2016)

A Figura 4 ilustra uma sugestão para calcular o tamanho da amostra de hospitais utilizando esta fórmula no Microsoft Excel®, para um determinado procedimento.

Figura 4. Ilustração da fórmula para cálculo da amostra de hospitais, por estrato, para 95\% de confiança, utilizando o Microsoft Excel®. São Paulo, 2018.

\begin{tabular}{|c|c|c|c|c|c|c|}
\hline 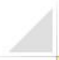 & A & B & C & D & $E$ & $\mathbf{F}$ \\
\hline 1 & $\begin{array}{l}\text { Histerectomia } \\
\text { laparoscópica }\end{array}$ & $z_{\alpha}$ & $E_{k}$ & $H_{j}^{k}$ & $n$ & $h_{j}^{k}$ \\
\hline 2 & Estrato I & 1,96 & 0,15 & 2 & $=\mathrm{B} 2^{\wedge} 2 /\left(4^{*}\left(\mathrm{C} 2^{\wedge} 2\right)\right)$ & $=E 2 /(1+((E 2-1) / D 2))$ \\
\hline 3 & Estrato II & 1,96 & 0,15 & 17 & $=B 3^{\wedge} 2 /\left(4^{*}\left(C 3^{\wedge} 2\right)\right)$ & $=E 3 /(1+((E 3-1) / D 3))$ \\
\hline 4 & Estrato III & 1,96 & 0,15 & 9 & $=\mathrm{B} 4^{\wedge} 2 /\left(4^{*}\left(\mathrm{C} 4^{\wedge} 2\right)\right)$ & $=\mathrm{E} 4 /(1+((\mathrm{E} 4-1) / \mathrm{D} 4))$ \\
\hline
\end{tabular}

*Na figura acima, a coluna " $\mathrm{D}$ " traz números hipotéticos de hospitais em cada estrato, apenas como exemplo para esta ilustração.

Caso $\boldsymbol{h}_{j}^{k}$ não seja um número inteiro, ele deve ser arredondado para o valor inteiro mais próximo acima dele.

Considerando o exemplo acima, o número de hospitais a serem visitados em cada estrato será: estrato $\mathbf{I}=2$, estrato $\mathbf{I I}=13$ e estrato $\mathbf{I I I}=8$. 
Após calculado o número de hospitais em cada estrato, deve-se proceder à seleção dos hospitais a serem visitados. Caso apenas um procedimento cirúrgico seja selecionado para a validação esta pode ser realizada utilizando-se o método descrito para a seleção aleatória dos prontuários (item 1.4.1. Amostragem em único estágio). Caso mais de um procedimento cirúrgico seja selecionado para a validaçõa, deve-se utilizar a metodologia descrita a seguir.

\subsubsection{Seleção de hospitais quando mais de um procedimentos cirúrgico for validado}

Caso de validação de dados de ISC envolva mais de um tipo de um procedimento cirúrgico, é vantajoso selecionar hospitais que realizem o maior número de tipos de procedimentos a serem validados, pois otimiza-se o recurso do deslocamento para a visita às instituições. Neste caso, o processo será realizado da seguinte forma:

- Para cada procedimento cirúrgico selecionado, e em cada estrato, realizar o cálculo da amostra de hospitais a serem validados utilizando a mesma metodologia descrita no item "1.4.1. Amostragem em único estágio".

- Estabelecer uma ordem de prioridade dentre os procedimentos cirúrgicos selecionados (por exemplo, utilizar como critério de prioridade a importância em termos de volume de procedimentos cirúrgicos volume). Exemplo: no estudo piloto realizado para elaboração deste protocolo, utilizamos "parto cesariano" como procedimento cirúrgico prioritário para a seleção de hospitais a serem aleatorizados.

- Fazer o sorteio aleatório entre os hospitais que realizaram o procedimento cirúrgico selecionado na etapa anterior.

- A seguir, verificar dentre estes hospitais que foram sorteados, quais também realizaram o segundo procedimento cirúrgico a ser validado e assim subsequentemente.

- Caso ainda faltem hospitais para atingir o número amostral calculado, deve-se realizar sorteio aleatório dos hospitais ainda não selecionados, até que se alcance o $\mathrm{N}$ necessário em cada estrato.

Após a seleção dos hospitais que serão validados, faz-se necessário o contato formal seguindo o mesmo método já apresentado na descrição referente à amostragem em único estágio (item 1.4.1). 


\section{RECURSOS NECESSÁRIOS}

\subsection{Formulário para a coleta de dados}

A revisão dos prontuários deve contemplar a verificação de registros médicos, de enfermagem, laboratoriais e, quando disponíveis, de retornos ambulatoriais. Para tal, sugerimos a utilizar de um formulário padrão, elaborado em Microsoft Word® versão 2013 (APÊNDICE $1)$.

Além de dados demográficos e de internação do paciente, este formulário possui um campo para anotações do validador, no qual pode-se registrar informações que ajudem o validador a identificar a ocorrência ou não de ISC, bem como outras informações que julgar pertinente. O formulário contém também um campo para a classificação do validador em relação à ocorrência ou não de ISC a partir dos critérios epidemiológicos vigentes no ano validado, bem como sua classificação topográfica, quando do diagnóstico da ISC.

\subsection{Banco de dados}

É necessário criar um banco de dados para a inserção dos dados coletados a partir da revisão de prontuários. Este banco de dados também pode ser elaborado em uma planilha Microsoft Excel®.

\subsection{Confirmar data, horário e local da visita para revisão dos prontuários}

Após seleção dos prontuários, enviar a lista ao hospital para que os prontuários selecionados estejam disponíveis no dia da visita.

\subsection{Recursos humanos}

A contratação de recursos humanos deve levar em consideração as possíveis variações de recursos entre as instituições a serem visitadas. Na prática, quanto maior o número de revisores menor tempo será utilizado para a revisão de todos os prontuários. Em instituições com prontuário eletrônico há necessidade de acesso a computadores e podem requerer um tempo maior para esta atividade. Desta forma, antes de calcular o número de profissionais necessários para a revisão dos prontuários deve-se identificar a disponibilidade destes recursos nas instituições que serão potencialmente visitadas.

Recomenda-se que o profissional que realizará a revisão dos prontuários não possua nenhum tipo de vínculo com a instituição cujos dados serão validados, de forma a evitar 
possíveis conflitos de interesse. O profissional que realiza validação deve possuir formação qualificada e registro em conselho profissional pertinente, assumir postura ética e salvaguardar a confidencialidade dos dados.

É altamente recomendado que este profissional possua experiência na área de vigilância das IRAS e que seja capacitado para o estudo de validação a ser realizado por meio de capacitação que inclua a apresentação do projeto e seus objetivos, orientações quanto ao correto preenchimento dos campos do instrumento de coleta de dados, dos critérios adotados para a classificação das ISC no ano considerado para a validação, datas, entre outros que a equipe responsável pela organização julgar necessário.

De acordo com o piloto de validação realizado pelo projeto de pesquisa intitulado "Desenvolvimento de um protocolo para a validação dos dados do sistema de vigilância das infecções de sítio cirúrgico (ISC) no Estado de São Paulo". (Mello DS, 2018), pode-se considerar uma média de 15,05 minutos para a revisão de cada prontuário.

Para garantias de confidencialidade sobre dados relativos à instituições, profissionais e pacientes o profissonal que realiza a validação deve assinar um documento onde constam responsabilidades e garantias de anonimato, no que diz respeito à divulgação de dados e outras informações referentes ao paciente e a instituição visitada.

\subsection{Recursos materiais necessários para a visita aos hospitais}

Estes itens devem ser preparados com antecedência suficiente para que estejam disponíveis na data da visita aos hospitais.

\subsubsection{Impressos}

- Lista com nome completo e contato dos profissionais integrantes da equipe de revisores;

- Endereço e horário de encontro dos revisores para deslocamento até a instituição.

- Confirmação da disponibilidade de transporte para a data da visita;

- Lista com horário e endereço do local onde será realizada a revisão dos prontuários (previamente acordado entre a equipe de validação e os responsáveis pela recepção e acompanhamento da equipe na instituição;

- Contato dos responsáveis na instituição de saúde pelo acompanhamento da equipe de validação;

- Lista com as IDs dos prontuários a serem revisados, selecionados aleatóriamente; 
- Lista com as IDs dos prontuários notificados pelas instituições de saúde como casos de ISC daquele (s) procedimento (s) cirúrgico selecionado (s), no ano a ser validado;

- Formulários para coleta de dados impressos, em número superior ao número de prontuários a serem revisados, para necessidades eventuais (rasura, por exemplo);

- Manual de orientações e critérios diagnósticos elaborado pela equipe do sistema de vigilância epidemiológica das IRAS do Estado de São Paulo, vigente no ano a ser validado (impresso);

- Apêndice com nomenclatura SUS para as cirurgias selecionadas, elaborado pela equipe do Sistema de Vigilância Epidemiológica das IRAS do Estado de São Paulo.

- Folhas para registros de anotações e/ outras observações, caso necessário.

- Canetas.

- Régua

- Pastas para armazenar os dados coletados por meio dos formulários.

\subsubsection{Dispositivos móveis}

A utilização de dispositivos eletrônicos como, por exemplo, tablets ou notebooks para a coleta e dados deve levar em consideração os seguintes aspectos: tamanho do equipamento já que grandes dimensões necessitam de maior espaço no local de revisão dos prontuários e dificultam o transporte; fonte de alimentação elétrica (disponibilidade no local próximo do computador ou da sala onde os prontuários serão revisados); bateria; realização de backups (cópias de segurança) periódicos, também em outro dispositivo que não apenas no equipamento utilizado.

\section{ANÁLISE DOS RESULTADOS}

Os resultados obtidos podem permitir ao GVE, verificar se há discrepâncias entre os dados notificados ao sistema de vigilância e aqueles observados pela validação, bem como a adequada aplicação dos critérios diagnósticos das ISC adotados. Estas observações podem direcionar ações para melhorar a qualidade dos dados notificados, como por exemplo, capacitações, orientações e esclarecimentos de dúvidas quanto à aplicação dos conceitos utilizados

A análise dos dados deve envolver a comparação dos dados relativos ao numerador, denominador e às taxas, notificados pelo hospital ao sistema de vigilância de ISC do estado de São Paulo com aqueles observados a partir da revisão da amostra de prontuários pela equipe de 
validadores. Para tanto, é apresentado a seguir um modelo de quadro que pode ser utilizado (Quadro 1).

Nos casos em que a ISC foi identificada pelo hospital por meio da vigilância pós-alta (VPA) e não for possível obter estas informações de retorno o paciente no prontuário, recomenda-se considerar o caso como verdadeiro positivo, desde que a equipe do hospital apresente os registros de obtenção dos sinais de ISC identificados pela VPA.

\subsection{Resultados gerais}

O Quadro 1 pode ser utilizado para apresentar os resultados gerais em relação ao numerador (número total de infecções), denominador (número total de cirurgias) e taxas de ISC (numerador/denominador*100), notificados e observados durante a revisão de prontuários realizada por este projeto. 
QUADRO 1. Resultados gerais em relação ao numerador, denominador e taxas de ISC, notificados e observados pela validação de dados. São Paulo, ANO.

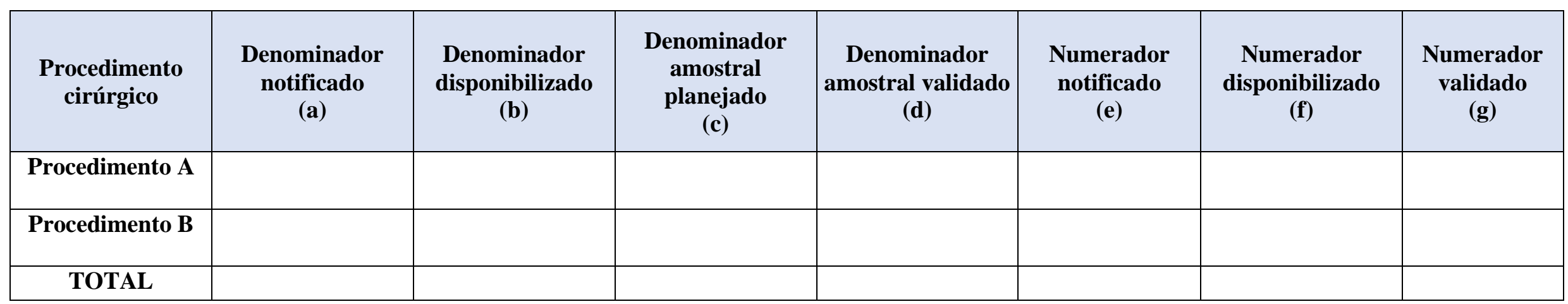

(a) = denominador notificado pelo hospital para o Estado, referente ao ano validado (2016)

(b) = denominador disponibilizado pelo hospital para o cálculo do tamanho da amostra e sorteio aleatório de prontuário a serem revisadas; observa-se que este número difere de "a" para alguns procedimentos.

(c) = amostra de prontuários a serem revisados referentes ao denominador, calculada com base em "b".

(d) = amostra final de prontuários revisados, após a exclusão de cirurgias que não preenchiam critério de inclusão definido previamente no projeto.

(e) = numerador notificado pelo hospital para o estado, referente ao ano validado (2016).

(f) = numerador disponibilizado pelo hospital para o cálculo do tamanho da amostra de prontuários a serem revisados para a validação de dados; observa-se que este número difere de "e" para alguns procedimentos.

$(\mathrm{g})=$ numerador identificado pelo validador.

(h) $=$ taxa notificada $(\mathrm{e} / \mathrm{a}) * 100$

(i) = taxa identificada pelo validador na amostra $(\mathrm{g} / \mathrm{b}) * 100$; observa-se que para este cálculo assume-se que o resultado encontrado na amostra é representativo da totalidade das cirurgias realizadas. 
As justificativas quanto à exclusão de denominadores deve ser apresentada para cada caso (Quadro 2).

QUADRO 2. Justificativa da exclusão do procedimento cirúrgico. São Paulo, ANO.

\begin{tabular}{|c|c|c|c|}
\hline \multicolumn{4}{|c|}{ Procedimento cirúrgico: $x$} \\
\hline $\begin{array}{l}\text { ID da cirurgia } \\
\text { revisada }\end{array}$ & $\begin{array}{l}\text { Data da } \\
\text { cirurgia }\end{array}$ & $\begin{array}{l}\text { Notificada } \\
\text { como ISC }\end{array}$ & Motivo da exclusão \\
\hline & & & \\
\hline & & & \\
\hline & & & \\
\hline & & & \\
\hline & & & \\
\hline & & & \\
\hline & & & \\
\hline & & & \\
\hline
\end{tabular}

\subsection{Avaliação da concordância de acordo com o critério diagnóstico das ISC.}

Também deve ser analisada a concordância entre os casos de ISC notificados pelo hospital para o sistema estadual de vigilância das ISC e aquele estabelecido pelo validador após a revisão do prontuário, considerado padrão-ouro. A Tabela 3 pode ser utilizada para a apresentação destes resultados.

Tabela 3. Resultados da validação de dados de ISC notificados para o sistema de VE das ISC, no ano $x$, considerando o (s) seguinte (s) procedimentos cirúrgicos analisados: descrever o (s) procedimento (s). GVE x. São Paulo, ANO.

Casos identificados pela validação

\begin{tabular}{|c|c|c|c|c|}
\hline Procedimento cirúrgico & Casos notificado pelo hospital & Com ISC & Sem ISC & Total \\
\hline Procedimento A & $\begin{array}{c}\text { ISC } \\
\text { Não ISC }\end{array}$ & & & \\
\hline Procedimento B & $\begin{array}{c}\text { ISC } \\
\text { Não ISC }\end{array}$ & & & \\
\hline
\end{tabular}


A partir destes resultados podem ser calculados o valor preditivo positivo, o valor preditivo negativo, a sensibilidade e a especificidade para cada um dos procedimentos utilizando-se os conceitos definidos a seguir:

- Verdadeiros positivos: casos notificados como ISC pelo hospital e confirmado pelo revisor como ISC.

- Falsos positivos: casos notificados como ISC pelo hospital e identificado pelo revisor como não ISC.

- Verdadeiros negativos: casos notificados como não ISC pelo hospital e confirmado pelo revisor como não ISC.

- Falsos negativos: casos notificados como não ISC pelo hospital e identificado pelo revisor como ISC.

- Valor preditivo positivo $($ VPP $)=$ proporção de pacientes notificados pelo hospital com ISC que foram confirmados pelo revisor com ISC.

Cálculo = VP/(VP+FP $)$

- Valor preditivo negativo $(\mathbf{V P N})=$ proporção de pacientes notificados pelo hospital como não ISC que foram confirmados pelo revisor como não ISC. Cálculo = $\mathrm{VN} /(\mathrm{VN}+\mathrm{FN})$

- Sensibilidade: proporção de pacientes com ISC identificados pelo revisor, que foram notificados como ISC pelo hospital (VP).

Cálculo = VP/(VP+FN)

- Especificidade: proporção de pacientes identificados pelo revisor como não ISC, que foram notificados como não ISC pelo hospital (VN).

Cálculo $=\mathrm{VN} /(\mathrm{VN}+\mathrm{FP})$

(Benseñor \& Lotufo, 2011) 


\subsection{Classificação de acordo com o plano tecidual acometido}

Concordâncias e discordâncias sobre a classificação de acordo com o plano tecidual acometido podem ser descritas utilizando-se a Tabela 3.

TABELA 3. Concordância e discordância quanto à classificação em relação ao plano tecidual acometido realizada pelos hospitais e aquela identificada pelos validadores. São Paulo, ANO.

\begin{tabular}{ccccc}
\hline & & \multicolumn{2}{c}{ Casos identificados pela validação } \\
\hline $\begin{array}{c}\text { Procedimento } \\
\text { cirúrgico }\end{array}$ & $\begin{array}{c}\text { Casos notificado pelo } \\
\text { hospital }\end{array}$ & Superficial & Profunda & $\begin{array}{c}\text { Órgão/ } \\
\text { cavidade }\end{array}$ \\
\hline \hline & $\begin{array}{c}\text { Superficial } \\
\text { Profunda } \\
\text { Orgão/ }\end{array}$ & & \\
& $\begin{array}{c}\text { Superficial } \\
\text { Profunda } \\
\text { Órgão/ }\end{array}$ & & \\
\hline
\end{tabular}

A justificativa para a divergência classificação da ISC de acordo com plano tecidual observada entre pela equipe que realiza a vigilância no hospital e a equipe de validação pode ser apresentada utilizando-se para tanto o Quadro 3.

QUADRO 3. Justificativa do critério diagnóstico estabelecido pelo validador para a classificação, de acordo com plano tecidual acometido para artroplastia total de quadril.. São Paulo, ANO.

\begin{tabular}{|l|l|l|l|l|}
\hline $\begin{array}{c}\text { ID da } \\
\text { cirurgia } \\
\text { revisada }\end{array}$ & $\begin{array}{c}\text { Data da } \\
\text { cirurgia }\end{array}$ & $\begin{array}{c}\text { Classificação- } \\
\text { equipe } \\
\text { hospital }\end{array}$ & $\begin{array}{c}\text { Classificação } \\
\text { - validador }\end{array}$ & $\begin{array}{l}\text { Justificativa do critério diagnóstico para } \\
\text { o diagnóstico estabelecido pelo validador }\end{array}$ \\
\hline & & & & \\
\hline & & & & \\
\hline & & & & \\
\hline & & & & \\
\hline
\end{tabular}

\section{RELATÓRIO PARA OS HOSPITAIS VISITADOS}

Cada hospital deve receber um relatório individual com os resultados obtidos pelo estudo. Além do apontamento das divergênicas identificadas, este relatório deve conter as recomendações pertinentes aos resultados obtidos durante a validação, que podem variar nas diferentes instituições. Esta recomendações poderão ser referentes a necessidade de adequação para a inclusão dos procedimentos cirúrgicos para notificação ou realização de treinamentos e atualização para aplicação dos critérios diagnósticos de ISC, quando pertinente. 


\section{REFERÊNCIAS}

Bensenor, I. M.; Lotufo, P.A. Epidemiologia, abordagem prática. São Paulo: Sarvier. 2011. 400p. Benseñor, I.M, Lotufo, P.A

Bolfarine, H. Bussab, W.O. (2005). Elementos de Amostragem. 1.ed., São Paulo: Edgard Blucer, 290p

Haley VB, van Antwerpen C, Tserenpuntsag B, Gase KA, Hazamy P, Doughty D, et al. Use of administrative data in efficient auditing of hospital- acquired surgical site infections, New York State 2009-2010. Infect Control Hosp Epidemiol 2012;33(6):565-571.

Geubbels ELPE, Nagelkerke NJD, Mintjes-De Groot AJ, Vandenbroucke-Grauls CMJE, Grobbee DE, De Boer AS. Reduced risk of surgical site infections through surveillance in a network. International Journal for Quality in Health Care. 2006;18(2):127-33

Gastmeier P, Sohr D, Schwab F, Behnke M, Zuschneid I, Brandt C, et al. Ten years of KISS: The most important requirements for success. J Hosp Infect. 2008;70(SUPPL. 1):11-6.

Manniën J, Van Der Zeeuw AE, Wille JC, Van Den Hof S. Validation of surgical site infection surveillance in The Netherlands. Infect Control Hosp Epidemiol 2007;28(1):36-41.

McBryde ES, Brett J, Russo PL, Worth LJ, Bull AL, Richards MJ. Validation of statewide surveillance system data on central line-associated bloodstream infection in intensive care units in Australia. Infect Control Hosp Epidemiol 2009;30(11):1045-1049.

Rioux C, Grandbastien B, Astagneau P. Impact of a six-year control programme on surgical site infections in france: Results of the INCISO surveillance. J Hosp Infect. 2007;66(3):217-23.

Passaretti CL, Barclay P, Pronovost P, Perl TM. Public reporting of health care-associated infections (HAIs): Approach to choosing HAI measures. Infection Control and Hospital Epidemiology. 2011;32(8):768-74.

McCoubrey J, Reilly J, Mullings A, Pollock KGJ, Johnston F. Validation of surgical site infection surveillance data in scotland. J Hosp Infect. 2005;61(3):194-200.

McKibben L, Horan TC, Tokars JI, Fowler G, Cardo DM, Pearson ML, et al. Guidance on public reporting of healthcare-associated infections: Recommendations of the healthcare infection control practices advisory committee. Infect Control Hosp Epidemiol 2005;26(6):580587.

Secretaria da Saúde do Estado de São Paulo. Coordenadoria de Controle de Doenças. Centro de Vigilância Epidemiológica "Prof. Alexandre Vranjac". Divisão de Infecção Hospitalar DIH/CVE. Manual de orientações e critérios diagnósticos. Hospital Geral. Sistema de vigilância epidemiológica das infecções hospitalares do Estado de São Paulo [Internet]. São Paulo, 2018. Disponível em: http://www.saude.sp.gov.br/resources/cve-centro-de-vigilanciaepidemiologica/areas-de-vigilancia/infeccaohospitalar/2018/ih18_manualcriteriosdiagnosticos_hospitalgeral2018.pdf

Wilson APR, Kiernan M. Recommendations for surveillance priorities for healthcareassociated infections and criteria for their conduct. J Antimicrob Chemother. 2012; 67(SUPPL.1): i23-8. 


\title{
MANUAL DE ORIENTAÇÕES E CRITÉRIOS DIAGNÓSTICOS
}

\author{
HOSPITAL GERAL
}

\section{SISTEMA DE VIGILÂNCIA \\ EPIDEMIOLÓGICA DAS \\ INFECÇÕES HOSPITALARES DO ESTADO DE SÃO PAULO}

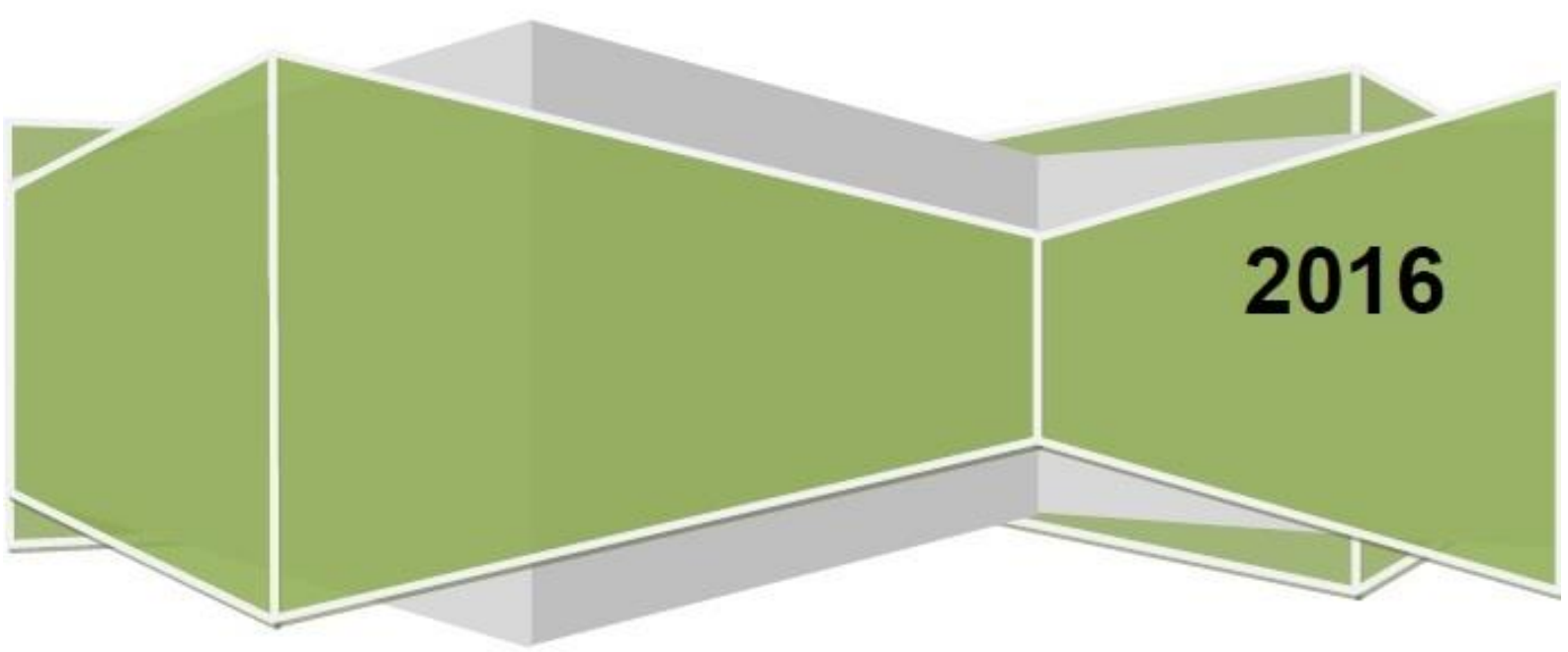

Fonte: Secretaria da Saúde do Estado de São Paulo. Coordenadoria de Controle de Doenças. Centro de Vigilância Epidemiológica "Prof. Alexandre Vranjac". Divisão de Infecção Hospitalar - DIH/CVE. Manual de orientações e critérios diagnósticos. Hospital Geral. Sistema de vigilância epidemiológica das infecções hospitalares do Estado de São Paulo. 6p. 


\section{ÍNDICE}

\begin{tabular}{|l|c|}
\hline ASSUNTO & Pág. \\
\hline 1. Critérios Diagnósticos para Infecção Hospitalar em Hospital Geral & 04 \\
\hline 1.1. Conceitos Gerais & 04 \\
\hline 1.1.1. Neonatolologia & 04 \\
\hline 1.1.2. Infeç̧ão de Sítio Cirúrgico & 06 \\
\hline 1.1.3. Pneumonia & 06 \\
\hline 1.1.4. Infeç̧ão Primária da Corrente Sangüinea (IPCS) & 07 \\
\hline 1.1.5. Infeç̧ão do Trato Urinário & 07 \\
\hline 1.1.6. Consumo de produto alcoólico para higiene das mãos em UTI & 17 \\
\hline 2. Instruções para o preenchimento da planilha de notificação de infecção hospitalar & 18 \\
\hline 2.1. Orientações Gerais & 18 \\
\hline 2.2. Arquivo "Hospital Geral" & 20 \\
\hline $\begin{array}{l}\text { Anexo 1 - Modelo de planilha para coleta de dados em UTI Adulto, Unidade } \\
\text { Coronariana e UTI Pediátrica }\end{array}$ & 41 \\
\hline Anexo 2 - Modelo de planilha para coleta de dados em UTI Neonatal & 42 \\
\hline
\end{tabular}

Fonte: Secretaria da Saúde do Estado de São Paulo. Coordenadoria de Controle de Doenças. Centro de Vigilância Epidemiológica "Prof. Alexandre Vranjac". Divisão de Infecção Hospitalar - DIH/CVE. Manual de orientações e critérios diagnósticos. Hospital Geral. Sistema de vigilância epidemiológica das infecções hospitalares do Estado de São Paulo. pg. 02. 


\begin{tabular}{|l|c|}
\hline QUADROS & Pág. \\
\hline Quadro 1. Sitio de Infecção e Periodo de Incubação. IRAS neonatal & 05 \\
\hline Quadro 2. Critérios diagnósticos de Infeç̧ão de Sítio Cirúrgico (ISC) & 08 \\
\hline Quadro 3. Cirurgias com vigilância por até 90 dias & 09 \\
\hline Quadro 4. Pneumonia definida por Critérios Clinicos ou Laboratoriais & 10 \\
\hline Quadro 5. Pneumonia por bactérias ou fungos filamentosos & 10 \\
\hline $\begin{array}{l}\text { Quadro 6. Pneumonia por vírus, Legionella, Chlamydia, Mycoplasma ou outros agentes } \\
\text { etiológicos atípicos }\end{array}$ & 11 \\
\hline Quadro 7. Pneumonia em paciente imunocomprometido & 12 \\
\hline $\begin{array}{l}\text { Quadro 8. Pneumonia em crianças: > 4 semanas até 1 ano de idade e entre 1 ano e 12 } \\
\text { anos }\end{array}$ & 13 \\
\hline Quadro 9. Pneumonia no período neonatal (recém nascido até 28 dias) & 13 \\
\hline $\begin{array}{l}\text { Quadro 10A: Critérios diagnósticos de Infecção Primária de Corrente Sangüinea (IPCS) } \\
\text { com confirmação laboratorial }\end{array}$ & 14 \\
\hline $\begin{array}{l}\text { Quadro 10B: Critérios diagnósticos de Infecção Primária de Corrente Sangüinea (IPCS) } \\
\text { clinica }\end{array}$ & 14 \\
\hline $\begin{array}{l}\text { Quadro 11A. Critérios diagnósticos de Infecção Primária de Corrente Sangüínea (IPCS) - } \\
\text { NEONATOS (recém-nascidos até 28 dias) com confirmacão laboratorial }\end{array}$ & 15 \\
\hline $\begin{array}{l}\text { Quadro 11B - Critérios diagnósticos de Infecção Primária de Corrente Sangüínea (IPCS) - } \\
\text { NEONATOS (recém-nascidos até 28 dias) clinica }\end{array}$ & 15 \\
\hline Quadro 12. Critérios diagnósticos de Infecção do Trato Urinário (ITU) - Sintomática & 16 \\
\hline Quadro 13. Especialidade cirúrgica e código de especialidade & 23 \\
\hline Quadro 14. Exemplos de cirurgias limpas por especialidade cirúrgica & 23 \\
\hline Quadro 15. Cirurgias selecionadas e critérios para notificação & 25 \\
\hline $\begin{array}{l}\text { Quadro 16. Exemplo de cálculo de pacientes-dia/procedimento-dia - UTI Adulto/ } \\
\text { UCO/ Pediátrica }\end{array}$ & 29 \\
\hline Quadro 17. Exemplo de cálculo de pacientes-dia/procedimento-dia- UTI Neonatal & 31 \\
\hline
\end{tabular}

Fonte: Secretaria da Saúde do Estado de São Paulo. Coordenadoria de Controle de Doenças. Centro de Vigilância Epidemiológica "Prof. Alexandre Vranjac". Divisão de Infecção Hospitalar - DIH/CVE. Manual de orientações e critérios diagnósticos. Hospital Geral. Sistema de vigilância epidemiológica das infecções hospitalares do Estado de São Paulo. pg. 03. 


\section{CRITÉRIOS DE SAIDA DA VIGILÂNCIA EPIDEMIOLÓGICA}

Esses pacientes deverão ser monitorados e computados no denominador enquanto permanecerem na unidade de terapia intensiva neonatal ou unidade de cuidados intermediários e deixarão de fazer parte desde tipo de vigilância quando os RN saírem de alta da unidade neonatal ou até 90 dias de vida.

Os critérios diagnósticos para infecções em Neonatologia em outras topografias e informaç̃̃es adicionais sobre a utilização destes critérios encontram-se no documento disponivel na Série Segurança do Paciente sobre Critérios Diagnósticos de Infecção relacionada à Assistência à Saúde Neonatologia (ANVISA 2013)

\subsubsection{Infecção de Sítio Cirúrgico}

São infeç̧ões relacionadas aos procedimentos cirúrgicos e podem ser classificadas em:

- Infecção incisional: superficial e/ou profunda

- Infecção de órgão ou espaço

Os critérios diagnósticos para esta topografia encontram-se no Quadro 2,e - período de vigilância determinado para cada tipo de cirurgia e infecção estão disponíveis no Quadro 3 , nas páginas 8 e 9 . Informações adicionais sobre a utilização destes critérios encontram-se no documento disponível na publicação de Critérios Diagnósticos para Infecção de Sítio Cirúrgico (CDC 2015)

\subsubsection{Pneumonia}

Os critérios de definição para pneumonia hospitalar envolvem várias combinações de evidências clínicas, radiográficas e laboratoriais de infecção.

Para efeito de notificação ao sistema estadual de infecção hospitalar serão consideradas somente as pneumonias associadas à ventilação mecânica (PAV) que é definida como infecção diagnosticada após $48 \mathrm{~h}$ de ventilaçäo mecânica até a sua suspensăo.

Ao avaliar o paciente para presença de pneumonia é importante distinguir entre alterações no estado clínico devido a outras condições como infarto do miocárdio, embolia pulmonar, síndrome do desconforto respiratório, atelectasia, malignidade, doença pulmonar obstrutiva crônica, doença de membrana hialina, displasia broncopulmonar, etc. Também é importante avaliar o paciente em uso de ventilação mecânica, para distinguir entre colonização traqueal e infecções do trato respiratório superior. Além disso, deve-se considerar a dificuldade na determinação de pneumonia nosocomial em pacientes idosos, lactentes e imunossuprimidos, uma vez que estas condições podem mascarar os sinais e sintomas associados à pneumonia. Critérios alternativos específicos para estes pacientes foram incluídos para definição de pneumonia nosocomial.

O diagnóstico médico isolado não constitui critério aceitável para definição de pneumonia nosocomial.

Os critérios diagnósticos para esta topografia encontram-se nos Quadros 4 a 9, nas páginas 10 a 13. Informações adicionais sobre a utilização destes critérios encontram-se no documento disponivel no Manual de Critérios Diagnósticos de Infecção relacionada à Assistência à Saúde (ANVISA 2013). 
QUADRO 2 - Critérios diagnósticos de Infecçāo de Sítio Cirúrgico (ISC)

\begin{tabular}{|c|c|c|}
\hline $\begin{array}{l}\text { Incisional Superficial } \\
\text { ISC - IS }\end{array}$ & $\begin{array}{l}\text { Ocorre nos primeiros } 30 \text { dias } \\
\text { após a cirurgia e envolve } \\
\text { apenas pele e subcutâneo. }\end{array}$ & $\begin{array}{l}\text { Com pelo menos um dos seguintes: } \\
\text { a) Drenagem purulenta da incisão superficial; } \\
\text { b) Cultura positiva de secreção ou tecido da } \\
\text { incisão superficial, obtido assepticamente } \\
\text { (não são considerados resultados de culturas } \\
\text { colhidas por swab); } \\
\text { c) A incisão superficial é deliberadamente aberta } \\
\text { pelo cirurgião na vigência de pelo menos um } \\
\text { dos seguintes sinais ou sintomas: dor, } \\
\text { aumento da sensibilidade, edema local, } \\
\text { hiperemia ou calor, EXCETO se a cultura for } \\
\text { negativa; } \\
\text { d) Diagnóstico de infecçăo superficial pelo } \\
\text { médico assistente. }\end{array}$ \\
\hline $\begin{array}{l}\text { Incisional Profunda } \\
\text { ISC - IP }\end{array}$ & $\begin{array}{l}\text { Ocorre nos primeiros } 30 \text { ou } \\
90 \text { dias (VER QUADRO 3) } \\
\text { após a cirurgia, e envolve } \\
\text { tecidos moles profundos à } \\
\text { incisấo (ex: fáscia e/ou } \\
\text { músculos). }\end{array}$ & $\begin{array}{l}\text { Com pelo menos um dos seguintes: } \\
\text { a) Drenagem purulenta da incisão profunda, mas } \\
\text { não de órgão/cavidade; } \\
\text { b) Deiscência parcial ou total da parede } \\
\text { abdominal ou abertura da ferida pelo } \\
\text { cirurgião, quando o paciente apresentar pelo } \\
\text { menos um dos seguintes sinais ou sintomas: } \\
\text { febre }>38^{*} \mathrm{C} \text {, dor ou aumento da } \\
\text { sensibilidade local, exceto se a cultura for } \\
\text { negativa; } \\
\text { c) Presença de abscesso ou outra evidência que } \\
\text { a infecção envolva os planos profundos da } \\
\text { ferida, identificada em reoperaçāo, exame } \\
\text { clinico, histocitopatologico ou exame de } \\
\text { imagem; } \\
\text { d) Diagnóstico de infecção incisional profunda } \\
\text { pelo médico assistente. }\end{array}$ \\
\hline $\begin{array}{l}\text { Orgão / Cavidade } \\
\text { ISC - OC }\end{array}$ & $\begin{array}{l}\text { Ocorre nos primeiros } 30 \text { ou } \\
90 \text { dias (VER QUADRO 3) } \\
\text { após a cirurgia, e envolve } \\
\text { qualquer orgão ou cavidade } \\
\text { que tenha sido aberta ou } \\
\text { manipulada durante a } \\
\text { cirurgia. }\end{array}$ & $\begin{array}{l}\text { Com pelo menos um dos seguintes: } \\
\text { a) Cultura positiva de secreção ou tecido do } \\
\text { orgão/cavidade obtido assepticamente; } \\
\text { b) Presença de abscesso ou outra evidência que } \\
\text { a infecção envolva os planos profundos da } \\
\text { ferida, identificada em reoperaçāo, exame } \\
\text { clinico, histocitopatológico ou exame de } \\
\text { imagem; } \\
\text { c) Diagnóstico de infecçăo de órgão/cavidade } \\
\text { pelo médico assistente. }\end{array}$ \\
\hline
\end{tabular}

Fonte: Secretaria da Saúde do Estado de São Paulo. Coordenadoria de Controle de Doenças. Centro de Vigilância Epidemiológica "Prof. Alexandre Vranjac". Divisão de Infecção Hospitalar - DIH/CVE. Manual de orientações e critérios diagnósticos. Hospital Geral. Sistema de vigilância epidemiológica das infecções hospitalares do Estado de São Paulo. pg. 08. 
QUADRO 3 - Cirurgias com vigilância por até 90 dias (com diagnóstico de ISC Incisional Profunda - IP e Órgão/Cavidade-OC)

- Cirurgias de mama

- Cirurgias cardiacas

- Revascularização do miocárdio

- Craniotomia

- Cirurgias por videoscopia (ex: herniorrafia, colecistectomia, apendicectomia. artroscopia) (*)

- Artrodese de coluna

- Osteossíntese

- Prótese de joelho

- Prótese de quadril

- Implante de marcapasso definitivo

- Cirurgia de bypass vascular periférica

- Derivação ventrículo-peritoneal (*) RDC ANVISA n08/2009

Fonte: Secretaria da Saúde do Estado de São Paulo. Coordenadoria de Controle de Doenças. Centro de Vigilância Epidemiológica "Prof. Alexandre Vranjac". Divisão de Infecção Hospitalar - DIH/CVE. Manual de orientações e critérios diagnósticos. Hospital Geral. Sistema de vigilância epidemiológica das infecções hospitalares do Estado de São Paulo. pg. 09. 


\section{ANEXO 2 \\ CENTRO DE ESTATÍSTICA APLICADA - CEA - USP RELATÓRIO DE CONSULTA}

TÍTULO: Desenvolvimento de uma ferramenta que permita a validação periódica do sistema de vigilância das infecções de sítio cirúrgico no estado de São Paulo

PESQUISADOR: Débora Silva de Mello

ORIENTADOR: Profa. Dra. Maria Clara Padoveze

INSTITUIÇÃO: Escola de Enfermagem da Universidade de São Paulo

PARTICIPANTES DA ENTREVISTA: Débora Silva de Mello Maria Clara Padoveze

Gisela Tunes da Silva

Carlos Alberto de Bragança Pereira

Isadora Avidos

Tales Dan Taira Tamada

DATA: $02 / 08 / 2016$

FINALIDADE DA CONSULTA: Elaboração de plano amostral

RELATÓRIO ELABORAdO POR: Bruno Franco Reimann, Isadora Avidos e Tales Dan Taira Tamada 
Sumário

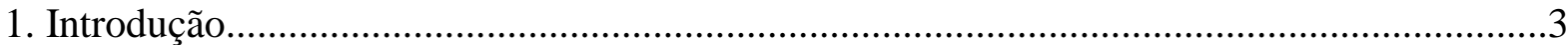

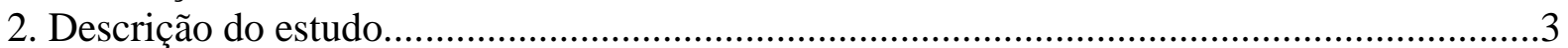

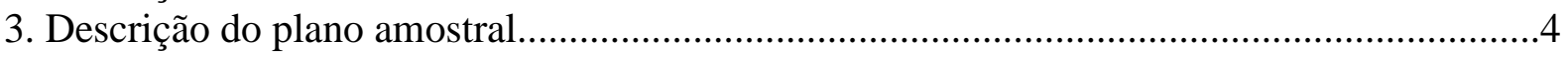

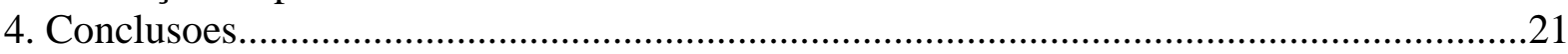

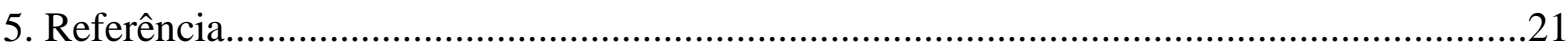

* As tabelas apresentadas neste relatório foram alteradas em relação ao texto original para preservar a confidencialidade das instituições. 


\section{Introdução}

No estado de São Paulo, a Divisão de Infecção Hospitalar do Centro de Vigilância Epidemiológica (CVE) possui um sistema que monitora as infecções de sitio cirúrgico (ISC) através de dados enviados mensalmente por hospitais que participam do sistema. Ainda não há uma metodologia que verifique a veracidade dos dados notificados, comprometendo a confiabilidade do sistema. O objetivo principal dos pesquisadores é elaborar uma metodologia que possa ser utilizada pelo serviço público de saúde para validar o sistema de vigilância epidemiológica relacionado à ISC.

Com o intuito de estabelecer o sistema de vigilância, propõe-se realizar um estudo observacional em que não haverá inferência de pesquisadores, baseado na análise de prontuários, amostrados em hospitais. Esse relatório de consulta é uma revisão do relatório realizado por Bruno Reimann no dia 22 de Setembro de 2015 (REINMANN, 2015), que tinha como objetivo principal apresentar um planejamento amostral necessário para auditar os dados dos Grupos de Vigilância Epidemiológica (GVE) fornecidos pelos hospitais. Nesta revisão, considera-se uma pequena modificação do plano amostral inicialmente proposto.

\section{Descrição do estudo}

No estado de São Paulo há 28 regiões administrativas de vigilância epidemiológica, que são chamadas de Grupos de Vigilância Epidemiológica (GVE). Cada GVE fiscaliza um determinado número de hospitais, que varia de acordo com cada grupo. Cada hospital realiza um determinado conjunto de procedimentos cirurgicos e deve informar mensalmente ao seu grupo de vigilância o correspondente número de cirurgias e infecções pós-operatórias.

Este relatório apresenta um método alternativo ao planejamento amostral elaborado pelo Bruno Reinmann (REINMANN, 2015). No trabalho anterior, é feito um planejamento em dois estágios, sendo amostragem aleatória simples em cada um dos estágios. Neste relatório, o plano amostral é modificado para que a amostra contemple hospitais de pequeno, médio e grande porte em todos os anos. 


\section{Descrição do plano amostral}

O CVE disponibilizou as seguintes informações provenientes de cada hospital: nome do procedimento, número de procedimentos realizados (total de prontuários), número de infecções observadas após o procedimento, total de leitos e a taxa de ISC observada. Além disso, a pesquisadora disponibilizou as taxas de infecção máximas para cada procedimento cirúrgico, obtidas na literatura da área.

Segundo a pesquisadora, é importante que em cada ano, para um determinado procedimento selecionado, a amostra de hospitais contemple hospitais de pequeno, médio e grande porte. Assim, os hospitais são particionados em três estratos:

- Hospitais pequenos: engloba aqueles com até 49 leitos (estrato 1);

- Hospitais médios: hospitais com 50 até 199 leitos (estrato 2);

- Hospitais grandes: hospitais com 200 ou mais leitos (estrato 3).

Para cada um dos estratos, deve-se escolher uma amostra de hospitais, e, em seguida, selecionar os prontuários que irão compor a amostra dentro de cada hospital. Dessa forma, a amostra de hospitais que deverão ser visitados englobará hospitais de cada um dos estratos. Como o objetivo principal é a estimação da taxa ISC por hospital (e não o total geral ou proporção geral de infecções), optou-se por fazer o plano amostral considerando-se que cada estrato seja a população de interesse. Assim, o problema recai no caso de amostragem por conglomerado em dois estágios (em que cada hospital representa um conglomerado), sendo que escolhemos uma amostra de hospitais para cada estrato (ou categoria de porte) e em seguida selecionamos uma amostra (aleatória simples) de prontuários dentro de cada hospital. É importante reforçar que, apesar da população estar estratificada pelo tamanho do hospital, a metodologia do plano amostral considera que cada estrato compõe uma população de interesse. Isso pode ser feito devido ao objetivo do estudo, que não é a estimação da taxa ISC geral, mas a estimação da taxa ISC por hospital.

Para um único GVE, considerando um determinado procedimento, o planejamento amostral apresentado considera os seguintes casos:

1. O número total de hospitais, que realizam o procedimento em questão, permite que todos os estabelecimentos sejam visitados, sendo feita somente a amostragem dos prontuários em cada hospital. Neste caso, teremos um esquema de amostragem em um único estágio; 
2. O número total de hospitais que realizam o procedimento sob avaliação na região é tal que não é possível visitar todos os estabelecimentos. Neste caso, será realizada uma amostragem em dois estágios, em que inicialmente selecionam-se hospitais dentro de cada estrato (primeiro estágio) e, em cada hospital, selecionam-se os prontuários de cirurgias do procedimento fixado (segundo estágio).

Segundo a pesquisadora, pode ser que, em um determinado ano e GVE, seja de interesse avaliar mais de um procedimento. Neste caso, será proposta uma forma de otimizar a seleção dos hospitais para todos os procedimentos conjuntamente.

O mesmo planejamento poderá ser usado em outras ocasiões caso haja necessidade. Para que isto seja plausível devem-se adaptar as variáveis de acordo com o número de leitos, de hospitais por região administrativa e de taxas de infecção máximas dos procedimentos de acordo com a literatura.

\subsection{Amostragem em um estágio}

Assume-se que o número de instituições que a equipe do GVE consegue verificar seja igual ao número de hospitais que aplicam um determinado procedimento na região observada. O número de instituições que podem ser verificados pela equipe do GVE é determinado pela verba destinada e pessoal disponível para a coleta de dados.

Seja $C_{j}$ o número (conhecido) de cirurgias do procedimento escolhido (ou seja, número de prontuários do procedimento) no período considerado, que são realizadas no hospital j, e seja o tamanho da amostra de prontuários no hospital $\mathrm{j}$ denominado por $\mathrm{a}_{\mathrm{j}}$. $\mathrm{O}$ número $\mathrm{a}_{\mathrm{j}}$ de prontuários a serem amostrados é dado pela relação:

$$
a_{j}=\frac{m_{j}}{1+\frac{m_{j}-1}{C_{j}}},
$$

em que $m_{j}=\frac{z_{\alpha}^{2} \widehat{p_{j}}\left(1-\widehat{p_{j}}\right)}{E^{2}}$. Nesta expressão, precisamos fixar cada um dos termos envolvidos. A quantidade $\mathrm{z}_{\alpha}$ (usada no processo de decisão) é determinada a partir do valor fixado para o coeficiente de confiança. Usualmente, utiliza-se um coeficiente igual a $95 \%$ (que produz $\left.\mathrm{z}_{\alpha}^{2}=(1,96)^{2} \cong 3,842\right)$ mas outros valores podem ser adotados. O valor de $\widehat{\mathrm{p}_{\mathrm{j}}}$ é a taxa de ISC informado pelo hospital para o CVE (considerando que o hospital está informando o valor verdadeiro). Caso a informação fornecida pelo hospital não seja confiável, é necessária uma abordagem conservadora, tomando o valor de $\widehat{\mathrm{p}_{\mathrm{j}}}$ igual a valores obtidos na literatura 
(informado pelas pesquisadoras); nestes casos a taxa usada será representada por $\mathrm{p}_{\mathrm{j}}$ ao invés de $\widehat{\mathrm{p}_{\mathrm{J}}}$. Finalmente, o E é o quanto se aceita de erro entre a proporção estimada e o valor verdadeiro (que seria observado caso todos os prontuários fossem analisados), que deve ser um valor entre 0 e 1. Caso $a_{j}$ não seja um número inteiro, ele será arredondado para o valor inteiro mais próximo acima dele.

Os prontuários devem ser selecionados de forma aleatória, sendo que cada prontuário de um hospital tem a mesma probabilidade de ser incluído na amostra.

\subsubsection{Exemplo para um estágio}

Selecionando o procedimento "Parto cesariano", observa-se que esse procedimento é realizado em 18 hospitais (Hospitais 1, 2, 4, 5, 7, 8, 9, 11, 13, 17, 18, 19, 20, 27, 30, 31, 38 e 44). Dessas instituições, 14 hospitais pertencem ao estrato 2 (médio porte) e 4 ao estrato 3 (grande porte). Vamos assumir que seja possível visitar todos os 18 hospitais.

Faremos o cálculo para dois coeficientes de confiança: $90 \%$ e 95\%. Obtemos, dessa forma, $\mathrm{z}_{\alpha}^{2}=(1,64)^{2} \cong 2,690$ para $90 \%$ e $\mathrm{z}_{\alpha}^{2}=(1,96)^{2} \cong 3,842$ para $95 \%$. Fixando-se o erro em 0,05 , tem-se que $E=0,05$. Supõe-se que as taxas de ISC informadas pelos hospitais sejam verdadeiras (caso a taxa seja menor do que 0,001, ela será fixada em 0,001).

No caso em que o coeficiente de confiança seja de 90\%, tem-se que o tamanho de amostra de prontuários para cada hospital deve ser conforme o apresentado na Tabela 1. 
Tabela 11: Número de infecções, prontuários e tamanho de amostra requerido considerando as taxas ISC dos hospitais para $90 \%$ de confiança.

\begin{tabular}{ccccccc}
\hline Hospital & \multicolumn{2}{c}{ Total de } & $\begin{array}{c}\text { Taxa ISC } \\
\text { Informada }\left(\widehat{p_{j}}\right)\end{array}$ & $m_{j}$ & $a_{j}$ & $\begin{array}{c}\text { Tamanho de } \\
\text { amostra }\left(a_{j}\right)\end{array}$ \\
\cline { 2 - 5 } A & Infecções & prontuários $\left(\mathrm{C}_{\mathrm{j}}\right)$ & 0,008 & 8,539 & 8,455 & 9 \\
$\mathrm{~B}$ & 5 & 757 & 0,009 & 9,597 & 9,45 & 10 \\
$\mathrm{C}$ & 5 & 553 & 0,005 & 5,353 & 5,298 & 6 \\
$\mathrm{D}$ & 64 & 417 & 0,083 & 81,895 & 74,128 & 75 \\
$\mathrm{E}$ & 0 & 772 & 0,001 & 1,075 & 1,075 & 2 \\
$\mathrm{~F}$ & 0 & 1662 & 0,001 & 1,075 & 1,074 & 2 \\
$\mathrm{G}$ & 1 & 916 & 0,001 & 1,075 & 1,075 & 2 \\
$\mathrm{H}$ & 3 & 439 & 0,007 & 7,479 & 7,37 & 8 \\
$\mathrm{I}$ & 0 & 285 & 0,001 & 1,075 & 1,075 & 2 \\
$\mathrm{~J}$ & 44 & 1628 & 0,027 & 28,268 & 27,802 & 28 \\
$\mathrm{~K}$ & 0 & 423 & 0,001 & 1,075 & 1,075 & 2 \\
$\mathrm{~L}$ & 0 & 1463 & 0,001 & 1,075 & 1,075 & 2 \\
$\mathrm{M}$ & 0 & 3898 & 0,001 & 1,075 & 1,075 & 2 \\
$\mathrm{~N}$ & 2 & 1910 & 0,001 & 1,075 & 1,075 & 2 \\
$\mathrm{O}$ & 12 & 1527 & 0,008 & 8,539 & 8,497 & 9 \\
$\mathrm{P}$ & 17 & 1756 & 0,01 & 10,652 & 10,594 & 11 \\
$\mathrm{Q}$ & 1 & 1130 & 0,001 & 1,075 & 1,075 & 2 \\
$\mathrm{R}$ & 0 & 1 & 0,001 & 1,075 & 1 & 1 \\
\hline
\end{tabular}

Caso o coeficiente de confiança escolhido seja de 95\%, o tamanho de amostra de prontuários para cada hospital deve ser conforme o apresentado na Tabela 2. 
Tabela 12: Número de infecções, prontuários e tamanho de amostra requerido considerando as taxas ISC dos hospitais para $95 \%$ de confiança.

\begin{tabular}{ccccccc}
\hline \multirow{2}{*}{ Hospital } & \multicolumn{2}{c}{ Total de } & $\begin{array}{c}\text { Taxa ISC } \\
\text { Informada }\left(\widehat{p}_{j}\right)\end{array}$ & $m_{j}$ & $a_{j}$ & $\begin{array}{c}\text { Tamanho de } \\
\text { amostra }\left(a_{j}\right)\end{array}$ \\
\cline { 2 - 6 } Infecções & prontuários $\left(C_{j}\right)$ & 0,008 & 12,196 & 12,018 & 13 \\
$\mathrm{~A}$ & 6 & 757 & 0,009 & 13,707 & 13,399 & 14 \\
$\mathrm{~B}$ & 5 & 553 & 0,005 & 7,646 & 7,526 & 8 \\
$\mathrm{C}$ & 2 & 417 & 0,083 & 116,967 & 101,692 & 102 \\
$\mathrm{D}$ & 64 & 772 & 0,001 & 1,535 & 1,535 & 2 \\
$\mathrm{E}$ & 0 & 1662 & 0,001 & 1,535 & 1,531 & 2 \\
$\mathrm{~F}$ & 0 & 175 & 0,001 & 1,535 & 1,534 & 2 \\
$\mathrm{G}$ & 1 & 916 & 0,007 & 10,682 & 10,452 & 11 \\
$\mathrm{H}$ & 3 & 439 & 0,001 & 1,535 & 1,532 & 2 \\
$\mathrm{I}$ & 0 & 285 & 0,027 & 40,373 & 39,42 & 40 \\
$\mathrm{~J}$ & 44 & 1628 & 0,001 & 1,535 & 1,533 & 2 \\
$\mathrm{~K}$ & 0 & 423 & 0,001 & 1,535 & 1,535 & 2 \\
$\mathrm{~L}$ & 0 & 1463 & 0,001 & 1,535 & 1,535 & 2 \\
$\mathrm{M}$ & 0 & 3898 & 0,001 & 1,535 & 1,535 & 2 \\
$\mathrm{~N}$ & 2 & 1910 & 0,008 & 12,196 & 12,107 & 13 \\
$\mathrm{O}$ & 12 & 1527 & 0,01 & 15,214 & 15,092 & 16 \\
$\mathrm{P}$ & 17 & 1756 & 0,001 & 1,535 & 1,535 & 2 \\
$\mathrm{Q}$ & 1 & 1130 & 0,001 & 1,535 & 1 & 1 \\
$\mathrm{R}$ & 0 & 1 & & &
\end{tabular}

Caso se faça uma abordagem conservadora, deve-se fixar a taxa ISC fornecida pela literatura para o procedimento Parto cesariano, ou seja, o valor de $\widehat{\mathrm{p}_{\mathrm{j}}}$ deve ser de 23,5\% (ou seja, 0,235). Com este valor fixado, tem-se que, considerando coeficiente de confiança de $90 \%$, $\mathrm{m}_{\mathrm{j}}=\frac{2,690 * 0,235(1-0,235)}{0,1^{2}}=193,438$ para todos os hospitais. Neste caso, o tamanho da amostra varia somente de acordo com o número de prontuários feitos por cada instituição, sendo conforme o exibido na Tabela 3. 
Tabela 13: Total de prontuários e tamanho de amostra requerido considerando a taxa ISC da literatura para $90 \%$ de confiança.

\begin{tabular}{cccccc}
\hline Hospital & $\begin{array}{c}\text { Total de } \\
\text { prontuários }\left(C_{j}\right)\end{array}$ & $\begin{array}{c}\text { Taxa ISC } \\
\text { pela } \\
\text { literatura } \\
\left(p_{j}\right)\end{array}$ & $m_{j}$ & $a_{j}$ & $\begin{array}{c}\text { Tamanho de } \\
\text { amostra }\left(a_{j}\right)\end{array}$ \\
\hline $\mathrm{A}$ & 757 & 0,235 & 193,438 & 154,231 & 155 \\
$\mathrm{~B}$ & 553 & 0,235 & 193,438 & 143,501 & 144 \\
$\mathrm{C}$ & 417 & 0,235 & 193,438 & 132,357 & 133 \\
5 & 772 & 0,235 & 193,438 & 154,841 & 155 \\
$\mathrm{E}$ & 1662 & 0,235 & 193,438 & 173,365 & 174 \\
$\mathrm{~F}$ & 175 & 0,235 & 193,438 & 92,129 & 93 \\
$\mathrm{G}$ & 916 & 0,235 & 193,438 & 159,855 & 160 \\
$\mathrm{H}$ & 439 & 0,235 & 193,438 & 134,485 & 135 \\
$\mathrm{I}$ & 285 & 0,235 & 193,438 & 115,47 & 116 \\
$\mathrm{~J}$ & 1628 & 0,235 & 193,438 & 172,99 & 173 \\
$\mathrm{~K}$ & 423 & 0,235 & 193,438 & 132,953 & 133 \\
$\mathrm{~L}$ & 1463 & 0,235 & 193,438 & 170,952 & 171 \\
$\mathrm{M}$ & 3898 & 0,235 & 193,438 & 184,337 & 185 \\
$\mathrm{~N}$ & 1910 & 0,235 & 193,438 & 175,732 & 176 \\
$\mathrm{O}$ & 1527 & 0,235 & 193,438 & 171,789 & 172 \\
$\mathrm{P}$ & 1756 & 0,235 & 193,438 & 174,333 & 175 \\
$\mathrm{Q}$ & 1130 & 0,235 & 193,438 & 165,289 & 166 \\
$\mathrm{R}$ & 1 & 0,235 & 193,438 & 1 & 1 \\
\hline
\end{tabular}

Considerando um coeficiente de confiança de 95\%, tem-se que $\mathrm{m}_{\mathrm{j}}=\frac{3,842 * 0,235(1-0,235)}{0,1^{2}}=276,278$, sendo o tamanho de amostra de prontuários dentro de cada um dos hospitais devem ser conforme o apresentado na Tabela 4. 
Tabela 14: Total de prontuários e tamanho de amostra requerido considerando a taxa ISC da literatura para $95 \%$ de confiança.

\begin{tabular}{cccccc}
\hline Hospital & $\begin{array}{c}\text { Total de } \\
\text { prontuários }\left(C_{j}\right)\end{array}$ & $\begin{array}{c}\text { Taxa ISC } \\
\text { pela } \\
\text { literatura } \\
\left(p_{j}\right)\end{array}$ & $m_{j}$ & $a_{j}$ & $\begin{array}{c}\text { Tamanho de } \\
\text { amostra }\left(a_{j}\right)\end{array}$ \\
\hline A & 757 & 0,235 & 276,278 & 202,603 & 203 \\
B & 553 & 0,235 & 276,278 & 184,457 & 185 \\
C & 417 & 0,235 & 276,278 & 166,419 & 167 \\
D & 772 & 0,235 & 276,278 & 203,658 & 204 \\
E & 1662 & 0,235 & 276,278 & 237,02 & 238 \\
F & 175 & 0,235 & 276,278 & 107,375 & 108 \\
G & 916 & 0,235 & 276,278 & 212,436 & 213 \\
H & 439 & 0,235 & 276,278 & 169,802 & 170 \\
I & 285 & 0,235 & 276,278 & 140,536 & 141 \\
J & 1628 & 0,235 & 276,278 & 236,319 & 237 \\
K & 423 & 0,235 & 276,278 & 167,363 & 168 \\
L & 1463 & 0,235 & 276,278 & 232,526 & 233 \\
M & 3898 & 0,235 & 276,278 & 258,054 & 259 \\
N & 1910 & 0,235 & 276,278 & 241,476 & 242 \\
O & 1527 & 0,235 & 276,278 & 234,08 & 235 \\
P & 1756 & 0,235 & 276,278 & 238,837 & 239 \\
Q & 1130 & 0,235 & 276,278 & 222,158 & 223 \\
R & 1 & 0,235 & 276,278 & 1 & 1 \\
\hline
\end{tabular}

\subsection{Amostragem em dois estágios}

Quando o número de hospitais sob a responsabilidade de um determinado GVE é tal que não é possível visitar todos os estabelecimentos que realizam o procedimento considerado, sugere-se o uso de uma amostragem em dois estágios.

A metodologia adotada é tecnicamente denominada "amostragem por conglomerados em dois estágios" (BOLFARINE e BUSSAB, 2005). Conforme já discutido, selecionam-se inicialmente os hospitais, que aplicam o procedimento escolhido, que serão visitados (esse é o primeiro estágio, sendo que cada hospital representa um conglomerado) e, em seguida, é feita uma amostra (aleatória simples) de prontuários do procedimento dentro de cada hospital. A seguir, descreveremos a metodologia a ser adotada.

Considere fixados o estrato $\mathrm{k}(\mathrm{k}=1,2,3)$ e o procedimento. Note que a metodologia descrita a seguir deverá ser realizada para cada um dos três estratos. O organograma da Figura 1 ilustra a estrutura da ideia proposta. A seleção de hospitais será feita dentro de cada estrato e, dentro de cada hospital, serão amostrados os prontuários. 


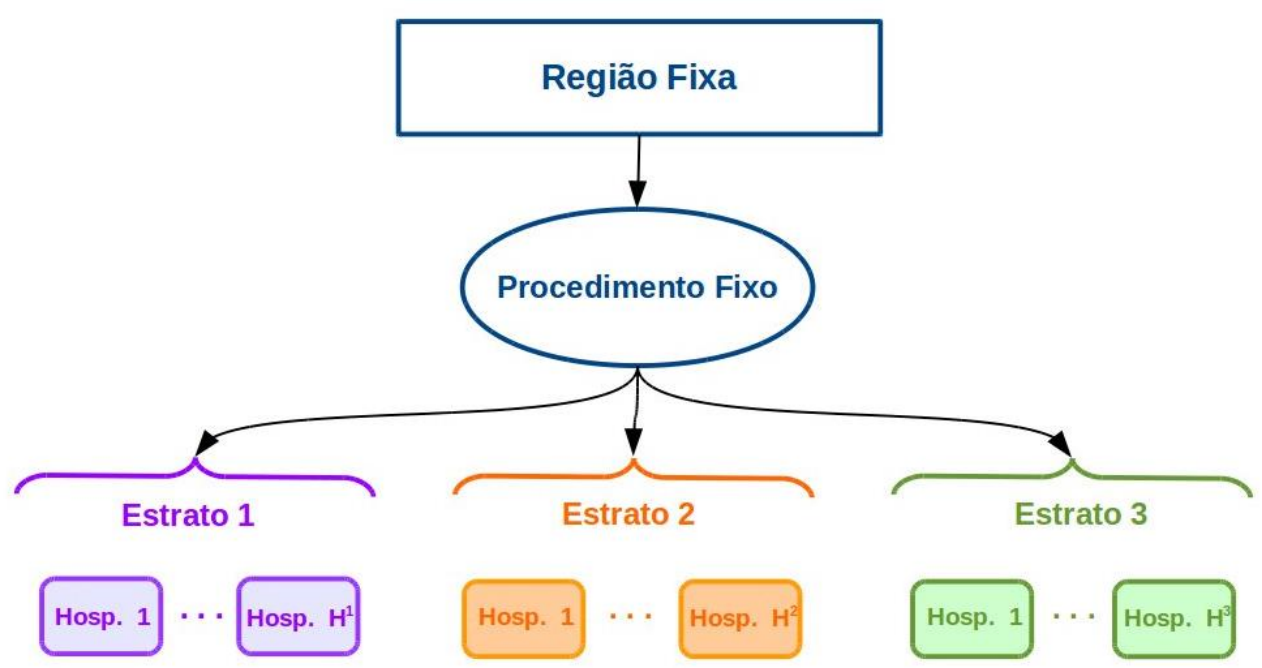

Figura 6: Organograma do planejamento amostral em dois estágios

\section{Denote por}

- $H_{j}^{k}$ : número de hospitais do estrato $\mathrm{k}$ que realizam o procedimento $\mathrm{j}$;

- $h_{j}^{k}$ : número de hospitais a serem amostrados no estrato $\mathrm{k}$ para o procedimento $\mathrm{j}$.

O número de hospitais do estrato $\mathrm{k}$ que fazem o procedimento $\mathrm{j}$ a serem amostrados é:

$$
\mathrm{h}_{j}^{k}=\frac{\mathrm{n}}{1+\frac{n-1}{H_{j}^{k}}},
$$

em que $n=z_{\alpha}^{2} /\left(4\left(E_{k}\right)^{2}\right)$, sendo $E_{k}$ o erro escolhido entre a proporção estimada de infecções dos hospitais do estrato k e o valor verdadeiro (não são recomendados erros abaixo de 0,15 , pois estes exigem tamanhos grandes de amostra de hospitais), e $z_{\alpha}$ é o valor obtido da tabela associado ao nível de confiança do intervalo na estimação da proporção (serão usados dois coeficientes de confiança nos exemplos: iguais a 90\% e 95\%, como feito na seção anterior, sendo $z_{\alpha}=1,64$ e $z_{\alpha}=1,96$ respectivamente).

Após o cálculo do número de hospitais a serem amostrados, deve-se fazer o sorteio dos hospitais para definir quais devem ser vistoriados e obter o número de prontuários a serem amostrados em cada instituição, conforme demonstrado na subseção 3.1.1.

\subsubsection{Primeiro exemplo para dois estágios e um procedimento}

Como exemplo, considere novamente o Parto cesariano. Neste caso, temos um total de 18 hospitais que realizam o procedimento. Desses hospitais, 14 são do estrato de hospitais médios e 4 são do estrato de hospitais grandes. É necessário, portanto, calcular quantos hospitais e 
prontuários devem ser selecionados nos estratos 2 (hospitais médios) e 3 (hospitais grandes). O número de prontuários a serem escolhidos será calculado de acordo com a taxa indicada pela literatura $(23,5 \%)$

O cálculo será iniciado com o estrato de hospitais médios (ou seja, k=2). Neste estrato, tem-se 14 hospitais $\left(H_{j}^{k}=14\right)$ e para calcular o número hospitais necessários, e prontuários de cada hospital, são considerados um coeficiente de confiança de $90 \%$ e $95 \%\left(z_{\alpha}=1,64\right.$ e $z_{\alpha}=1,96$ respectivamente), um erro de 0,15 para a proporção estimada de infecções dos hospitais $\left(E_{k}=0,15\right)$ e um erro de 0,05 para a proporção estimada dentro de cada hospital $(E=0,05)$. Neste caso, temos o seguinte resultado com $90 \%$ de confiança para o número de hospitais a serem visitados:

$$
\mathrm{h}_{j}^{k}=\frac{\mathrm{n}}{1+\frac{n-1}{H_{j}^{k}}}=\frac{30,062}{1+\frac{30,062-1}{14}}=9,774 \cong 10,
$$

arredondando para cima, tem-se que o número de hospitais $\left(\mathrm{h}_{j}^{k}\right)$ a serem amostrados neste estrato é de 10, dentre 14. Considerando uma amostragem aleatória simples, ou seja, sorteandose aleatoriamente 10 dentre os 14 hospitais, tem-se que os hospitais a serem amostrados são: 7 , $8,9,17,18,19,27,31,38$ e 44. Caso se deseje um número menor de hospitais, é possível aumentar o $E_{k}$.

Tabela 15: Tamanho de amostra de prontuários por hospital da amostra para o procedimento Parto cesariano no estrato 2 para $90 \%$ de confiança.

\begin{tabular}{ccccc}
\hline Hospital & Estrato & Taxa ISC & $\begin{array}{c}\text { Total de } \\
\text { prontuários }\left(C_{j}\right)\end{array}$ & $\begin{array}{c}\text { Tamanho de } \\
\text { amostra }\left(a_{j}\right)\end{array}$ \\
\hline E & 2 & 0,235 & 1662 & 174 \\
F & 2 & 0,235 & 175 & 93 \\
G & 2 & 0,235 & 916 & 160 \\
J & 2 & 0,235 & 1628 & 173 \\
K & 2 & 0,235 & 423 & 133 \\
L & 2 & 0,235 & 1463 & 171 \\
N & 2 & 0,235 & 1910 & 176 \\
P & 2 & 0,235 & 1756 & 175 \\
Q & 2 & 0,235 & 1130 & 166 \\
R & 2 & 0,235 & 1 & 1 \\
\hline
\end{tabular}


Considerando $95 \%$ de confiança, o número de hospitais a serem visitados no estrato 2 é definido por:

$$
\mathrm{h}_{j}^{k}=\frac{\mathrm{n}}{1+\frac{n-1}{H_{j}^{k}}}=\frac{42,683}{1+\frac{42,683-1}{14}}=10,731 \cong 11
$$

arredondando para cima, tem-se que o número de hospitais $\left(\mathrm{h}_{j}^{k}\right)$ a serem amostrados neste estrato é de 11, dentre os 14 . Considerando uma amostragem aleatória simples tem-se que os hospitais a serem amostrados são: 8, 9, 11, 13, 17, 18, 27, 30, 31, 38 e 44.

Tabela 16: Tamanho de amostra de prontuários por hospital da amostra para o procedimento Parto cesariano no estrato 2 para $95 \%$ de confiança.

\begin{tabular}{ccccc}
\hline Hospital & Estrato & Taxa ISC & $\begin{array}{c}\text { Total de } \\
\text { prontuários }\left(C_{j}\right)\end{array}$ & $\begin{array}{c}\text { Tamanho de } \\
\text { amostra }\left(a_{j}\right)\end{array}$ \\
\hline F & 2 & 0,235 & 175 & 108 \\
G & 2 & 0,235 & 916 & 213 \\
H & 2 & 0,235 & 439 & 170 \\
I & 2 & 0,235 & 285 & 141 \\
J & 2 & 0,235 & 1628 & 237 \\
K & 2 & 0,235 & 423 & 168 \\
N & 2 & 0,235 & 1910 & 242 \\
O & 2 & 0,235 & 1527 & 235 \\
P & 2 & 0,235 & 1756 & 239 \\
Q & 2 & 0,235 & 1130 & 223 \\
R & 2 & 0,235 & 1 & 1 \\
\hline
\end{tabular}

No caso dos hospitais grandes, temos um total de 4 instituições apenas $\left(H_{j}^{k}=4\right)$. Neste caso, repetiremos a mesma metodologia feita no caso anterior para um coeficiente de confiança de $90 \%$, sendo o número de hospitais a serem amostrados:

$$
\mathrm{h}_{j}^{k}=\frac{\mathrm{n}}{1+\frac{n-1}{H_{j}^{k}}}=\frac{30,062}{1+\frac{30,062-1}{4}}=3,637 \cong 4,
$$

ou seja, a amostra de hospitais é equivalente a toda população de hospitais que fazem Parto cesariano e que são considerados hospitais de grande porte. A Tabela 7 mostra quantos prontuários devem ser amostrados das 4 instituições, considerando um coeficiente de confiança de $90 \%$. 
Tabela 17: Tamanho de amostra de prontuários por hospital da amostra para o procedimento Parto cesariano no estrato 3 para $90 \%$ de confiança.

\begin{tabular}{ccccc}
\hline Hospital & Estrato & Taxa ISC & $\begin{array}{c}\text { Total de } \\
\text { prontuários }\left(C_{j}\right)\end{array}$ & $\begin{array}{c}\text { Tamanho de } \\
\text { amostra }\left(a_{j}\right)\end{array}$ \\
\hline A & 3 & 0,235 & 757 & 155 \\
B & 3 & 0,235 & 553 & 144 \\
C & 3 & 0,235 & 772 & 155 \\
M & 3 & 0,235 & 3898 & 185 \\
\hline
\end{tabular}

Considerando um coeficiente de confiança de 95\%, tem-se que o número de hospitais a serem amostrados é de:

$$
\mathrm{h}_{j}^{k}=\frac{\mathrm{n}}{1+\frac{n-1}{H_{j}^{k}}}=\frac{42,683}{1+\frac{42,683-1}{4}}=3,737 \cong 4,
$$

ou seja, a amostra de hospitais é equivalente a toda população de hospitais de grande porte que fazem Parto cesariano. O tamanho da amostra de prontuários, considerando coeficiente de confiança de 95\%, nestes hospitais está apresentado na Tabela 8.

Tabela 18: Tamanho de amostra de prontuários por hospital da amostra para o procedimento Parto cesariano no estrato 3 para $95 \%$ de confiança.

\begin{tabular}{ccccc}
\hline Hospital & Estrato & Taxa ISC & $\begin{array}{c}\text { Total de } \\
\text { prontuários }\left(C_{j}\right)\end{array}$ & $\begin{array}{c}\text { Tamanho de } \\
\text { amostra }\left(a_{j}\right)\end{array}$ \\
\hline A & 3 & 0,235 & 757 & 203 \\
B & 3 & 0,235 & 553 & 185 \\
D & 3 & 0,235 & 772 & 204 \\
M & 3 & 0,235 & 3898 & 259 \\
\hline
\end{tabular}

\subsubsection{Segundo exemplo para dois estágios e um procedimento}

Considerando o procedimento Artroplastia de joelho, tem-se que 16 instituições realizam essa cirurgia. Dos 16 hospitais, 1 é de pequeno porte, 11 são de médio porte e 4 são de grande porte. O número de prontuários a serem escolhidos neste caso será calculado de acordo com a taxa ISC indicada pela literatura $(7,4 \%)$, e o coeficiente de confiança é de $90 \%$. Considerando o estrato 1 (hospitais de pequeno porte, $\mathrm{k}=1$ ), a própria população deve ser selecionada, por ser de apenas 1 instituição, e o número de prontuários a serem amostrados está apresentado na Tabela 5. 
Tabela 5: Tamanho de amostra de prontuários por hospital da amostra para o procedimento Artroplastia de joelho no estrato 1 para $90 \%$ de confiança.

\begin{tabular}{ccccc}
\hline Hospital & Estrato & Taxa ISC & $\begin{array}{c}\text { Total de } \\
\text { prontuários }\left(C_{j}\right)\end{array}$ & $\begin{array}{c}\text { Tamanho de } \\
\text { amostra }\left(a_{j}\right)\end{array}$ \\
\hline $\mathrm{D}$ & 1 & 0,074 & 115 & 46 \\
\hline
\end{tabular}

Para o estrato 2 (hospitais de médio porte, $\mathrm{k}=2$ ), tem-se 11 hospitais $\left(H_{j}^{k}=11\right.$ ) e para calcular o número de hospitais necessários é considerado um coeficiente de confiança de $90 \%$ $\left(z_{\alpha}=1,64\right)$ e um erro de $0,15\left(E_{k}=0,15\right)$. Neste caso, tem-se que:

$$
\mathrm{h}_{j}^{k}=\frac{\mathrm{n}}{1+\frac{n-1}{H_{j}^{k}}}=\frac{30,062}{1+\frac{30,062-1}{11}}=8,254,
$$

arredondando para cima, tem-se que o número de hospitais $\left(h_{j}^{k}\right)$ a serem amostrados neste estrato é de 9, dentre 11 da população do estrato. Considerando uma amostragem aleatória simples, tem-se que os hospitais a serem amostrados são 4, 7, 11, 18, 19, 37, 38, 43, 44. O número de prontuários a serem amostrados de cada uma destas instituições estão apresentados na Tabela 6.

Tabela 6: Tamanho de amostra de prontuários por hospital da amostra para o procedimento Artroplastia de joelho no estrato 2 para $90 \%$ de confiança.

\begin{tabular}{ccccc}
\hline Hospital & Estrato & Taxa ISC & $\begin{array}{c}\text { Total de } \\
\text { prontuários }\left(C_{j}\right)\end{array}$ & $\begin{array}{c}\text { Tamanho de } \\
\operatorname{amostra}\left(a_{j}\right)\end{array}$ \\
\hline C & 2 & 0,074 & 3 & 3 \\
E & 2 & 0,074 & 14 & 12 \\
H & 2 & 0,074 & 1 & 1 \\
K & 2 & 0,074 & 176 & 53 \\
L & 2 & 0,074 & 19 & 16 \\
T & 2 & 0,074 & 97 & 43 \\
Q & 2 & 0,074 & 9 & 9 \\
U & 2 & 0,074 & 11 & 10 \\
R & 2 & 0,074 & 1 & 1 \\
\hline
\end{tabular}

No caso do estrato 3 (hospitais de grande porte, $\mathrm{k}=3$ ), temos um total de 4 hospitais apenas $\left(H_{j}^{k}=4\right)$. Repetindo a mesma metodologia feita no caso anterior, para um coeficiente de confiança de $90 \%$ e um erro de 0,15 , o número de hospitais a serem amostrados será: 


$$
\mathrm{h}_{j}^{k}=\frac{\mathrm{n}}{1+\frac{n-1}{H_{j}^{k}}}=\frac{30,062}{1+\frac{30,062-1}{4}}=3,637 \cong 4,
$$

ou seja, a amostra de hospitais é equivalente ao tamanho população de hospitais que fazem Artroplastia de joelho e que possuem mais de 200 leitos. O número de prontuários a serem amostrados para cada hospital estão apresentados na Tabela 7.

Tabela 7: Tamanho de amostra de prontuários por hospital da amostra para o procedimento Artroplastia de joelho no estrato 3 para $90 \%$ de confiança.

\begin{tabular}{ccccc}
\hline Hospital & Estrato & Taxa ISC & $\begin{array}{c}\text { Total de } \\
\text { prontuários }\left(C_{j}\right)\end{array}$ & $\begin{array}{c}\text { Tamanho de } \\
\text { amostra }\left(a_{j}\right)\end{array}$ \\
\hline A & 3 & 0,074 & 8 & 8 \\
M & 3 & 0,074 & 52 & 31 \\
V & 3 & 0,074 & 92 & 42 \\
X & 3 & 0,074 & 11 & 10 \\
\hline
\end{tabular}

\subsubsection{Amostragem dois estágios e dois procedimentos}

Nesta seção será proposta uma maneira de otimizar os números de hospitais selecionados no caso em que mais de um procedimento for de interesse do pesquisador. No entanto, essa proposta apresenta algumas limitações e deve ser usada quando o objetivo do estudo é apenas verificar se o hospital reportou corretamente a taxa de ISC; não deve ser usada para estimar, por exemplo, a taxa de ISC de um determinado procedimento geral em todos os hospitais de um determinado estrato. Em outras palavras, pode-se utilizar o procedimento somente quando o objetivo é a estimação da taxa de ISC dentro de cada hospital.

Considere inicialmente a amostragem em dois estágios e dois procedimentos fixados. Nesta proposta deve-se escolher um dos dois procedimentos (o que for mais importante) e utilizar a metodologia para amostragem em dois estágios descritos anteriormente. Após feito o sorteio dos hospitais que serão visitados para verificação do primeiro procedimento, deve-se então calcular o número de hospitais a serem visitados para verificação do segundo procedimento, utilizando a mesma metodologia. A alteração nesse caso ocorre no sorteio dos hospitais a serem visitados para verificação do segundo procedimento: verifica-se, dentre os hospitais sorteados para o primeiro procedimento, quais realizam também o segundo procedimento e esses hospitais são incluídos na amostra do segundo procedimento. Caso ainda faltem hospitais para a amostra do segundo procedimento, seleciona-se aleatoriamente dentre 
os restantes o número que falta até atingir o tamanho amostral necessário. A metodologia para a amostragem pode ser organizado da seguinte forma:

1. Calcula-se o número de hospitais que compõe a amostra do primeiro procedimento para cada estrato;

2. Seleciona-se os hospitais que compõe a amostra do primeiro procedimento para determinado estrato;

3. Calcula-se o número de hospitais que compõe a amostra do segundo procedimento para cada estrato;

4. Verifica-se quais hospitais da amostra do primeiro procedimento também executam o segundo procedimento;

5. Inicia-se a seleção da amostra do segundo procedimento considerando apenas os hospitais que fazem ambos os procedimentos;

6. Caso o segundo procedimento necessite de uma amostra maior do que o número de hospitais selecionados que executam ambos os procedimentos, deve-se complementar a amostra considerando os hospitais que fazem apenas o segundo procedimento e não fazem o primeiro.

A amostragem dos prontuários dentro de cada hospital deve seguir a mesma metodologia descrita, sem alterações. Note que esta metodologia de seleção de hospitais altera a probabilidade de seleção de hospitais para o segundo procedimento, dando mais peso aos hospitais que realizam ambos procedimentos. Por esta razão, a estimação da taxa de ISC comum a todos os hospitais dentro de um estrato não pode ser feita da maneira usual e deve-se considerar esse esquema amostral, tornando o cálculo bastante complexo. No entanto, como as seleções dos prontuários dentro de cada hospital é feita por amostragem aleatória simples, a estimação da taxa de ISC dentro de cada hospital pode ser feita de forma usual.

Por exemplo, considere o procedimento Parto cesariano e Artroplastia de joelho, nesta ordem de prioridade. A partir dos resultados do primeiro exemplo (subseção 3.2.1), tem-se que a amostra para hospitais médios que realizam Parto cesariano será de 8 hospitais e para hospitais grandes será de 4 hospitais. Para o procedimento Parto cesariano, os hospitais médios escolhidos para compor a amostra (neste exemplo) foram 7, 17, 18, 19, 27, 31, 38 e 44 e os hospitais grandes selecionados foram 1, 20, 21 e 32.

Considerando a Artroplastia de joelho e os resultados da subseção 3.2.2, tem-se que são necessários 1 hospital de pequeno porte, 9 hospitais médios e 4 hospitais grandes. Considerando a amostra do Parto cesariano, tem-se que somente os hospitais 1, 7, 18, 19, 20, 
38 e 44 também fazem Artroplastia de joelho. Com isso, todos os hospitais que fazem os procedimentos Parto cesariano e Artroplastia de joelho foram também selecionados para compor a amostra dos hospitais que realizam o segundo procedimento nos estratos 2 e 3. Após complementar conforme a necessidade em cada um dos estratos, os hospitais selecionados para a amostragem do procedimento Artroplastia de joelho foram: 28 (pequeno porte), 4, 7, 11, 18, 19, 37, 38, 43, 44 (médio porte), 1, 20, 21 e 32 (grande porte).

\section{CONCLUSÕES}

Neste relatório, é apresentada uma proposta para a seleção de hospitais de forma estratificada pelo número de leitos e, para cada hospital, o número de prontuários, com a finalidade de se verificar a qualidade da notificação das taxas de ISC de cada instituição. Para o desenvolvimento da análise, recomenda-se submeter o trabalho como um projeto do CEA, que poderia ser desenvolvido durante o primeiro semestre de 2017.

\section{REFERÊNCIAS}

[1] BOLFARINE, H. e BUSSAB, W. O. (2005). Elementos de Amostragem. 1.ed., São Paulo: Edgard Blucer, 290p.

[2] REINMANN, B. F. . Relatório de consulta: "Desenvolvimento de uma ferramenta que permita a validação periódica do sistema de vigilância das infecções de sítio cirúrgico no estado de São Paulo”. São Paulo, IME-USP, 2015. 
ANEXO 3

\begin{tabular}{|c|c|c|c|} 
USP - ESCOLA DE \\
ENFERMAGEM DA \\
UNIVERSIDADE DE SÃO
\end{tabular}

PARECER CONSUBSTANCIADO DO CEP

\section{DADOS DO PROJETO DE PESQUISA}

Título da Pesquisa: Desenvolvimento de um Protocolo para a Validação do Sistema de Vigilância das Infecções de Sítio Cirúrgico (SVISC) no Estado de São Paulo.

Pesquisador: Debora Silva de Mello

Área Temática:

Versäo: 4

CAAE: 64237917.9 .0000 .5392

Instituição Proponente: Escola de Enfermagem da Universidade de São Paulo - EEUSP

Patrocinador Principal: Financiamento Próprio

\section{DADOS DO PARECER}

Número do Parecer: 2.125.503

\section{Apresentação do Projeto:}

Projeto previamente aprovado por este CEP em cujo último parecer as considerações sobre os termos de apresentação obrigatória se referiam à atualização necessária no documento informações básicas do projeto no tocante à supressão da etapa de coleta de dados em que seria aplicado o formulário II, e as recomendações foram o ajuste dos riscos e beneficios devem ser ajustados no mesmo documento, conforme constante na versão do projeto enviada à época para apreciação.

\section{Objetivo da Pesquisa:}

\section{GERAL}

Elaborar um protocolo que possa ser utilizado pelo serviço público de saúde brasileiro para validar o sistema de vigilância epidemiológica (VE) das ISC no Estado de São Paulo, com base em critérios científicos.

\section{OBJETIVOS ESPECÍFICOS}

Desenvolver uma metodologia para a elaboração de um instrumento que possa ser utilizado na validação de um SVISC.

Realizar levantamento de informações sobre métodos de validação de dados adotados por diferentes sistemas governamentais de VE das ISC.

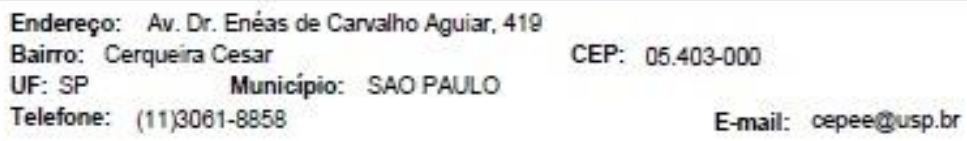




\section{USP - ESCOLA DE
ENFERMAGEM DA
UNIVERSIDADE DE SÃO}

Contunuaç5̆o do Parecer: 2125.503

Elaborar um instrumento que possa ser utilizado na validação do sistema de VE das ISC no Estado de São Paulo e demais sistemas govemamentais que adotem a mesma metodologia de vigilância epidemiológica das ISC.

Avaliação dos Riscos e Beneficios:

Segundo as pesquisadoras "os riscos relacionam-se ao possivel desconforto pela necessidade de revisar dados institucionais, perda do anonimato e da confidencialidade, extravio, perda e rasura de documentos. Para minimizar estes riscos as pesquisadoras do estudo irão assinar um "TERMO DE RESPONSABILIDADE* que será entregue à direção do hospital garantindo sigilo de todos os dados que identifiquem o paciente $e$ a instituição e de que não haverá dano moral, psicológico ou físico aos participantes do estudo e para que o responsável autorize a participação do serviço de saúde no estudo. Os prontuários serão avaliados em local pertencente ao serviço participante, indicado por seu responsável, com o objetivo de evitar o transporte destes documentos, o que poderia implicar em perda ou extravio ou mesmos rasuras aos prontuários."

Quanto aos benefícios, afirmam que "protocolo desenvolvido ficará disponível para sua utilização pelo Sistema Único de Saúde (SUS) para ser aplicado no estado de São Paulo, com vistas a avaliar a qualidade da informação notificada pelas instituições de saúde sobre suas taxas de infecção de sítio cirúrgico. $O$ resultado desta avaliação permitirá identificar falhas no processo de notificação, quando houver e apontar necessidades de implementação de estratégias que promovam a melhoria deste processo, permitindo ao estado identificar taxas acuradas deste tipo de agravo à saúde".

\section{Comentários e Considerações sobre a Pesquisa:}

Trata-se de estudo de desenvolvimento metodológico, a ser realizado em duas fases. "A fase I contempla um estudo de revisão das estratégias adotadas por sistemas governamentais de VE das ISC. Nesta fase serão realizados levantamento de publicações na literatura científica, acesso à áginas web de sistemas governamentais que realizam VE das ISC em busca de informações sobre a validação de dados e visita a um sistema governamental de VE das IRAS. O desenvolvimento desta fase do estudo tem como propósito conhecer elementos utilizados para validação de dados de infecção de sítio (ISC) por autoridades de saúde, que auxiliem na elaboração dos componentes estruturantes do protocolo de validação a ser estabelecido pelo presente estudo. A FASE II contempla o desenvolvimento do protocolo de validação de dados de ISC para o estado de São Paulo. Esta fase do projeto comporta o desenvolvimento de um documento contendo o PASSO A PASSO de todas as etapas a serem desenvolvidas na execução da validação propriamente dita.

Endereço: Av. Dr. Enéas de Carvalho Aguiar, 419

Bairro: Cerqueira Cesar

UF: SP Município: SAO PAULO

CEP: $05.403-000$

Telefone: (11)3061-8858

E-mail: cepeegusp.br 


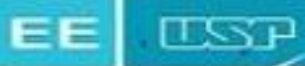

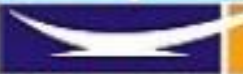 \\ ENFERMAGEM \\ USP - ESCOLA DE \\ ENFERMAGEM DA UNIVERSIDADE DE SÃO

Continuaçăo do Parecer. 2125.503

Nesta fase estão previstas a elaboração do instrumento a ser utilizado "in loco" na aplicação da validação, o estabelecimento de fórmula a ser utilizada para a seleção de instituiçōes e dos prontuários a serem validados e a aplicação do processo de validação."

Considerações sobre os Termos de apresentação obrigatória:

Nada a comentar.

Recomendaçöes:

Não há.

Conclusôes ou Pendências e Lista de Inadequações:

Aprovado.

Considerações Finais a critério do CEP:

- Este CEP informa a necessidade de registro dos resultados parciais e finais na Plataforma Brasil;

- Esta aprovação não substitui a autorização da instituição coparticipante, antes do inicio da coleta de dados.

Este parecer foi elaborado baseado nos documentos abaixo relacionados:

\begin{tabular}{|c|c|c|c|c|}
\hline Tipo Documento & Arquivo & Postagem & Autor & Situação \\
\hline $\begin{array}{l}\text { Informações Básicas } \\
\text { do Projeto }\end{array}$ & $\begin{array}{l}\text { PB_INFORMAÇÖES_BÁSICAS_DO_P } \\
\text { ROJETO_839551.pdf }\end{array}$ & $\begin{array}{c}29 / 05 / 2017 \\
17: 04: 23\end{array}$ & & Aceito \\
\hline Outros & $\begin{array}{l}\text { CartaEsclarecimento_MelloDS25052017 } \\
\text { doc }\end{array}$ & $\begin{array}{c}29 / 05 / 2017 \\
17: 00: 10\end{array}$ & $\begin{array}{l}\text { Debora Silva de } \\
\text { Mello }\end{array}$ & Aceito \\
\hline $\begin{array}{l}\text { Projeto Detalhado I } \\
\text { Brochura } \\
\text { Investiqador }\end{array}$ & $\begin{array}{l}\text { ProjetoPesquisa_MelloDS25052017_CE } \\
\text { P.doc }\end{array}$ & $\begin{array}{c}29 / 05 / 2017 \\
16: 59: 32\end{array}$ & $\begin{array}{l}\text { Debora Silva de } \\
\text { Mello }\end{array}$ & Aceito \\
\hline Outros & $\begin{array}{l}\text { TERMORESPONSABILIDADE_MelloDS } \\
\text { 02052017.doc }\end{array}$ & $\begin{array}{l}02 / 05 / 2017 \\
22: 24: 36\end{array}$ & $\begin{array}{l}\text { Debora Silva de } \\
\text { Mello }\end{array}$ & Aceito \\
\hline Outros & CARTAAUTORIZACAO.doc & $\begin{array}{c}02 / 05 / 2017 \\
15: 43: 45\end{array}$ & $\begin{array}{l}\text { Debora Silva de } \\
\text { Mello }\end{array}$ & Aceito \\
\hline Outros & CartaAnuencia_CVE_2017.pdf & $\begin{array}{c}30 / 01 / 2017 \\
08: 46: 30\end{array}$ & $\begin{array}{l}\text { Debora Silva de } \\
\text { Mello }\end{array}$ & Aceito \\
\hline Folha de Rosto & Diretoria_EEUSP.pdf & $\begin{array}{c}23 / 01 / 2017 \\
11: 43: 16\end{array}$ & $\begin{array}{l}\text { Debora Silva de } \\
\text { Mello }\end{array}$ & Aceito \\
\hline
\end{tabular}

Situação do Parecer:

Aprovado

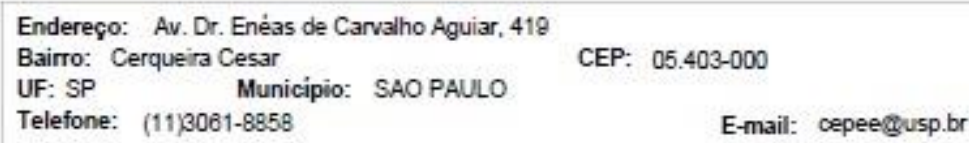




USP - ESCOLA DE
ENFERMAGEM DA
UNIVERSIDADE DE SÃO

Contunuaç5̆o do Parecer: 2125503

Necessita Apreciação da CONEP:

Não

SAO PAULO, 19 de Junho de 2017

Assinado por:

Marcelo José dos Santos

(Coordenador)

Endereço: Av. Dr. Enéas de Carvalho Aguiar, 419

Bairro: Cerqueira Cesar

CEP: $05.403-000$

UF: SP Município: SAO PAULO

Telefone: (11)3061-8858

E-mail: cepeegusp.br

Psgins o4 de o4 


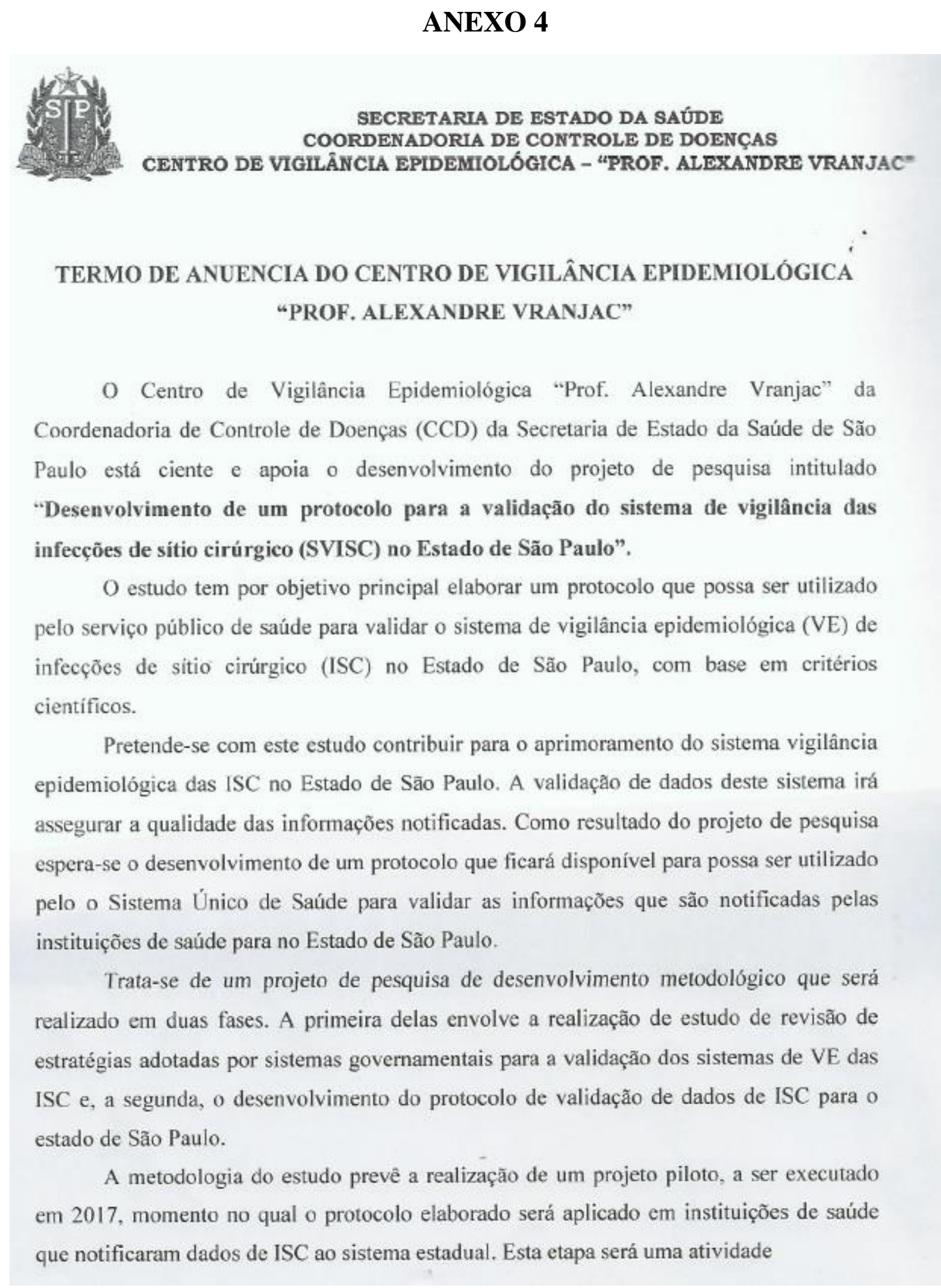




\section{SECRETARIA DE ESTADO DA SAÚDE COORDENADORIA DE CONTROLE DE DOENÇAS CENTRO DE VIGILÂNCLA EPIDEMIOLÓGICA - "PROF. ALEXANDRE VRANJAC"}

desenvolvida em cooperação com a Divisão de Infecção Hospitalar do Centro de Vigilância Epidemiológica. Para tanto, um número de hospitais definido por cálculo amostral será contatado para a participação na pesquisa, a qual terá caráter voluntário. Esta etapa prevê a ida de pesquisadores treinados para a validação pela equipe executora do estudo aos hospitais participantes para coletar informações relativas à estrutura disponível para o controle de IRAS e informações de prontuários de pacientes, buscando identificar a ocorrência e a não ocorrência de casos de ISC. Os dados obtidos permitirão calcular posteriormente a sensibilidade e especificidade do sistema adotado pela instituição.

O estudo será conduzido pela pesquisadora MsC Débora Silva de Mello sob orientação da Prof ${ }^{\natural}$. Dra. Maria Clara Padoveze, professora Doutora do Departamento de Enfermagem em Saúde Coletiva da Escola de Enfermagem da Universidade de São Paulo (EEUSP), com participação das pesquisadoras Dra Denise Brandão de Assis e Dra Geraldine Madalosso, Diretora e Técnica a Divisão de Infecção Hospitalar, respectivamente.

O projeto será submetido ao Comitê de Ética em Pesquisa (CEP) da EEUSP.

Os critérios de autoria para futuras publicações cientificas deverão ser definidos pela equipe de pesquisadores.

Săo Paulo, 21 de janeiro de 2017.

Demi suondaó dohe

Dra. Denise Brandão de Assis

Diretora da Divisão de Infecção Hospitalar do Estado de São Paulo

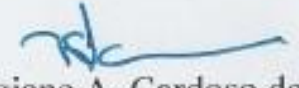

Dra. Regiane A. Cardoso de Paula Diretora Técnica do Centro de Vigilância Epidemiológica "Prof. Alexandre Vranjac". 